\title{
Descriptive skeletal anatomy of Blommersia transmarina (Amphibia: Anura: Mantellidae) from the Comoro Islands
}

\author{
Javier H. Santos-Santos \\ Department of Biogeography and Global Change (BGC-MNCN-CSIC), \\ Museo Nacional de Ciencias Naturales, C/José Gutiérrez Abascal 2, 280o6, Madrid, Spain \\ Department of Animal Biology, University of Barcelona, Avenida Diagonal 645, 08028, \\ Barcelona, Spain \\ jssantos@usal.es
}

\section{Mireia Guinovart-Castán}

Department of Biogeography and Global Change (BGC-MNCN-CSIC), Museo Nacional de Ciencias Naturales, C/José Gutiérrez Abascal 2, 280o6, Madrid, Spain

\author{
David R. Vieites \\ Department of Biogeography and Global Change (BGC-MNCN-CSIC), \\ Museo Nacional de Ciencias Naturales, C/José Gutiérrez Abascal 2, 280o6, Madrid, Spain \\ vieites@mncn.csic.es
}

\begin{abstract}
Mantellid frogs present an extensive adaptive radiation endemic to Madagascar and Comoros, being the subfamily Mantellinae the most morphologically and ecologically diverse. The Mantellinae present key innovative evolutionary traits linked to their unique reproductive behavior, including the presence of femoral glands and a derived vomeronasal organ. In addition, previous studies pointed to size differentiation in playing an important role in species' dispersal capacities and shaping of their geographic ranges. Despite the high phenotypic variation observed in this clade, to date an exhaustive morphological analysis of their anatomy has still not been performed, much less in relation to internal structures. Here, we present a comprehensive skeletal description of a mantellid species, Blommersia transmarina, from the island of Mayotte in the Indian Ocean, which has potentially undergone a process of moderate gigantism compared to other Blommersia species. We describe its intraspecific skeletal variation utilizing non-destructive volume renderings from $\mu$ CT-scans, and characterize the presence of sexual dimorphism and size covariation in skeletal structures. Notably, we found numerous signs of hyperossification, a novel structure for mantellids: the clavicular process, and the presence of several appendicular sesamoids. Our findings suggest that skeletal phenotypic variation in this genus may be linked to biomechanical function for reproduction and locomotion.
\end{abstract}

(C) SANTOS-SANTOS ET AL., 2020 | DOI:10.1163/18759866-20191405

This is an open access article distributed under the terms of the CC-BY 4.o License. 


\section{Keywords}

Anura: Mantellidae - computed tomography - hyperossifcation - intraspecific variation - osteology size variation

\section{Introduction}

The Mantellidae represents the most speciesrich and ecologically diverse anuran family endemic to the islands of Madagascar and Mayotte (Glaw \& Vences, 2007). It is divided into three subfamilies: Mantellinae (Laurent, 1946), Laliostominae (Vences \& Glaw, 2001), and Boophinae (Vences \& Glaw, 2001). Extensive work (Guibé, 1978; Scott, 2005; Glaw \& Vences, 2006; Vieites et al., 2009) has been carried out in view of resolving their systematics, biogeography, and phylogenetic relationships to elucidate their evolutionary history and shed light on the nature of active speciation processes. In this respect, variation in body size has been found to influence species' range sizes and biogeographic setting, linking smaller body sizes to higher clade diversity and geographically closer and more fragmented ranges (Wollenberg et al., 2011; Pabijan et al., 2012).

The Mantellidae is phylogenetically nested within Indian frogs and its most recent common ancestor is estimated to have dispersed from this landmass and colonized the island of Madagascar in the Early Cretaceous between $87-76$ Mya (Million years ago) (Crottini et al., 2012; Samonds et al., 2013). In addition, there have been two more recent colonization events by oceanic dispersal that are estimated to have occurred between 8-6 Mya (Vences et al., 2003; Crottini et al., 2012) from mainland Madagascar to the neighboring island of Mayotte in the Comoros, $300 \mathrm{~km}$ off the northwest coast of Madagascar, involving Boophinae and Mantellinae members of this family, which have recently been described as Boophis nauticus and Blommersia transmarina (Glaw et al., 2019). Mayotte consists of a main island, Maore, and a small island, Pamanzi; with transmarine colonization having occurred exclusively on Maore. B. transmarina appears to have likely having undergone a process of moderate gigantism (Glaw et al., 2019), a common phenomenon in oceanic islands (Daugherty et al., 1993; Lomolino, 2005; Li et al., 2011).

Several recent works studied anatomical subsystems of various species within Mantellidae, including external morphology (e.g., Blommersia Vences et al., 2010; Pabijan et al., 2011; Gephyromantis Scherz et al., 2017a; Guibemantis Vences et al., 2015; Mantidactylus Vences et al., 2002; Tysingymantis Glaw et al., 2006), femoral glands (Vences et al., 2007; Altig, 2008), intercalary elements (Manzano et al., 2007), etc. However, there is currently no study of skeletal data that makes reference to size differentiation, especially in view that body size is known to influence dispersal and evolutionary rates within the genus (Wollenberg et al., 2011; Pabijan et al., 2012). Since $B$. transmarina is the largest Blommersia species identified to date (Glaw et al., 2019), it constitutes the perfect starting point to set a base to study the processes of miniaturization in the internal anatomy of mantellids on the grounds that miniaturization can lead to reduced ossification of post-metamorphic skeletal elements, hyperossification, and presents more structural trade-offs than enlargement (Hanken, 1993; Yeh, 2002; Hall, 2005; PérezBen et al., 2018).

Here, we present the first comprehensive skeletal description of a species within the Mantellidae (but see Guibé, 1978; Scott, 2005), 
elaborating precise anatomical descriptions of all skeletal elements, and define the level of intraspecific phenotypic variation $(n=10)$ of highly variable elements. Anatomical descriptions are based on high-resolution rendered skeletons obtained from $\mu \mathrm{CT}$ (i.e., computed tomography) volume scans of individuals recently captured in Mayotte, Comoros. Approximations of non-calcified structures were inferred from additional CT-scans of stained specimens (see Santos-Santos, 2019). Descriptions are made with elements referenced in a primary anterior (rostral) to posterior (caudal) axis and a secondary proximal (medial) to distal (lateral) axis. With this anatomical study we aim to create a reference for future comparative studies with other mantellids species, as well as explore their phenotypic evolutionary processes, including miniaturization / size variation in the family.

\section{Material and methods}

A total of 10 (five male and five female) adult Blommersia transmarina individuals were retrieved from the collections at the National Museum of Natural History (MNCN-CSIC) in Madrid, Spain (table 1). Individuals were fixed with cotton and submerged in $70 \%$ ethanol within $50 \mathrm{~mL}$ polypropylene falcon tubes before CT-scanning in a Nikon XT H-16o system [reconstructed voxel size $(\mu \mathrm{m})=29.5^{-42}$ (isometric); X-ray $(\mathrm{kV})=53-56$; X-ray $(\mu \mathrm{A})=$ 172-188; Projections $=1800$; voxels $=1008]$ at the internal Service of Non-destructive Techniques of the MNCN-CSIC. The CT-scans were reconstructed with CT Pro $3 \mathrm{D}$ software. Individual skeletons were volume rendered and visualized in Avizo version 9.2 software with volrenWhite and physics colormaps to observe bone densities. Images were taken in perspective mode in Avizo ${ }^{\circledR}$ to capture the largest amount of skeletal features in each view. Additional CT-scans of priorly softtissue-stained specimens were performed to corroborate the position of non-calcified anatomical elements; these were performed with a custom setup [reconstructed voxel size $(\mu \mathrm{m})=$ 30-35 (isometric); $\mathrm{X}$-ray $(\mathrm{kV})=80 ; \mathrm{X}$-ray $(\mu \mathrm{A})=$ 375; Projections $=1801$; voxels $=1166]$ at the Center for X-ray Tomography (UGCT) in collaboration with the Evolutionary Morphology of Vertebrates Lab of Ghent University, Belgium (see Santos-Santos, 2019). The specimen $\mathrm{MNCN}_{50446}$ was used as a reference for the generalized anatomical description. The .stl file of its skeletal segmentation is

TABLE 1 Data and external snout-vent length $\left(\mathrm{SVL}_{\text {ext }}\right)$ in mm of the Blommersia transmarina individuals used for the current study.

\begin{tabular}{lllll}
\hline Collection n $^{\circ}$ & Field n $^{\circ}$ & Sex & SVL $_{\text {ext }}$ & Locality \\
\hline MNCN50430 $_{\text {MNCN50431 }}$ & DRV6835 & F & 29.28 & Mont Choungui \\
MNCN50432 $_{\text {DRV6848 }}$ & F & 26.5 & Mont Combani \\
MNCN50433 $_{\text {MNV6805 }}$ & F & 29.13 & Mont Combani \\
MNCN50436 $_{\text {DRV6813 }}$ & DRV6832 & F & 30.38 & Mont Tsapere \\
MNCN50437 & DRV6833 & M & 25.5 & Mont Bénara \\
MNCN50439 & DRV6841 & M & 27.5 & Mont Bénara \\
MNCN50446 & DRV6836 & M & 24.64 & Mont Bénara \\
N/A & DRV6807 & M & 27 & Mont Bénara \\
\hline
\end{tabular}


available on the Spanish National Research Council (CSIC) repository (https://digital.csic .es/handle/10261/190938).

In addition, a total of 123 linear distances (see Appendix 1) were measured on the rendered skeletons of all individuals to obtain the intraspecific range of variation of skeletal characters. Descriptive statistics were obtained and sexual dimorphism and size covariation evaluated through analysis of (co) variance $(\alpha=0.05)$ in IBM SPSS Statistics for Windows version 24.0. Of the three snoutvent length (SVL) measurements taken (i.e., $\mathrm{SVL}_{\text {ext }}, \mathrm{SVL}_{\text {sk }}, \mathrm{SVL}_{\text {sum }}$; Appendix 1), we determined which one covaried best with skeletal distances by including all SVL measurements as covariates in univariate three-way analyses of covariance (ANCOVA). Pelvis length (pelvL) was also explored as a covariate, and included with the best resulting SVL covariate from the prior analysis in univariate two-way ANCOVAs with skeletal measurements to determine which covaried best with each skeletal linear distance.

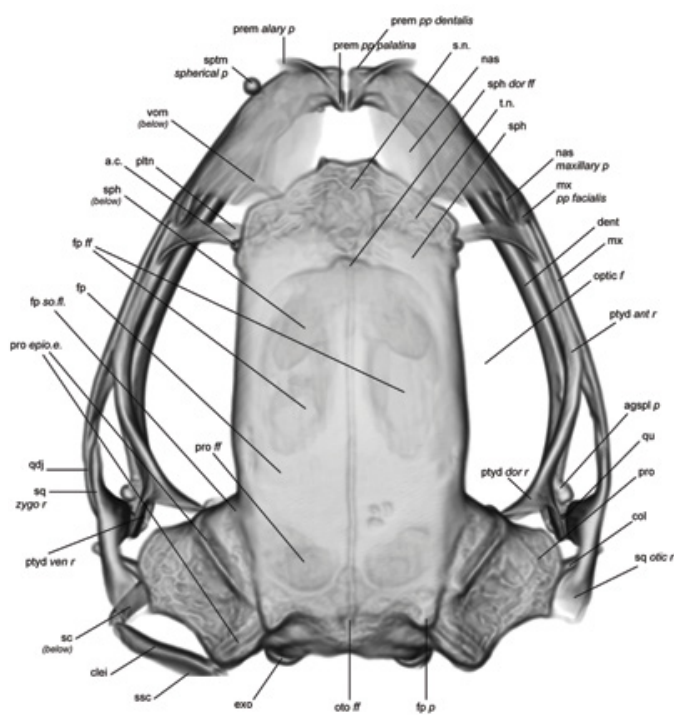

\section{Results}

\section{Skull}

There are two types of bone in the cranium: endochondral (i.e., develops from osteoblasts within cartilage) and dermal or membranous (i.e., develops intramembranously inside connective tissue) (Hall, 2005). The neurocranium represents an inverted T-shaped box: the longitudinal branch going anteroposteriorly from the nasal to the auditory region, and each tip of the transverse branch ending at an auditory capsule (fig. 1).

\section{Endochondral neurocranium}

Sphenethmoid. The sphenethmoid is a central element of the skull. It is ossified anteriorly, encircling the anterior part of the brain, contributing to the posterior walls of the nasal capsule, and forming the anterior margin of the optic foramen. The bone extends further ventrolaterally (fig. 2), creating a pair of small alae that penetrate the orbitonasal foramen slightly to either side of the parasphenoid. On

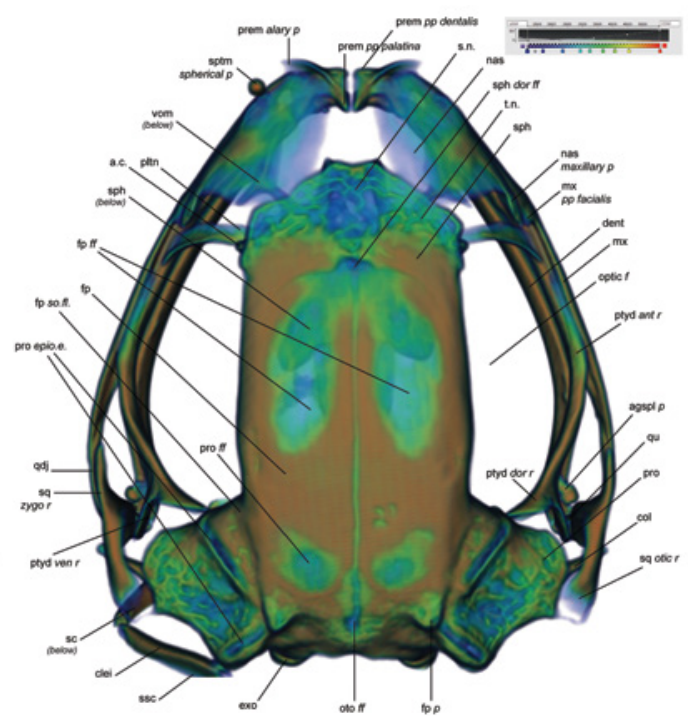

FIGURE 1 Dorsal view of the Blommersia transmarina skull [MNCN50446 male; volrenWhite (A) and physics colormaps (B), grey [density] values: $12000-55500]$. 

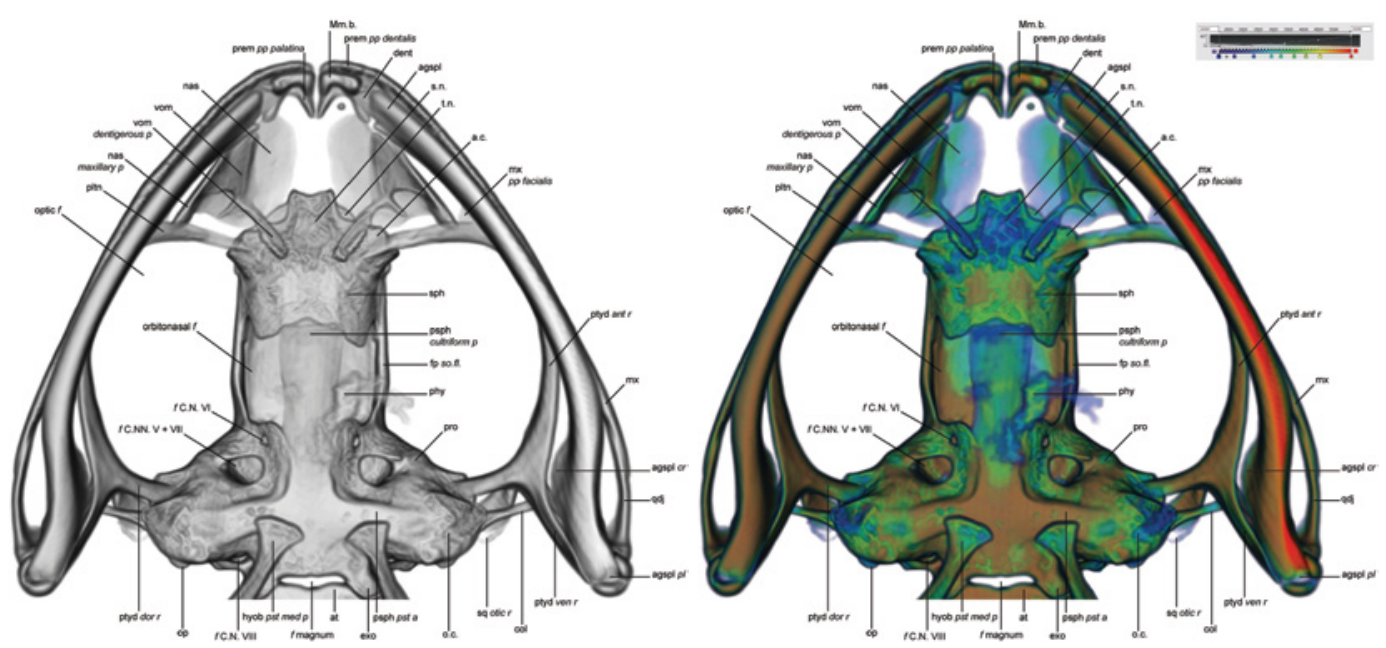

FIGURE 2 Ventral view of the Blommersia transmarina skull [MNCN50446 male; volrenWhite (A) and physics colormaps (B), grey [density] values: $12000-55500$ ].

the ventral side there are exostoses (Duellman \& Trueb, 1994), a sign of hyperossification evidenced by the presence of superficial sculpted patterns. Anteriorly it presents two bilaterally symmetric olfactory foramina that open to the internasal septum (fig. 3). Posterodorsally the sphenethmoid separates medially forming the frontoparietal fontanelle, which is completely covered by the frontoparietals, except for its anterior tip, and extends dorsally for slightly more than half their length (fig. 1).

Prootics and Exoccipitals. The prootics lie at a distance posterior to the sphenethmoid and expand laterally to cover the auditory capsules both anteriorly, forming the posterior margin of the optic foramen, and posterodorsally (fig. 4). The prootics in B. transmarina present signs of hyperossification evidenced in an exostosed surface and fusion with each other and with the exoccipitals to form a single massive element (i.e., otoccipital; Clack, 2001). They unite dorsomedially at their posteriormost point, where they also fuse with the exoccipitals (fig. 1). Each prootic presents anteriorly a large dorsal fenestra with a rostrolateral extension that is discontinuous with the frontoparietal fontanelle. In addition, there is a diamond-shaped fenestra (i.e., otoccipital fenestra) between the prootics anterior to the dorsal fusion point of the otoccipital. The three fenestrae are completely covered by the frontoparietals, except for the posterior tip of the otoccipital fenestra. Below the protuberance at the posterolateral corner of the frontoparietal, the prootic presents two prominent epiotic eminences (Trueb, 1968a) that extend both antero- and postero-laterally (figs. 1 and 4); the latter (i.e., opisthotic sensu Ecker, 1889) terminates in the prominentia ducti semicircularis posterioris (Laloy et al., 2013). This structure is narrowly separated from the anteromedial margin of the suprascapula.

The exoccipitals are fused completely ventrally and dorsally in a ring-like structure that unites dorsoanteriorly with the prootics, ventroanteriorly with the parasphenoid, flanks the foramen magnum, and forms the occipital condyles posteriorly (fig. 3). Immediately anterior to each occipital condyle is a large circular foramen (i.e., foramen jugulare) that corresponds to the exit of cranial nerves (C.NN.) IX (glossopharyngeal) and X 

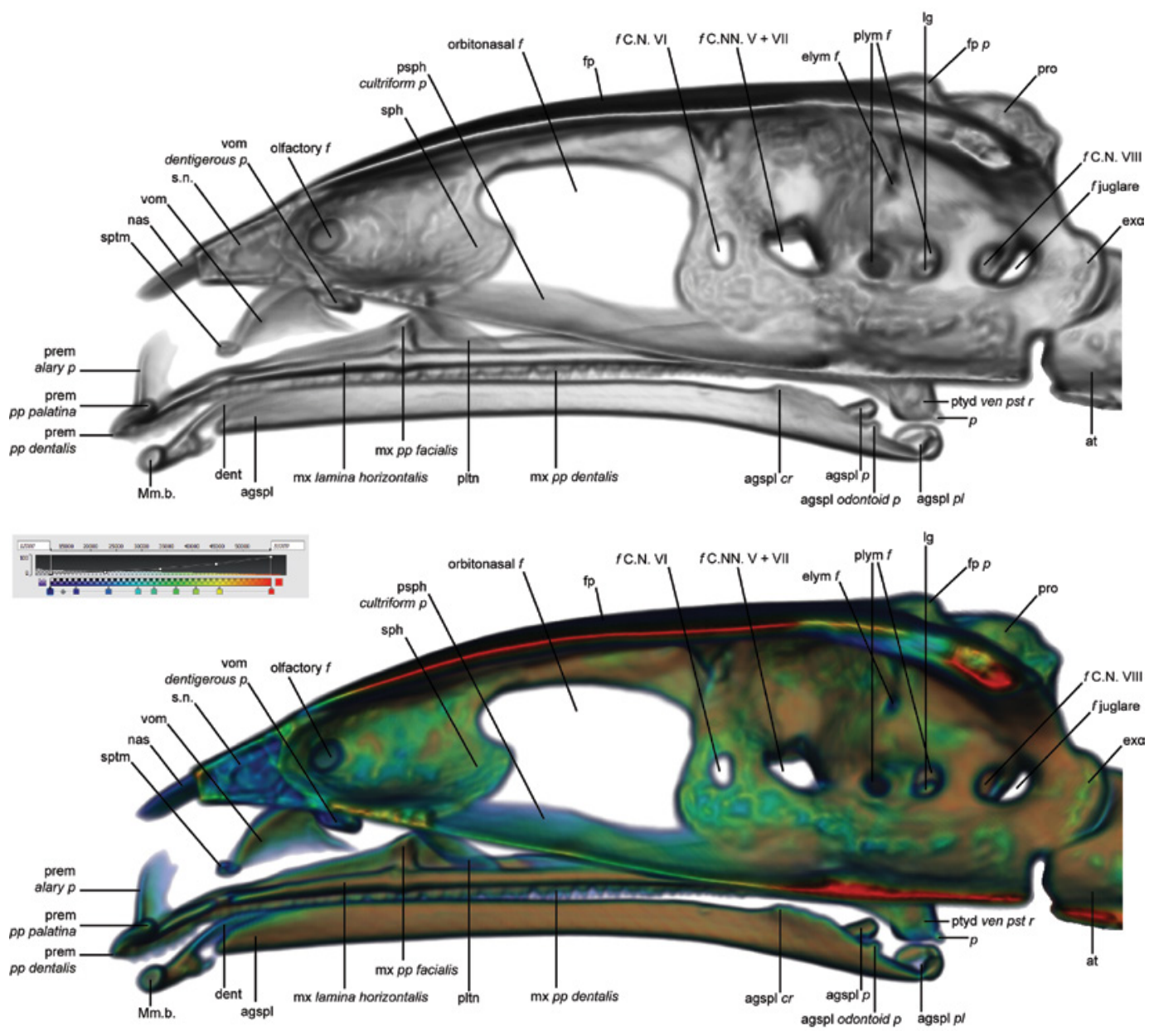

FIGURE 3 Medial view of the right side of the Blommersia transmarina skull [MNCN50446 male; volrenWhite (A) and physics colormaps (B), grey [density] values: $12000-55500$ ].
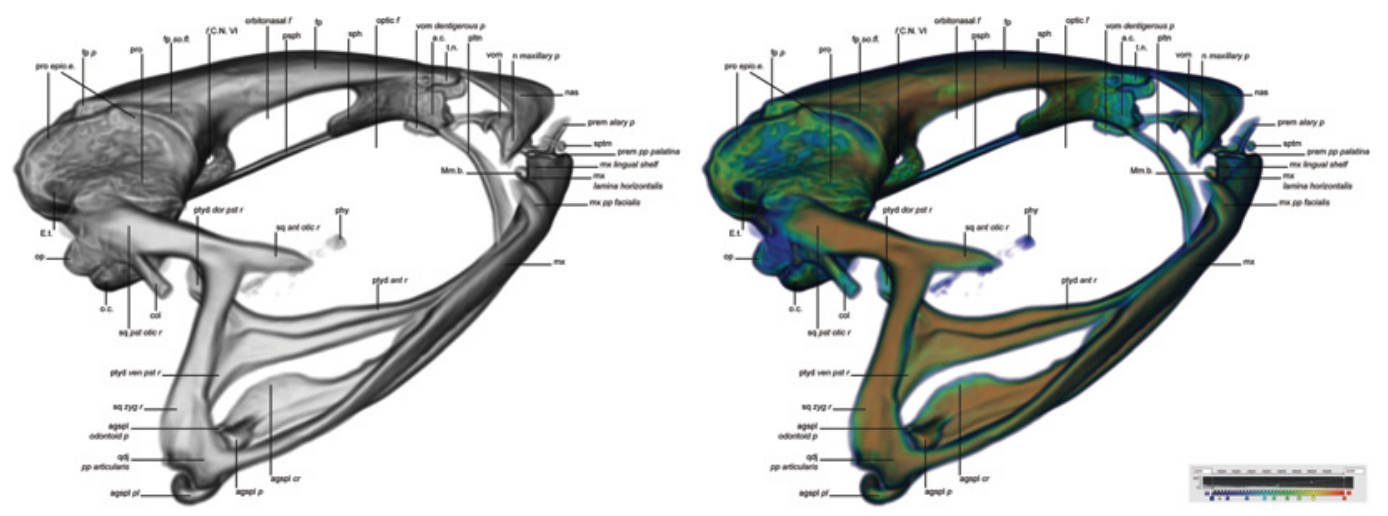

FIGURE 4 Lateral view of the right side of the Blommersia transmarina skull. The skull presents a dorsoventral inclination in the caudal direction. Its left half and exoccipitals have been clipped to facilitate visualization [MNCN50446 male; volrenWhite (A) and physics colormaps (B), grey [density] values: 12000-55500]. 
(vagus), which is separated laterally by a thin bone wall from another slightly more ovoid foramen located under the auditory capsule that corresponds to the exit of C.N. VIII (vestibulocochlear).

Auditory/Otic capsules. The tympanic membrane in B. transmarina is located at the level of the otic ramus of the squamosal bone. Below the posterior otic ramus of the squamosal lies the ossified portion (i.e., stylus) of the columella (i.e., middle ear ossicle) with an expanded proximal end (i.e., footplate), which articulates medially with the membrane of the oval window (i.e., fenestra ovalis), anterior to the operculum (fig. 4). Ventroposteriorly covering the fenestra ovalis lies the operculum, a lightly calcified cartilaginous element (fig. 2). The Eustachian tubes, which connect the middle ear to the buccal cavity, exit the prootics at a posterolateral fenestra behind the articulation with the squamosal otic ramus. The inner ear is situated more medially within the auditory capsule and consists of a membranous labyrinth suspended within the otic capsule by loose connective tissue (Duellman \& Trueb, 1994). The endolymphatic system (i.e., otic labyrinth) is suspended within the perilymphatic cistern, which connects with the perilymphatic sac within the neurocranium through two medial foramina (fig. 3 and supplementary fig. S1); the round window (Duellman \& Trueb, 1994) being located anterior to that of the C.N. VIII (Simmons et al., 1992). The endolymphatic system in $B$. transmarina consists of a large saccule divided by a central constriction that divides it into two compartments: the dorsal utriculus (semicircular canals) and the ventral sacculus (sensory epithelium). An endolymphatic duct leads from the sacculus to the endolymphatic torus surrounding the brain in the neurocranium (Dempster, 1930). The shape of the saccule compartments varied greatly between individuals, and due to the resolution of our CT-scans $(\sim 30 \mu \mathrm{m})$ the identification of homologous structures at the nanoscale was not possible (but see Mason et al., 2015). However, there were some recurrent structures across individuals (fig. 5): The shelf-like projection of the papilla amphibiorum recess was visible situated rostromedially on the utriculus; in some individuals (e.g., MNCN50446) one or two additional round diverticula (the dorsal larger when both present) were visible extending medially from the amphibiorum recess (Richards, 2006). Medially at the level of the posterior perilymphatic duct and separated narrowly lateral to the sacculus lies the lagena (Duellman \& Trueb, 1994), a saddle-shaped pouch with its seat oriented toward the sacculus. The endolymphatic system presents grooves that may correspond to the periotic canals of the perilymphatic system (Mason et al., 2015), the most common around its center circumference, and also frequent, dividing the utriculus roughly into left and right sections.

Nasal capsule. Blommersia transmarina has a calcified internasal septum (Trueb, 1968b; Laloy et al., 2013) that projects rostrally from the anterior sphenethmoid, taking on a rhomboid shape. Exostosed mineralization of this cartilaginous element evidences hyperossification of the $B$. transmarina skull once more (figs. 1-3). The central region (i.e., septum nasi) presents the shape of a hollow rectangular prism invaded by spongy bone and is situated between the olfactory foramina of the sphenethmoid, extending forward to the level of the posteromedial margin of the nasals where it terminates in a slightly concave rectangular tip. From both dorsal corners of the tip of the septum nasi, a calcified tectum nasi extends posterolaterally, terminating at the dorsal anterolateral corners of the sphenethmoid. The anterior margin of the tectum nasi 

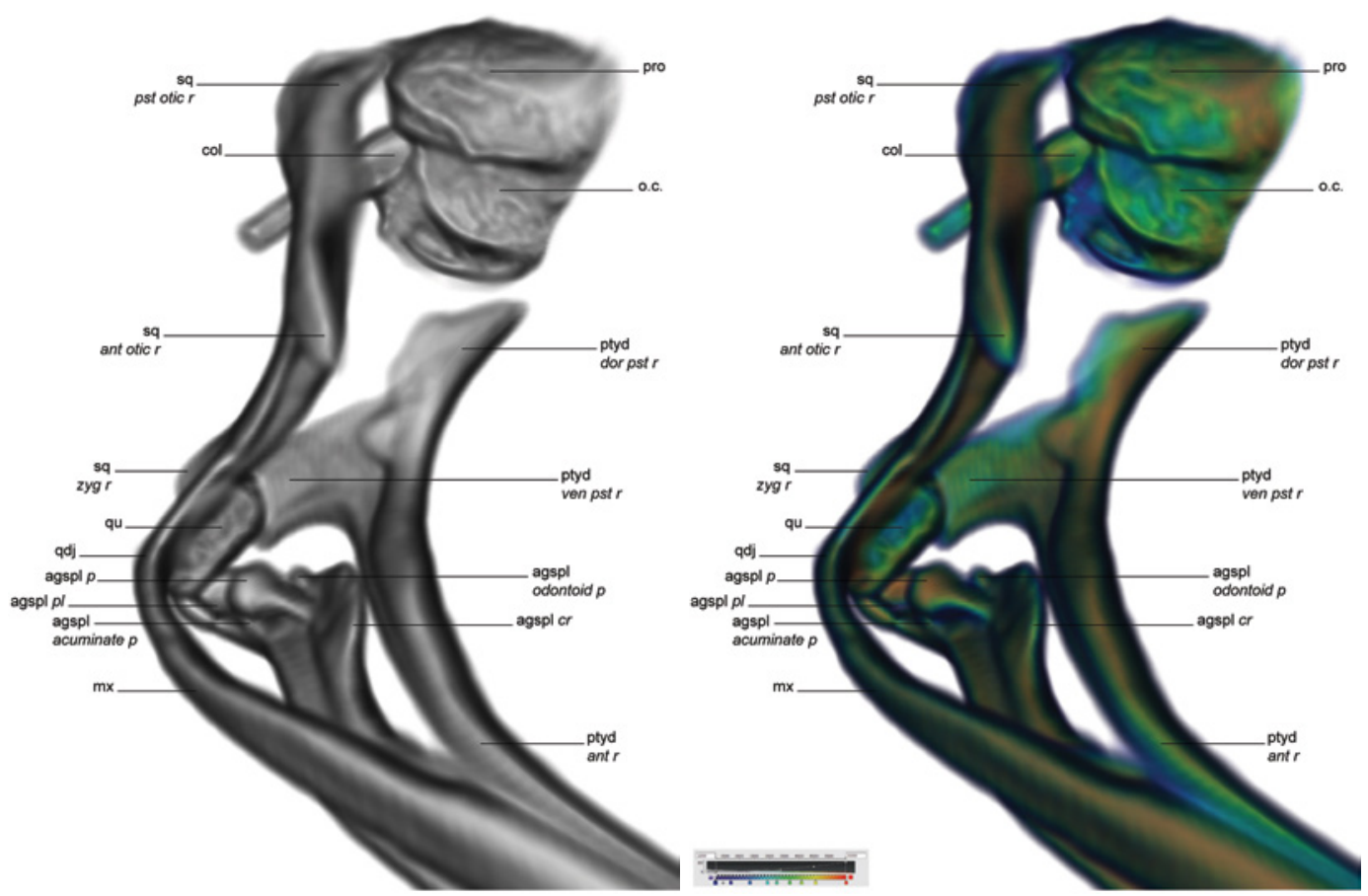

FIGURE 5 (A) Right lateral view of the Blommersia transmarina otic capsule. The cranium has been clipped laterally, posteriorly, and dorsally to facilitate visualization of the interior of the otic capsule. The anterior portion of the skull is clipped at the articulation of the palatine and alary cartilage. (B) Corresponding left sagittal plane, medial view of the B. transmarina otic capsule. The volume has been clipped to facilitate visualization of the interior of the otic capsule [MNCN50446 male; volrenWhite (A) and physics colormaps (B), grey [density] values: 12000-55500].

articulates with the nasals along three-fourths of its length on both sides. The posterior region of the cup-shaped alary cartilages is narrowly separated, lateral, and ventral to the tectum nasi's posterior borders; it is calcified and fuses anteromedially with the ventral septum nasi at slightly over half its ventral-rostral length (fig. 4). As a whole, the tectum nasi and alary cartilages serve as a roof and floor, respectively, to create a pair of large concavities (i.e., cavum principale; Trueb, 1968b) to either side of the septum nasi that ultimately lead to the olfactory foramen of the sphenethmoid. The palatine articulates with the ventrolateral border of the alary cartilage, bracing the nasal capsule against the maxilla. The vomer's cupshaped anterior segment delimits the posterior nares, while the exterior anterior nares are located at the anterolateral margin of the nasals (Reynolds, 1897).

Septomaxillae. The septomaxilla is a paired membrane bone that forms on top of the nasal capsule and is situated above the maxilla and anterior to the vomer's rostral tip. In two individuals (i.e., MNCN50430 and 50437) it was observed to contact the vomer. It has the shape of a ventrolaterally oriented loop with a thickened ellipsoidal cap facing the maxilla (Trueb, 1968b) (fig. 4). In several individuals (e.g., MNCN50431, 50433, 50446) an unpaired dense spherical object of unknown nature was observed dorsal to the septomaxilla (fig. 1).

\section{Dorsal dermal neurocranium}

Nasals. The nasal is a lightly ossified paired bone that lies dorsal of the nasal capsule and 
anterior to the ossified region of the sphenethmoid. It presents an extensive cartilaginous articulation with the medial margin of the dorsal ridge of the tectum nasi. Posterolaterally, the nasal has a more heavily ossified maxillary process (Duellman \& Trueb, 1994) that terminates above the palatine and in line with the pars facialis of the maxilla (fig. 2).

Frontoparietals. The frontoparietal is a paired bone that originates dorsal to the sphenethmoid and extends posteriorly to slightly before the medial fusion of the prootics (fig. 1). Additionally, in B. transmarina it extends a short distance laterally above the anterior auditory capsule, covering about 1/4 of the posterodorsal medial optic foramen (i.e., supraorbital flanges), which is yet another sign of hyperossification (Duellman \& Trueb, 1994). The paired bones articulate at their medial margin, investing the entire dorsal roof of the neurocranium. At the posterolateral corner above the prootic they present a dorsal odontoid protuberance presumably resulting again from hyperossification in $B$. transmarina (fig. 4).

\section{Ventral dermal neurocranium}

In $B$. transmarina the ventral cartilaginous wall of the neurocranium is calcified. There are two large bilaterally symmetric foramina anterior to the posterior alae of the parasphenoid that correspond to the exit of C.NN. V (trigeminal) and VII (facial) (Ecker, 1889; Reynolds, 1897). Slightly anterior and more medial to these are another pair of smaller foramina that correspond to the exit of C.N. VI (abducens). The orbitonasal foramen (fig. 3) serves as an exit for C.NN. II (optic nerve), III (oculomotor), and IV (trochlear) (Reynolds, 1897; Duellman \& Trueb, 1994).

Vomers. The vomer is a paired bone located below the nasal capsule (fig. 2). Its anterior segment resembles a shark's dorsal fin with an elongated leading edge (i.e., anterior portion;
Maglia et al., 2007) and a cup-shaped trailing edge (i.e., prechoanal and postchoanal portions), whose base aligns almost parallel to the pars palatina of the maxilla. Along the leading edge before reaching the tip, the posterior segment branches off the anterior segment posteromedially via a peduncle. The posterior segment (i.e., dentigerous portion) is cylindrical, covers a minimal part of the palate, and bears a dentigerous process three-fourths its distal length below the nasal capsule. The dentigerous process bears ventrolaterally oriented vomerine teeth three-fourths its distal length, as well as presenting vomerine teeth on its posterior tip, which terminates immediately posterior to the olfactory foramen of the sphenethmoid. The vomer has no visible osteological connection to either the premaxilla or the maxilla in B. transmarina. The septomaxilla is contiguous with the base of the vomer's leading edge above the maxilla (fig. 3).

Parasphenoid. The parasphenoid is an inverted T-shape bone that invests the braincase ventrally. Its anterior ramus (i.e., cultriform process; Duellman \& Trueb, 1994) extends from the posteromedial margin of the sphenethmoid to the prootic region, and its posterolateral alae cover the auditory capsules ventrally. In B. transmarina the parasphenoid is less dense along its cultriform process; however, it is hyperossified posteriorly fusing with the neurocranium and otoccipital posteroventrally (fig. 2). Blommersia transmarina does not have parasphenoid odontoids.

Palatines. The palatine is a slim paired transverse element that braces the upper jaw against the neurocranium. Its medial end articulates laterally below the alary cartilages of the nasal capsule (fig. 2), and its distal end widens and articulates with the medial lamina horizontalis of the maxilla immediately posterior to its pars facialis (fig. 4). In B. transmarina it is smooth and does not bear a serrate bony ridge. 
Pterygoids. The pterygoid is a paired triradiate medial brace between the upper jaw, suspensorium, and neurocranium (Duellman \& Trueb, 1994). It has the shape of an inverted "Y" laying horizontally (figs. 2 and 4). The anterior ramus presents a broad articulation with the maxilla and the ventral posterior ramus articulates laterally with the quadrate. The latter presents a caudoventrally oriented process at the ventroposterior edge of its medial surface (fig. 3). The anterior ramus is thicker along its dorsal edge, presenting a groove below its lateral margin that extends posteriorly to the base of the dorsal posterior ramus, investing the cartilaginous pterygoid process of the quadrate. The dorsal posterior ramus extends medially toward the lateral anteroventral auditory capsule; however, it is not completely ossified; ossification extends along its leading edge about half the distance and its lateral face remains open like a saddle, embracing the cartilaginous pseudobasal process of the quadrate.

\section{Lateral dermal neurocranium}

Squamosal bones. The squamosal in lateral view looks like an anteriorly inclined "T" and participates in the suspension of the upper jaws from the skull (fig. 4). The dorsal ramus (i.e., otic ramus) is oriented dorsomedially, articulating posteriorly with the dorsolateral margin of the prootic above the auditory capsule at a cartilaginous joint. The anterior otic ramus extends toward the maxilla a short distance, terminating in an acuminate tip at the level of the posterior margin of the orbitonasal foramen of the neurocranium. The ventral ramus (i.e., zygomatic ramus) extends ventroposteriorly at a slightly over $50^{\circ}$ angle with the maxilla and articulates with the quadratojugal laterally and with the quadrate medially at its ventral end (fig. 6). The medial surface
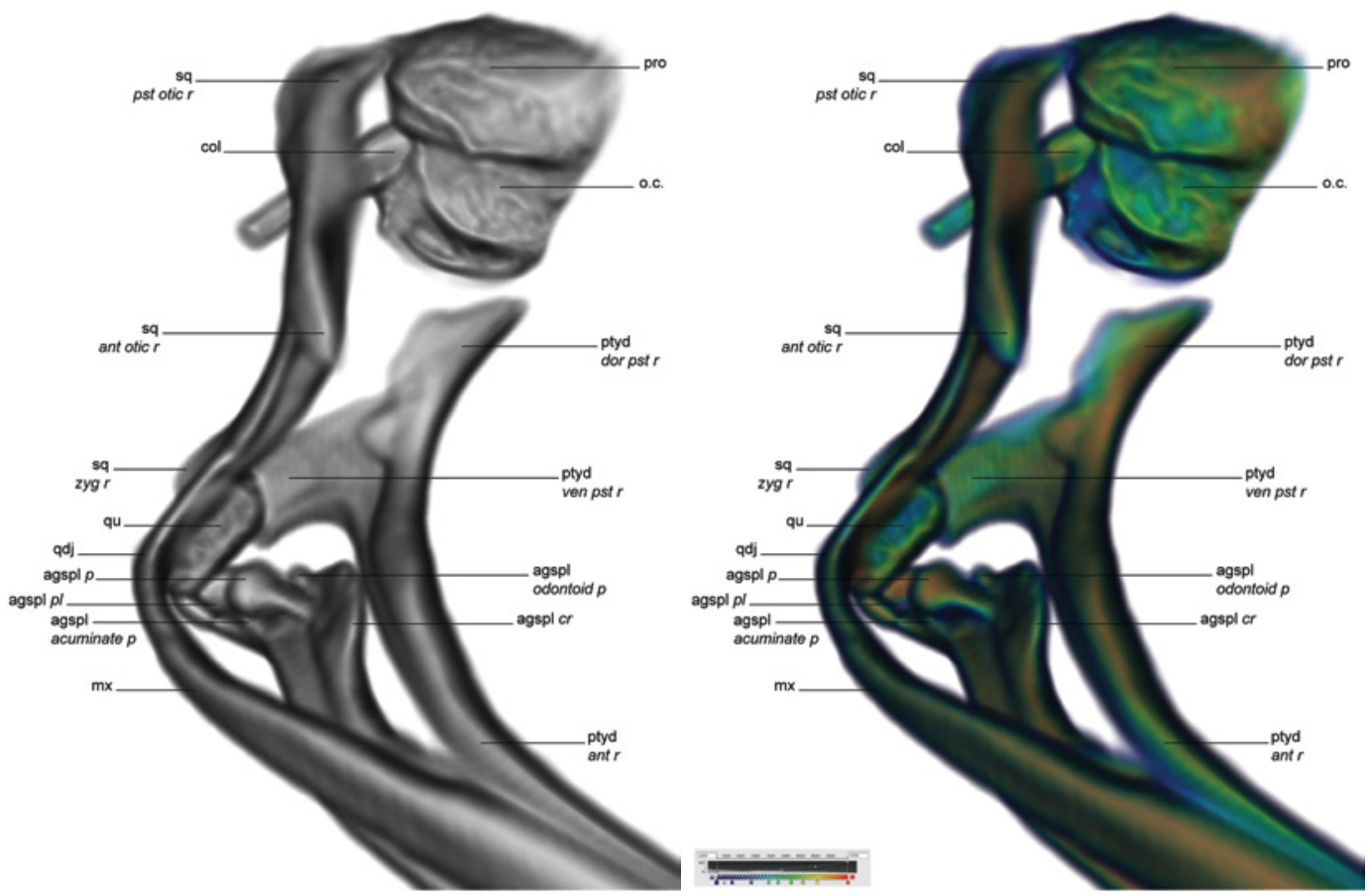

FIGURE 6 Dorsal and internal view of the right Blommersia transmarina suspensorium / jaw articulation [MNCN50446 male; volrenWhite (A) and physics colormaps (B), grey [density] values: 12000-55500]. 
of the zygomatic ramus presents a groove that continues into the posterior otic ramus, which invests the cartilaginous otic process of the quadrate.

\section{Upper and lower jaws}

Premaxillae. The premaxillae are located anteromedially in the head and are united syndesmotically medially to each other and laterally to the maxillae. Anteriorly, the maxillae slightly overlap the premaxillae laterally. Each premaxilla is like a plate with a curved downward leading edge that bifurcates posteriorly in two acuminate branches. From the center of the leading edge a less dense vertical strut extends posterodorsally. Medially the bone presents a less dense circular fenestra. Traditionally the premaxilla is divided into three parts (Duellman \& Trueb, 1994) (fig. 3): the pars dentalis has a curved downward leading edge and bears a dental ridge with teeth; the pars palatina serves as the lingual shelf and consists of two posterior acuminate branches; and the alary process is a dorsal vertical strut that serves as a vertical abutment for the nasal capsule.

Maxillae. Each maxilla resembles a longitudinal plank following a parabolic curve in the anterior-posterior direction. It overlaps the premaxilla slightly anteriorly and articulates with the quadratojugal posteriorly. The lamina horizontalis (Roček, 1994) runs along the midline of its medial surface, which terminates caudally slightly anterior to the articulation with the quadratojugal and posterior to the articulation with the pterygoid (fig. 3). This lamina expands medially from the bone's surface in the caudal-rostral direction immediately at the level of the pars facialis, creating a lingual shelf between the maxilla and its acuminate branch tip that terminates at the height of the septomaxilla (i.e., pars palatina). One individual (i.e., MNCN50435) presented paired circlet processes on the lingual shelf at the level of the vomer's anterolateral tip. Anterior to the articulation with the palatine the maxilla's external margin extends into a flat and wide triangular process (i.e., pars facialis) directed dorsally toward, and at the level of, the posterior tip of the nasal. The ventral border of the maxilla bears a dental ridge with teeth from its anterior tip to slightly before its articulation with the quadratojugal (i.e., pars dentalis).

Quadratojugals. The quadratojugals complete the upper jaw posteriorly. They articulate with the maxillae anteriorly and with the ventrorostral margin of the zygomatic arch of the squamosals posteriorly in an upward curve (i.e., pars articularis) (fig. 4).

Mentomeckelian bones. The Mentomeckelian bones are paired bones that form anteromedially replacing the Meckel's cartilage. They fuse syndesmotically with each other medially and have the shape of cylindrical hooks that are oriented dorsally and face toward each other medially (fig. 2). They form a short less dense acuminate process ventrolaterally, and dorsolaterally they articulate with the dentary (fig. 3).

Dentaries. The dentary is a paired bone that covers the Meckel's cartilage anterolaterally. It articulates medially with the dorsolateral margin of the Mentomeckelian bone and invests the dorsal region of the angulosplenial (fig. 3). As in most anurans, in B. transmarina the dentary bears no teeth and covers almost half the anterior length of the angulosplenial; both bones are solidly connected and their differentiation is inconspicuous.

Angulosplenials. The angulosplenial invests the ventrolateral, medial, and posterior regions of the Meckel's cartilage and is situated lateral to the ventral margin of the mentomeckelian bone. It is an arcuate paired bone that extends anteroposteriorly, forming a tight sigmoidal curve before its posterior articulation with the quadrate. In its caudal region, 
following the sigmoidal curve, there is a large groove along the midline of its lateral surface that opens up and flattens to terminate in an upward facing lobular plate, which embraces ventrally the quadratojugal-quadratepterygoid articulation of the suspensorium (fig. 3). Along the dorsomedial border of its posterior curved region there is a crest that terminates in a curved upward odontoid process anterior to the quadratojugal-quadratepterygoid articulation. Prior to this odontoid process, a bony process extends posterolaterally from the crest's base supporting a large rounded head that curves downward toward a tiny acuminate process that protrudes from the dorsolateral border of the angulosplenial parallel to the odontoid process (fig. 6). The head of the bony process that extends from the crest is in line with an edge of the ossified cuboid quadrate (fig. 6).

\section{Suspensorium}

Quadrates. The quadrate is the central element that suspends and braces the jaws to the skull and is mostly cartilaginous. Its pars articularis (Duellman \& Trueb, 1994) presents perichondral ossification along its medial margin and buttresses the quadratojugal with the squamosal and the posteroventral ramus of the pterygoid at the mandibular articulation (fig. 6). The quadrate is cuboid in shape.

\section{Hyobranchial apparatus}

In B. transmarina the hyoid plate (i.e., parahyoid) is very lightly calcified at its center with no obvious pattern across individuals (fig. 7). The hyoid plate in this species bears two long bony posteromedial processes whose anterior ends lie at the level of and dorsal to the anterior process of the omosternum, each laying roughly on either side just rostral of the fork in the omosternum. The posteromedial processes present an expanded anterior epiphysis and terminate as a truncated cylinder. Most individuals (excluding $\mathrm{MNCN}_{50430}$, 50431,50432 ) have a lateral crest on the posterior margin that terminates slightly rostral of its posterior limit, and which displays varying degrees of development. They are flattened dorsoventrally and exhibit an upward inclination in the anteroposterior direction, terminating at the level slightly before the scapulasuprascapula articulation.

\section{Pectoral girdle}

Blommersia transmarina presents a firmisternal pectoral girdle (Emerson, 1983) in that the epicoracoid cartilages lack horns and are
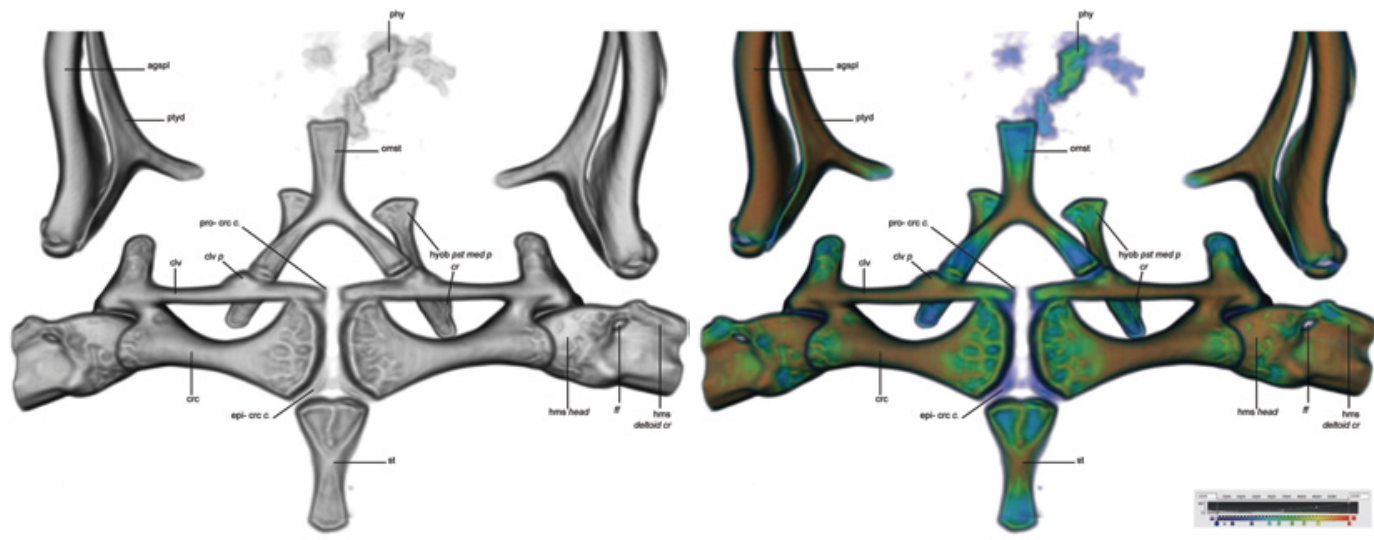

FIGURE 7 Ventral view of the Blommersia transmarina pectoral girdle. The dorsal coronal plane is clipped at the mandible to facilitate visualization [ $\mathrm{MNCN}_{50446}$ male; volrenWhite (A) and physics colormaps (B), grey [density] values: $12000-55500]$. 
fused medially; the sternum is fused to the pectoral arch and possesses relatively lengthier prezonal (i.e., omosternum) and postzonal (i.e., mesosternum) elements than in arcifery. Anteroposteriorly the prezonal elements include a cartilaginous episternum and an ossified omosternum; the postzonal elements consist in an ossified (meso)sternum and a cartilaginous xiphisternum (Duellman \& Trueb, 1994).

Episternum. The episternum is an anterior cartilaginous extension of the omosternum that does not ossify. It envelops the end of the anterior branch of the omosternum and presents a rhomboid shape like a craniallydirected angled spade.

Omosternum. The omosternum is an elongated bone that bifurcates posterolaterally and articulates with both clavicles at a process along the first third of their proximal end, but never at their medial tip (fig. 7). The length, width, and degree of ossification of the posterior branches of the omosternum vary across individuals (table 2).

Mesosternum. The (meso)sternum is relatively lengthened compared to arciferal anurans and its shape depends on its level of ossification. The mesosternum is an elongated bone that articulates cranially with the medial ends of both coracoids at the epicoracoid cartilages (fig. 7). It presents either of two configurations: a wide anterior end that tapers toward the center (e.g., MNCN50430, 50432, $50435,50436,50446$ ), or a bifurcated anterior end, with wider branches than those of the omosternum, in which each branch articulates anteriorly with one of the coracoids (e.g., MNCN50431, 50433, 50437, 50439). One individual (i.e., DRV6851) has a sternum with similar widths at the anterior and posterior ends that resembles an hourglass. The xiphisternum does not ossify and consists of a heart-shaped cartilage posterior to the mesosternum.

Clavicles. The clavicle is a paired, thin, and mostly straight dermal bone that is flattened along its dorsoventral axis. It articulates with the procoracoid cartilage proximally, the coracoid ventrally, and with the scapula distaldorsally (fig. 7). Ossification of the clavicle penetrates the procoracoid cartilage to various degrees depending on the individual. Its distal end widens cranially and its degree of ossification also varies across individuals (table 2). The clavicle presents a yet undescribed process positioned cranially at its proximal end, distal to the clavicle-coracoid articulation, which appears to articulate with the posterior branches of the omosternum and serve as an attachment site for several muscles (e.g., mm. deltoideus and coracoradialis) (fig. 7).

Coracoids. The coracoid is a paired chondral bone with a flattened proximal end and a rounded distal end. Its distal end articulates with the scapula at the glenoid cavity, whereas its proximal end articulates medially with the epicoracoid cartilage (fig. 7). The degree of ossification of its proximal end is variable and its shaft is smooth.

Scapulae. The scapula is a dorsoventrally elongated paired chondral bone that resembles an hourglass in shape. At the suprascapular articulation (fig. 8) the corpus scapulae (Špinar, 1972) is flat and triangular in shape. It tapers in the ventral direction and converges into the collum scapulae, which is elevated medially, at approximately half the scapula's length (table 2). At the glenoid cavity, the caput scapulae is divided into the pars acromialis anteriorly, which articulates with the clavicle, and the pars glenoidalis posteriorly, which articulates with the coracoid (Roček, 1994). These are of similar width, length, and thickness in $B$. transmarina. In the medial view, there is a deep cleft (i.e., sinus interglenoidalis; Roček, 2005) between the pars acromialis and pars glenoidalis.

Suprascapulae and Cleithra. The suprascapula is a paired dermal bone with varying degrees of ossification that covers roughly $2 / 3$ of its surface. The bony leading edge of the 


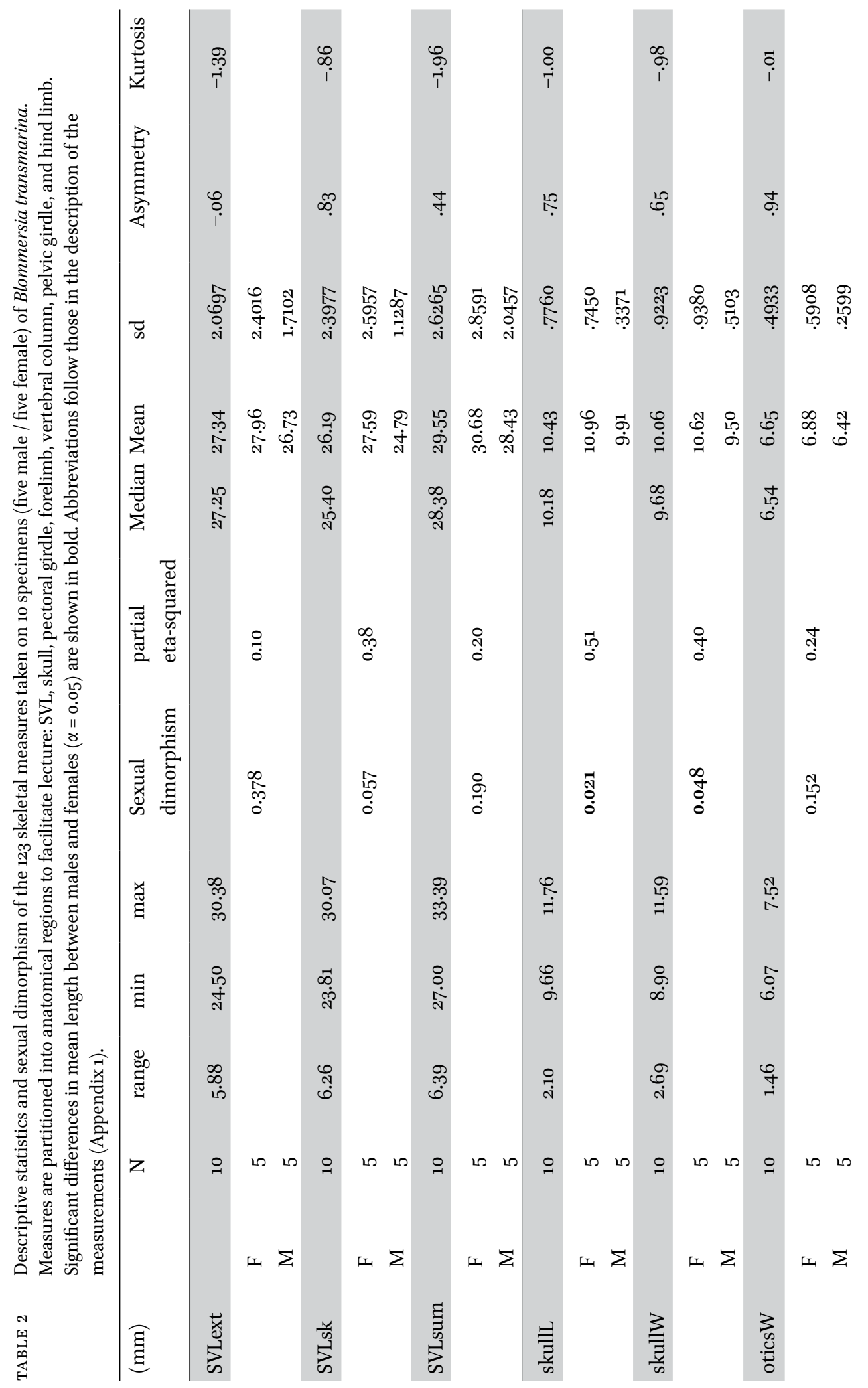




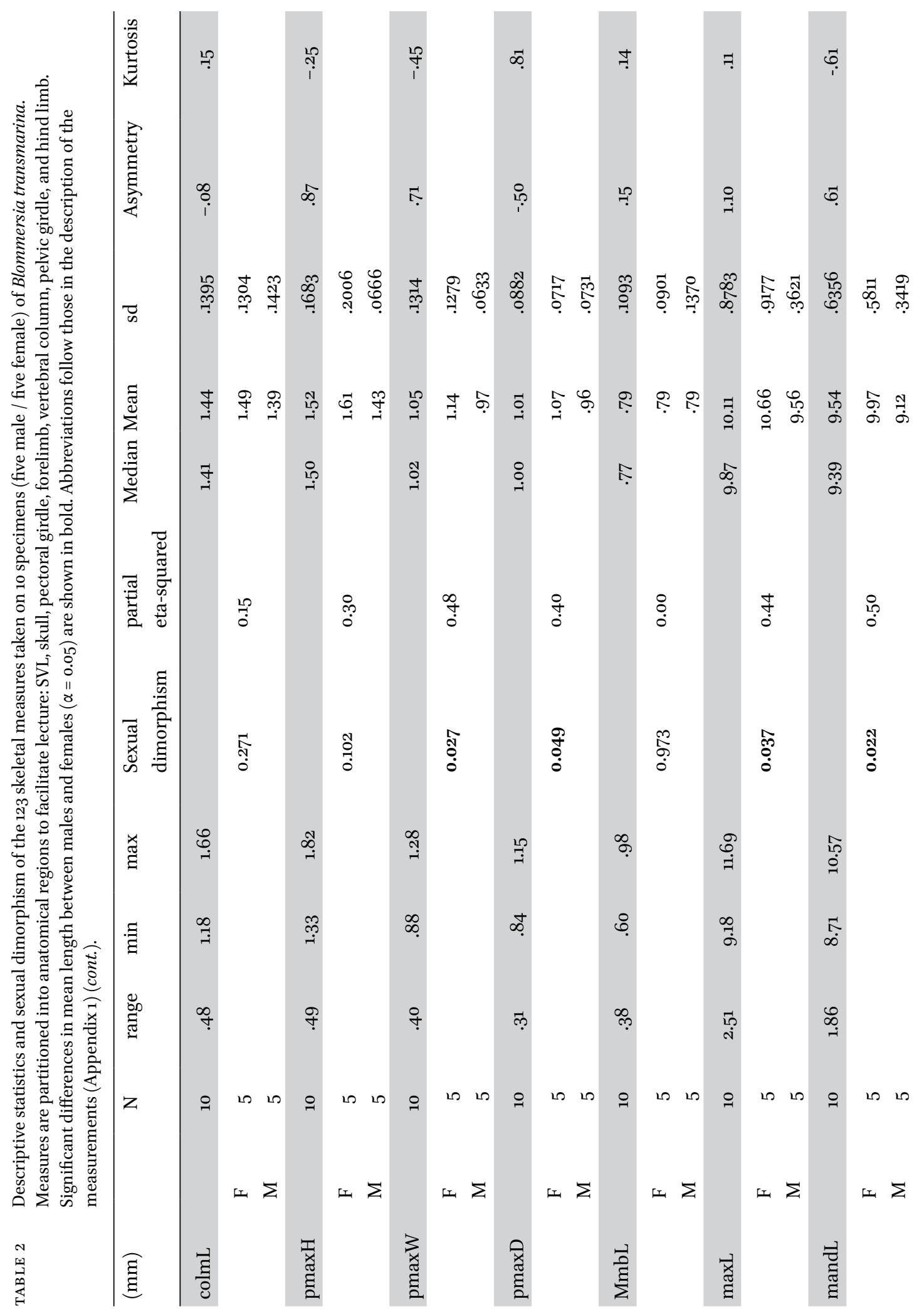




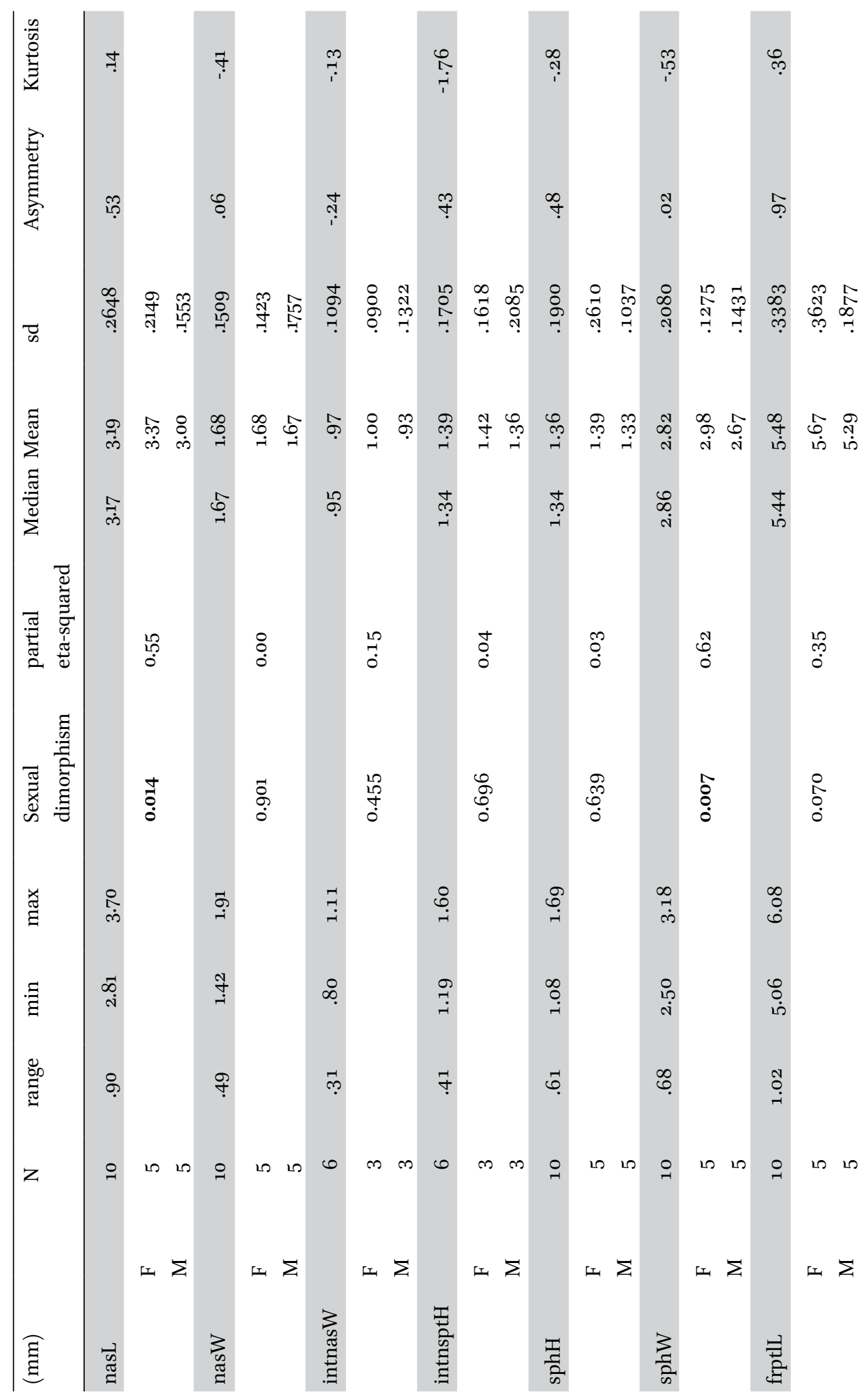




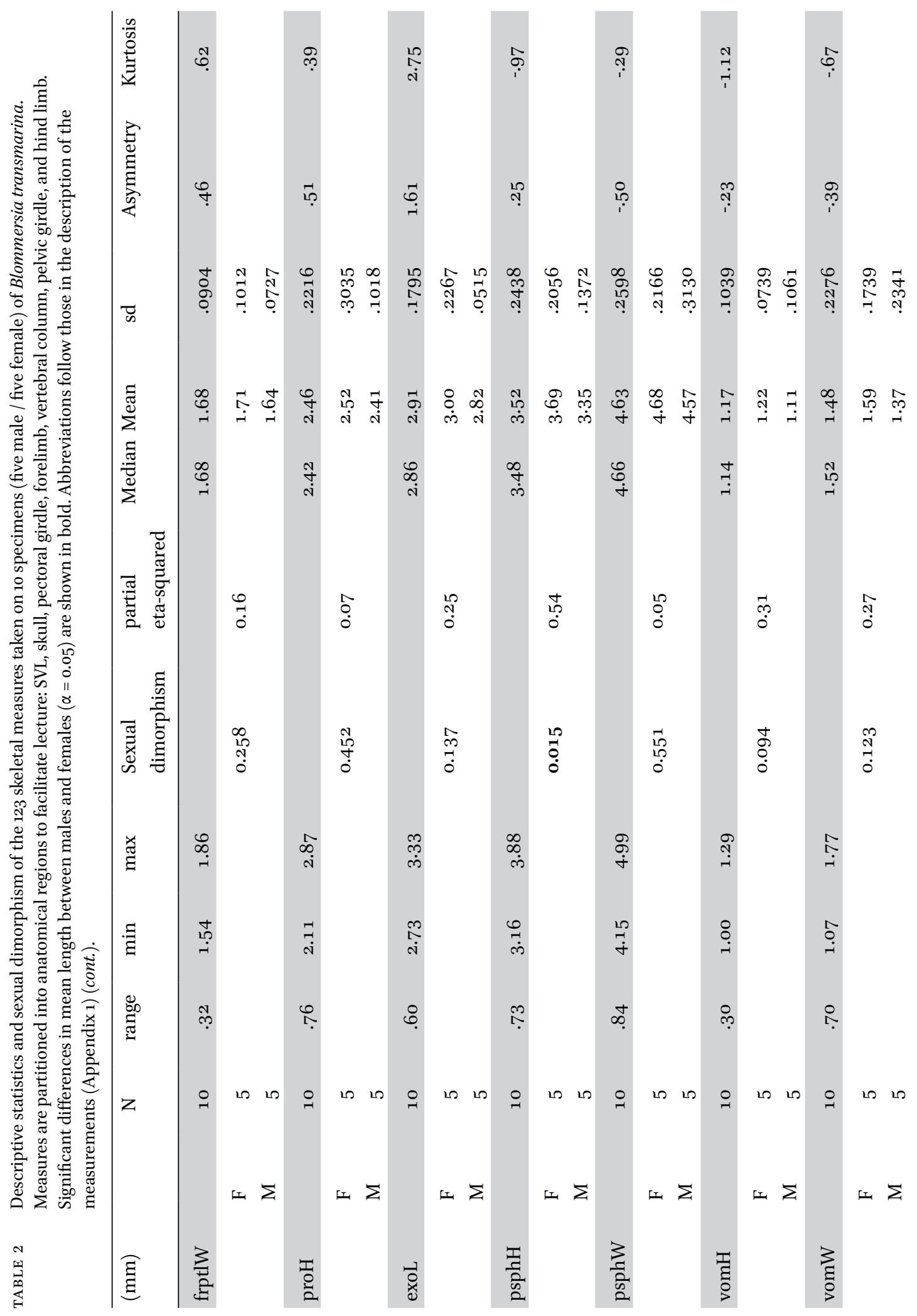




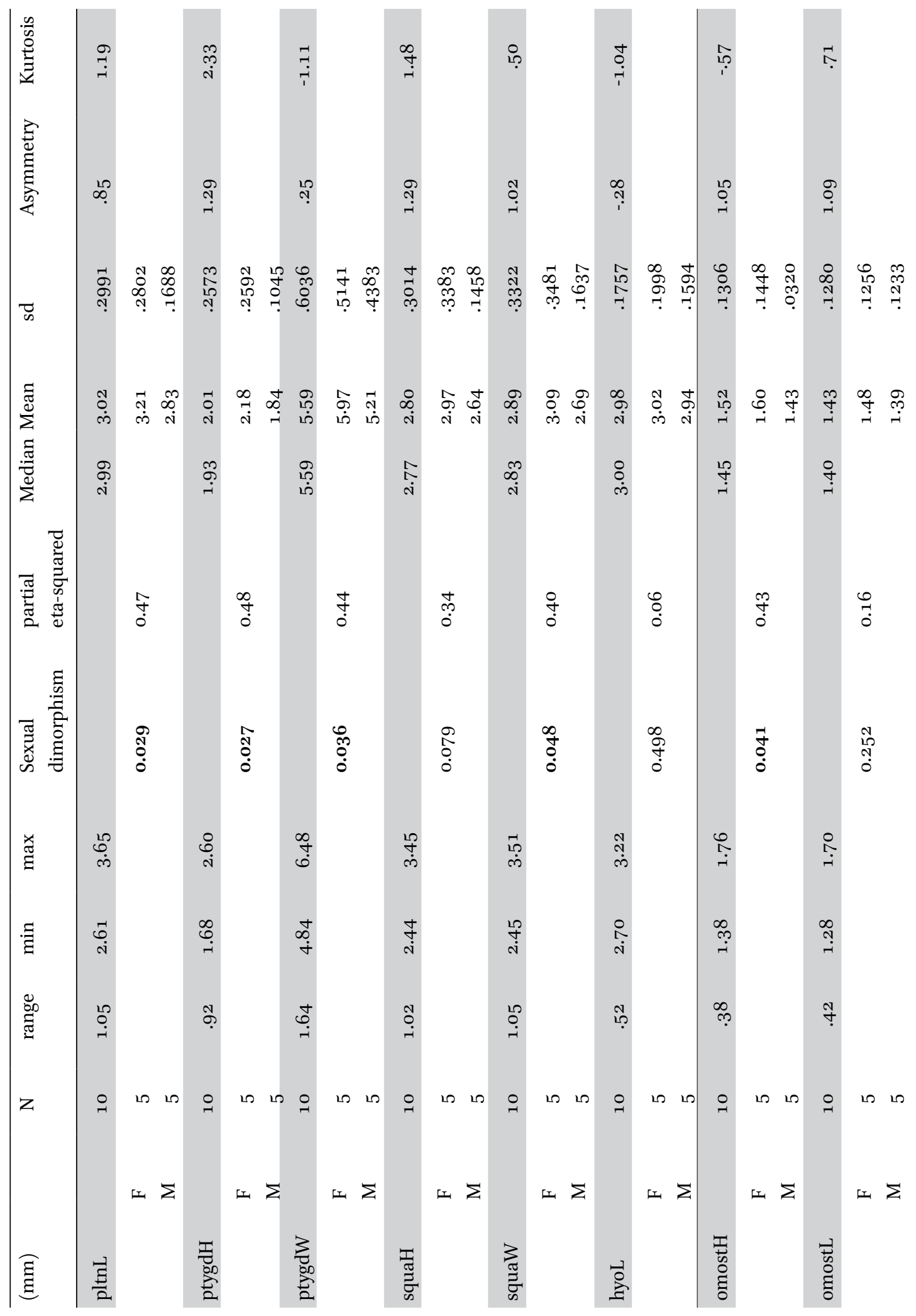




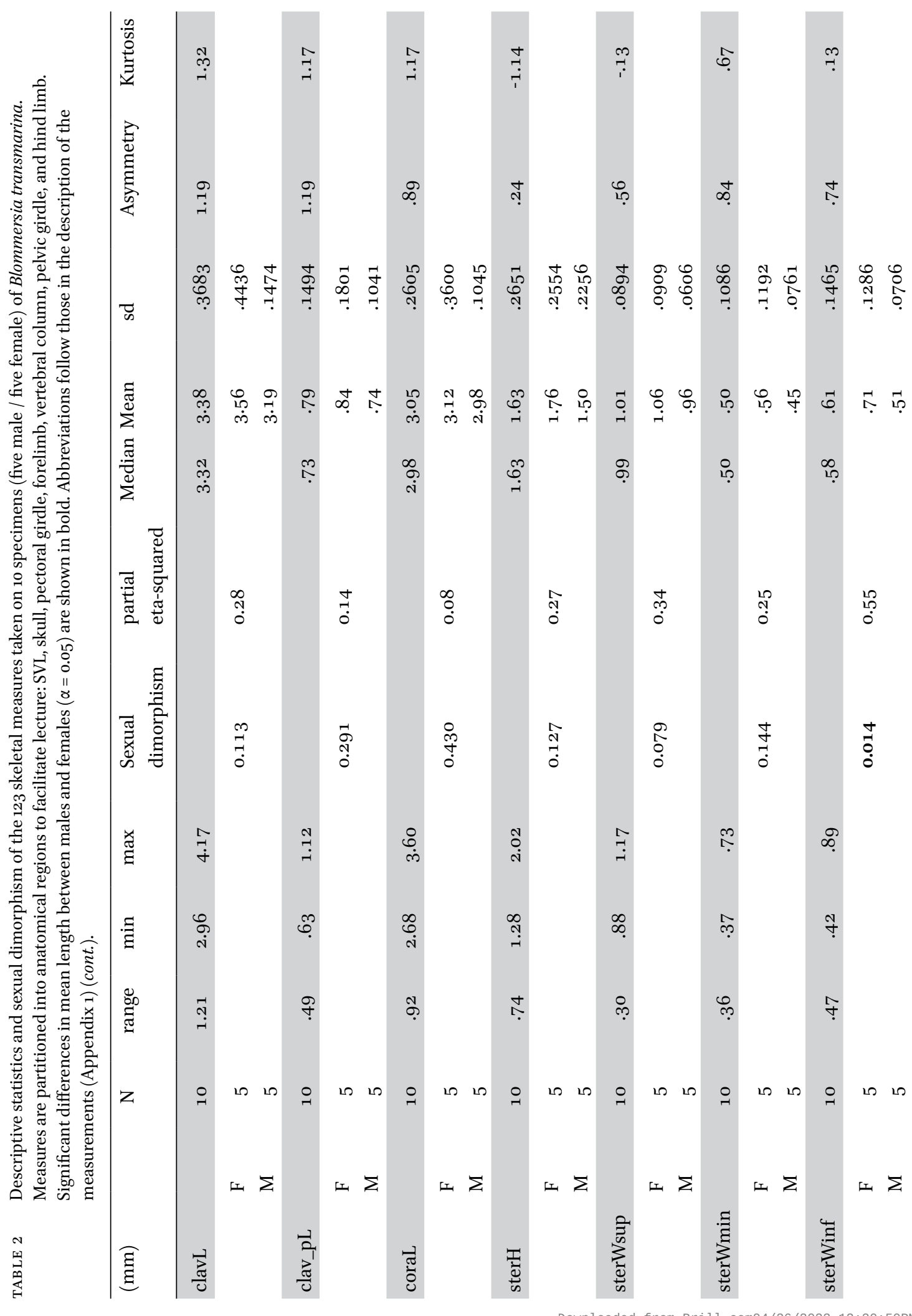




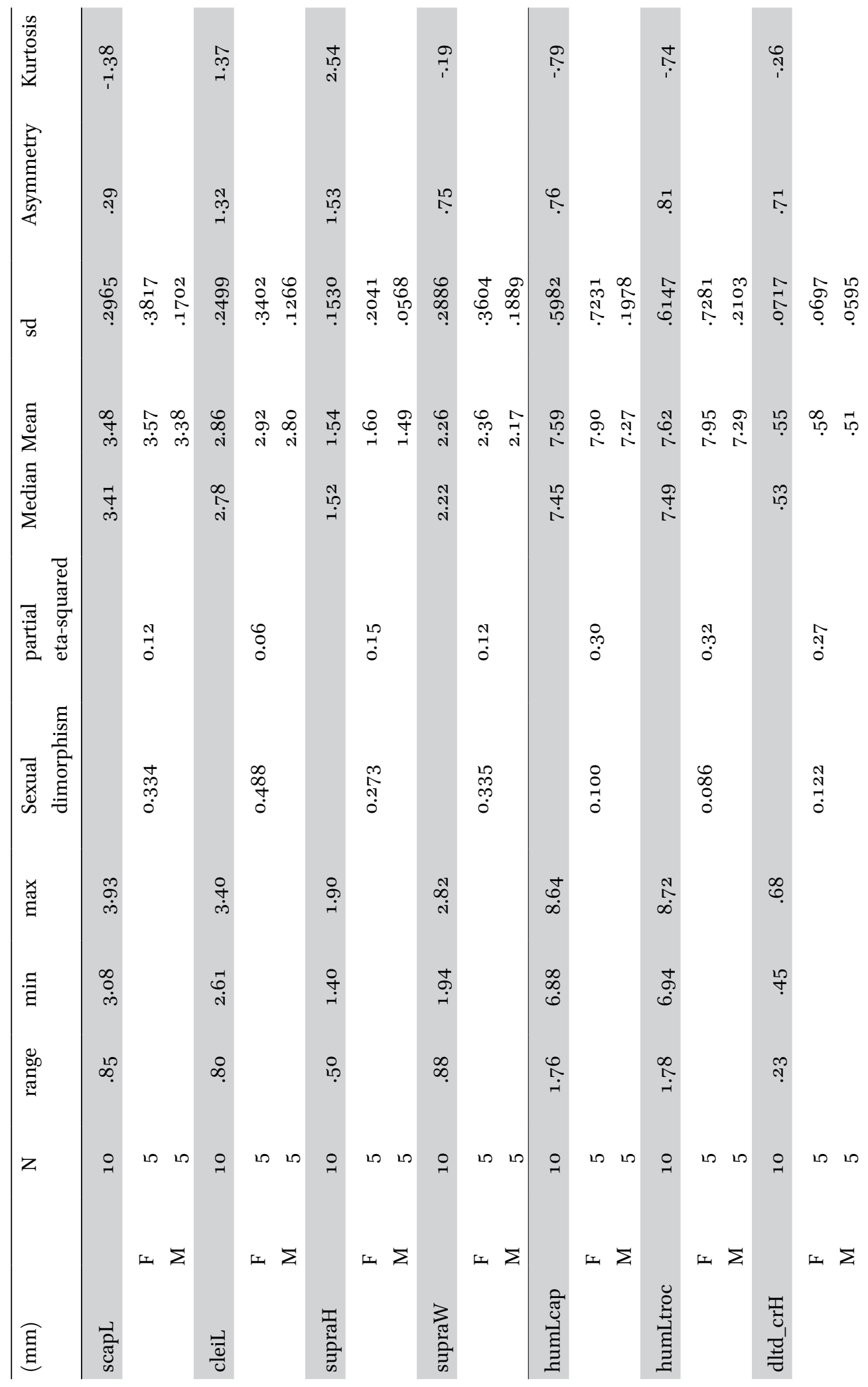




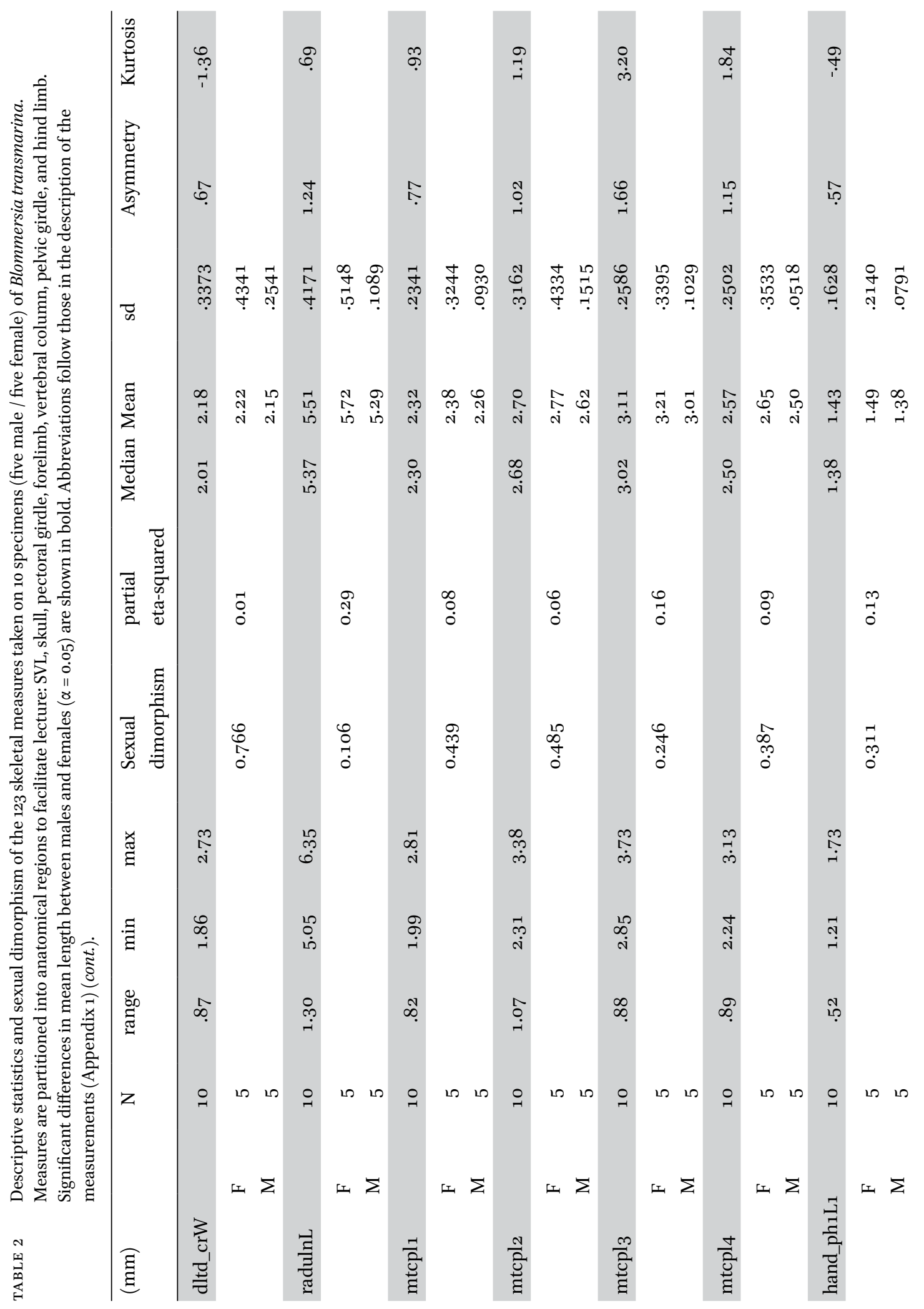




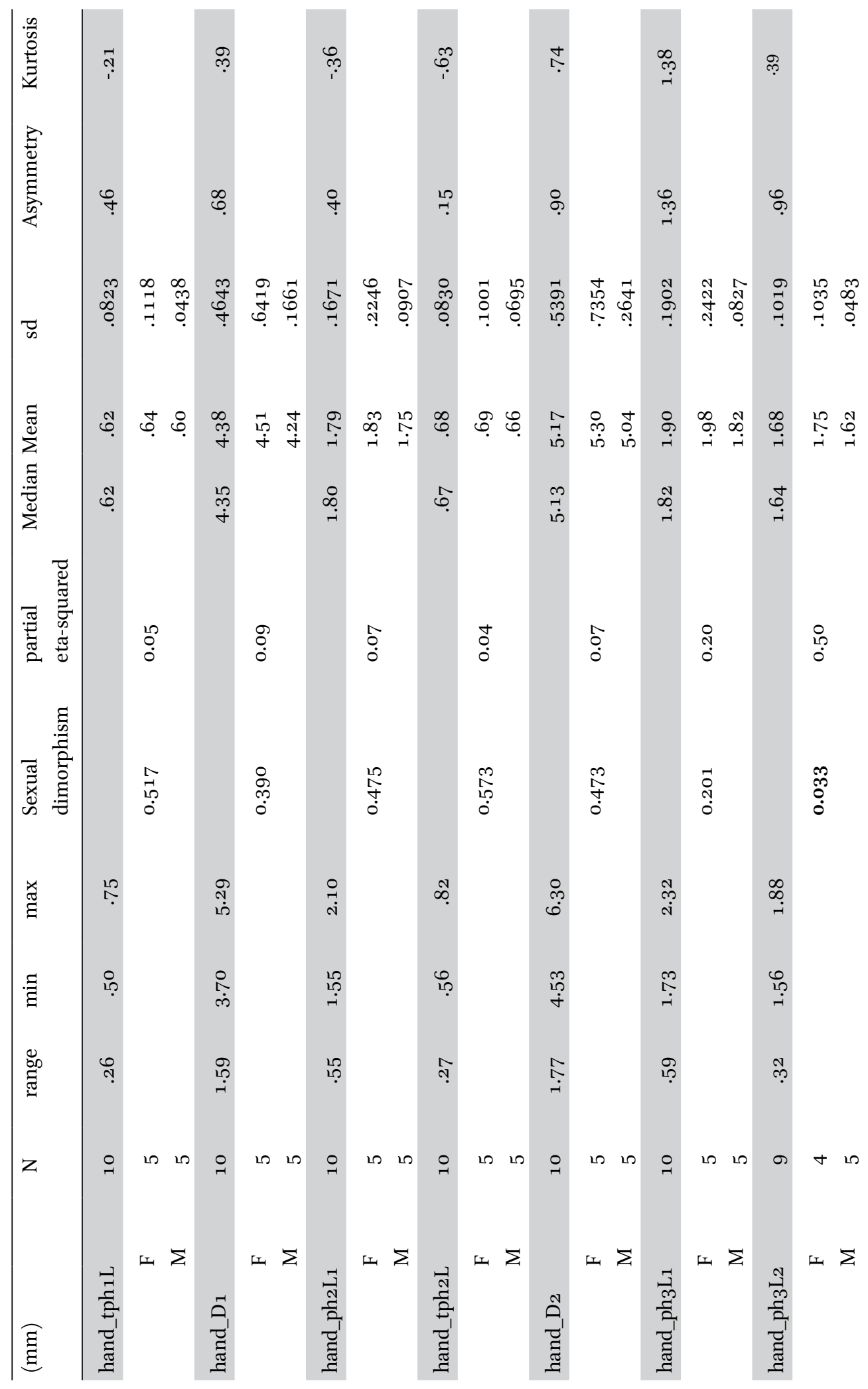




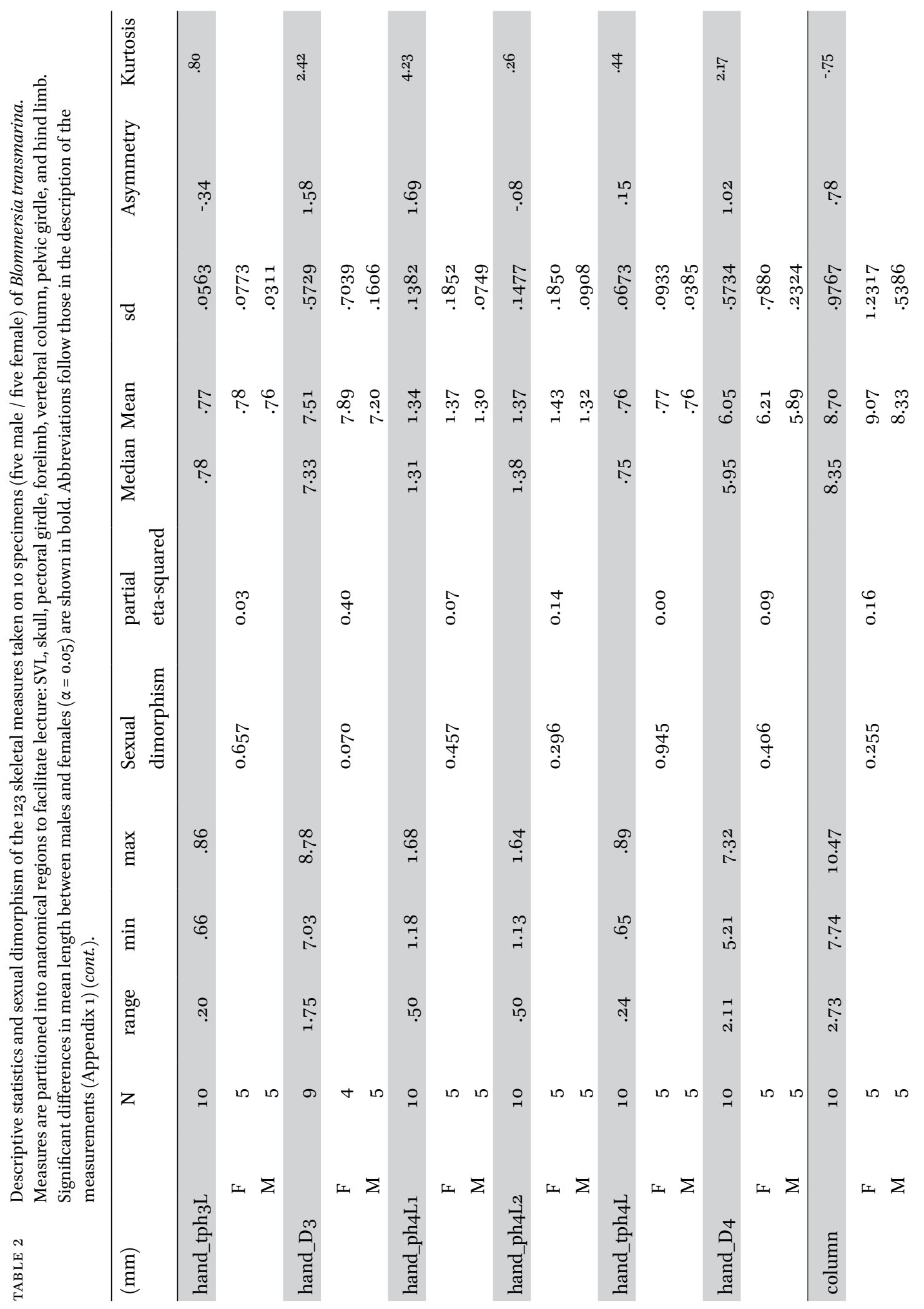




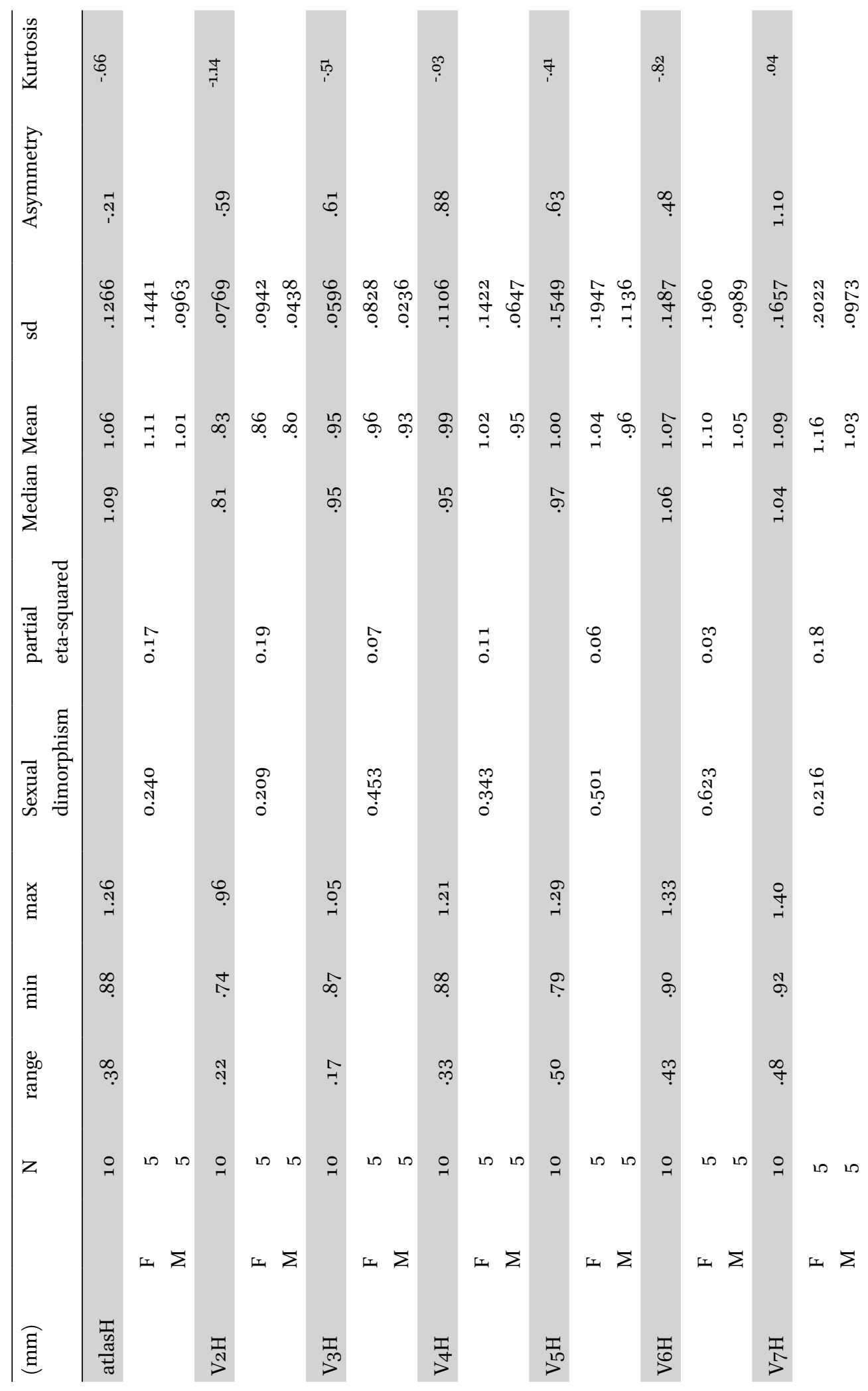




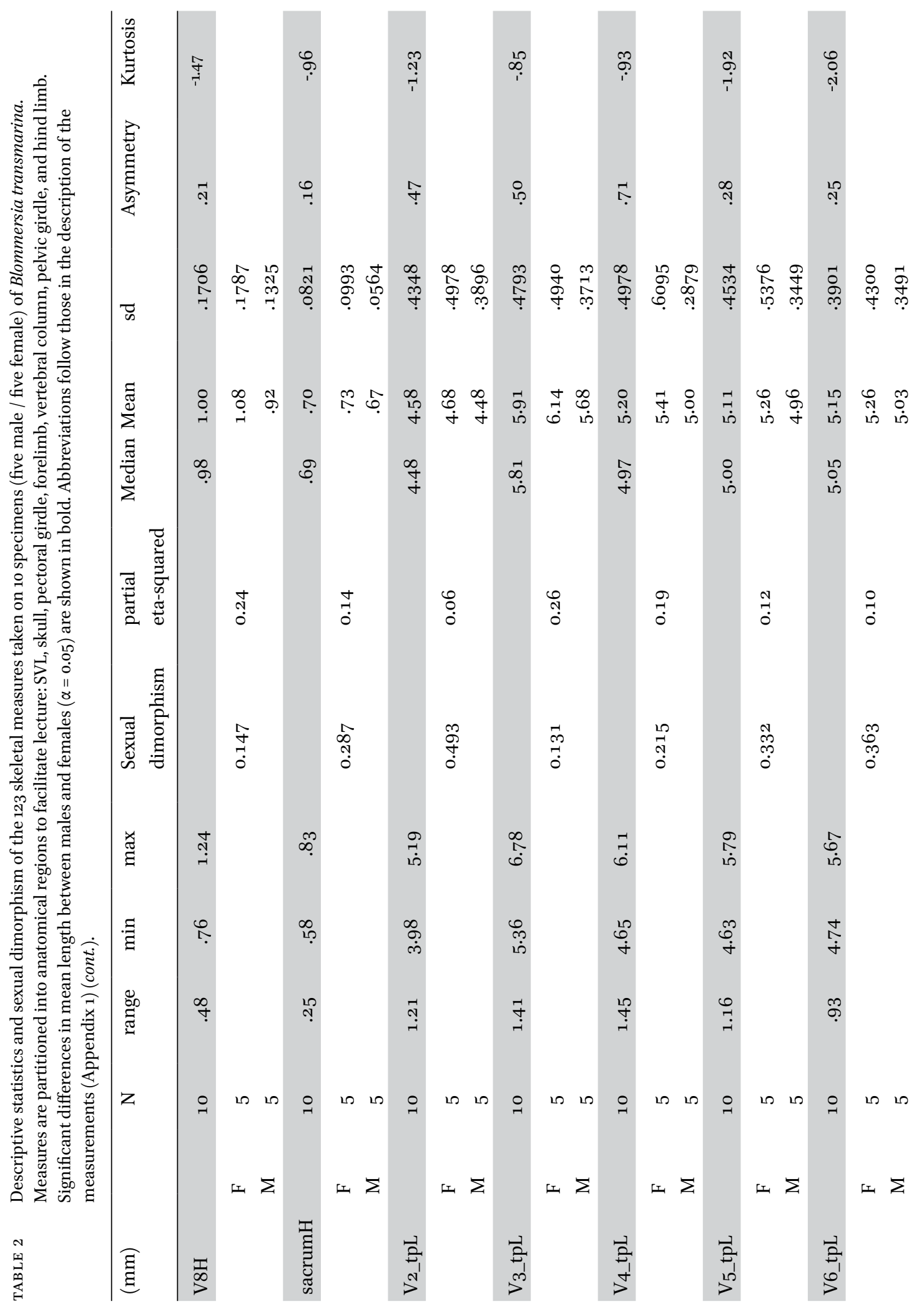




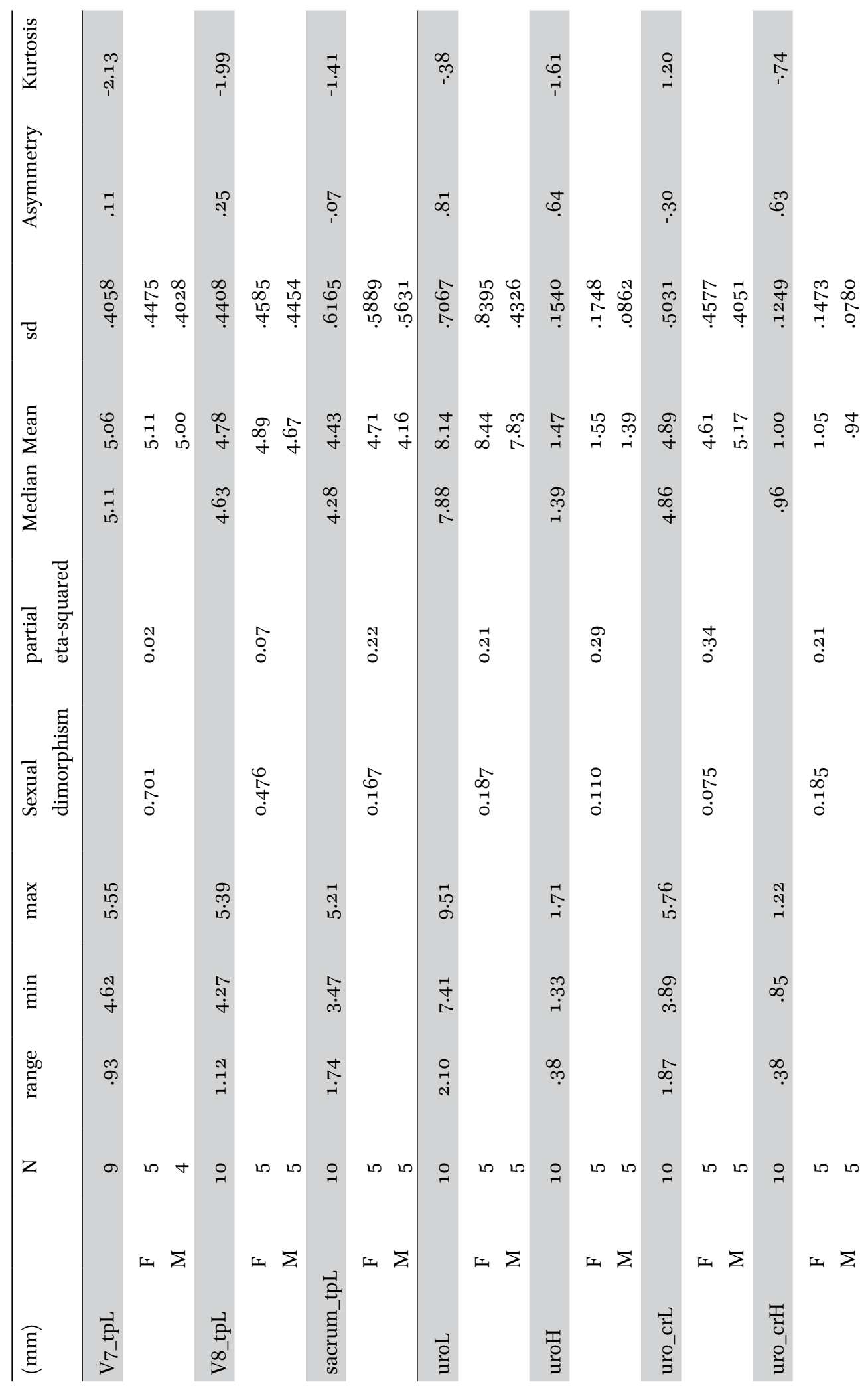




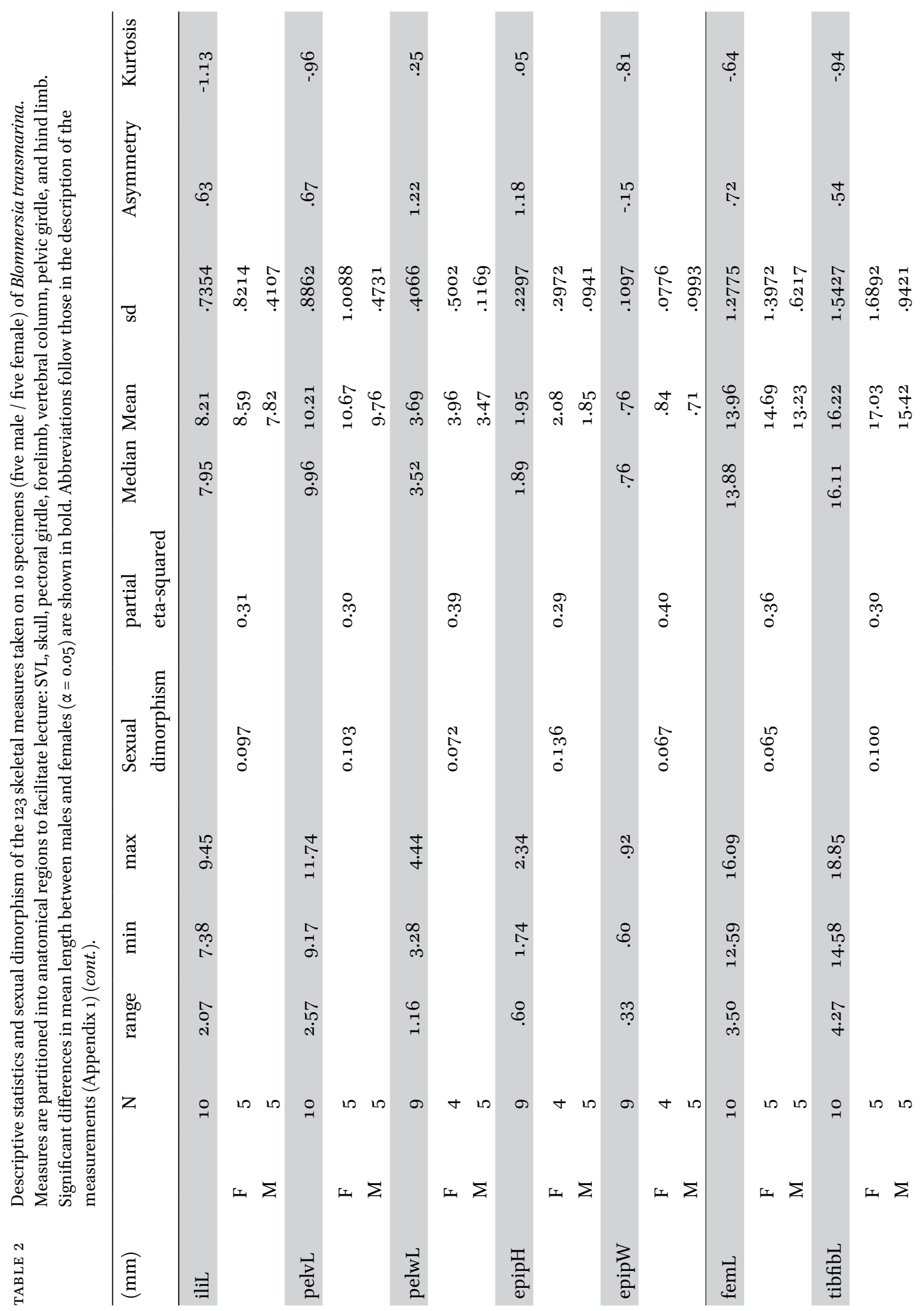




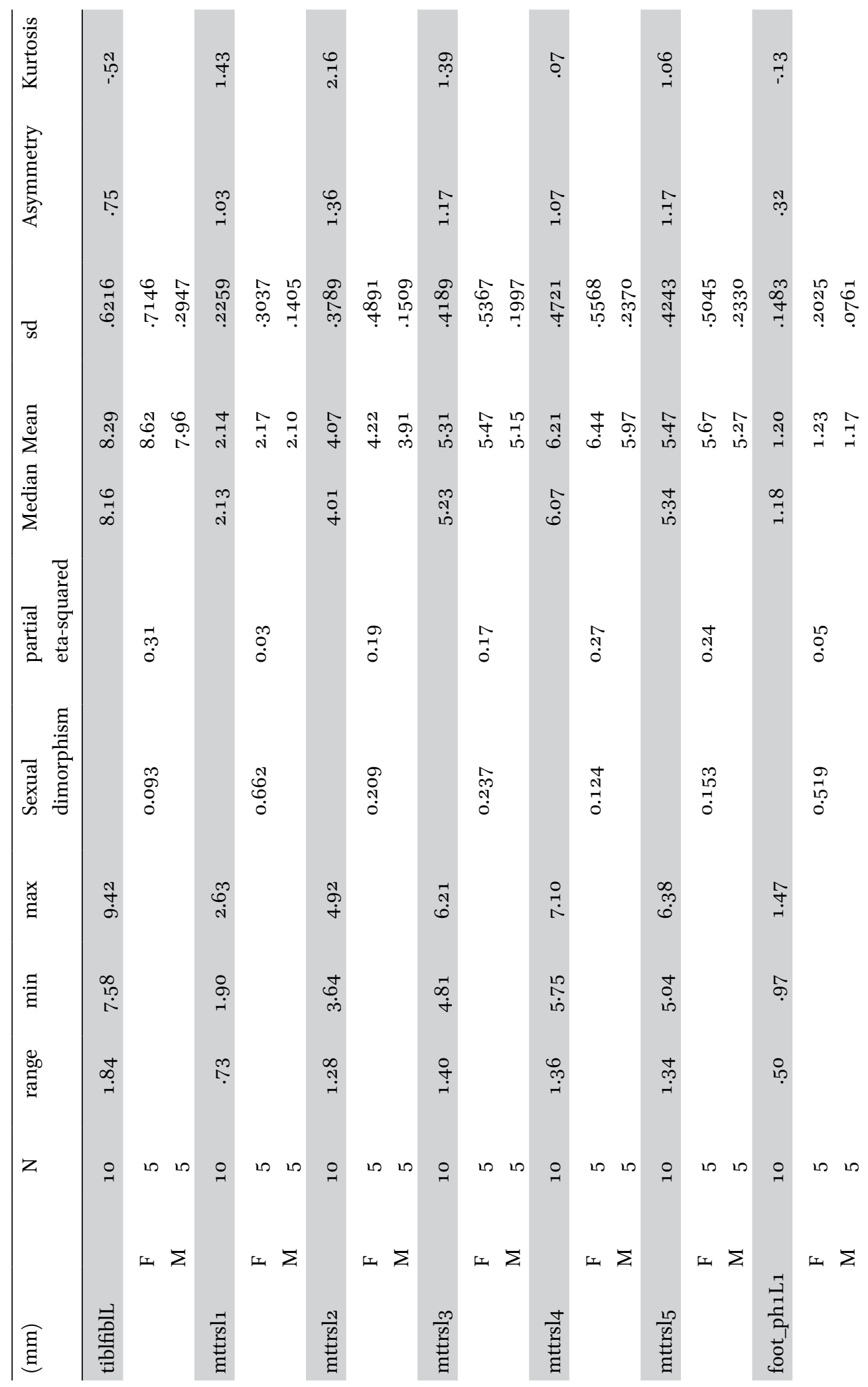




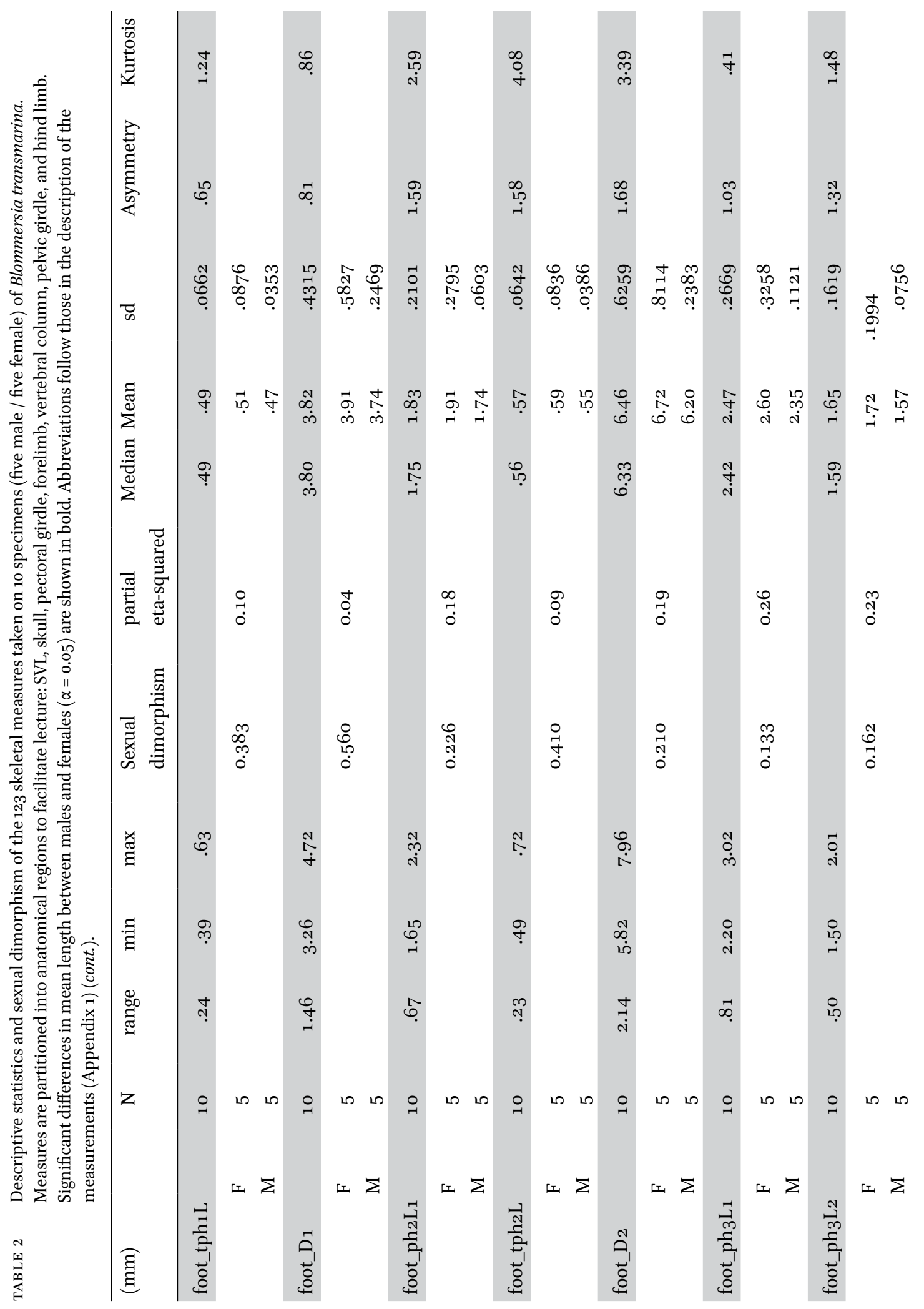




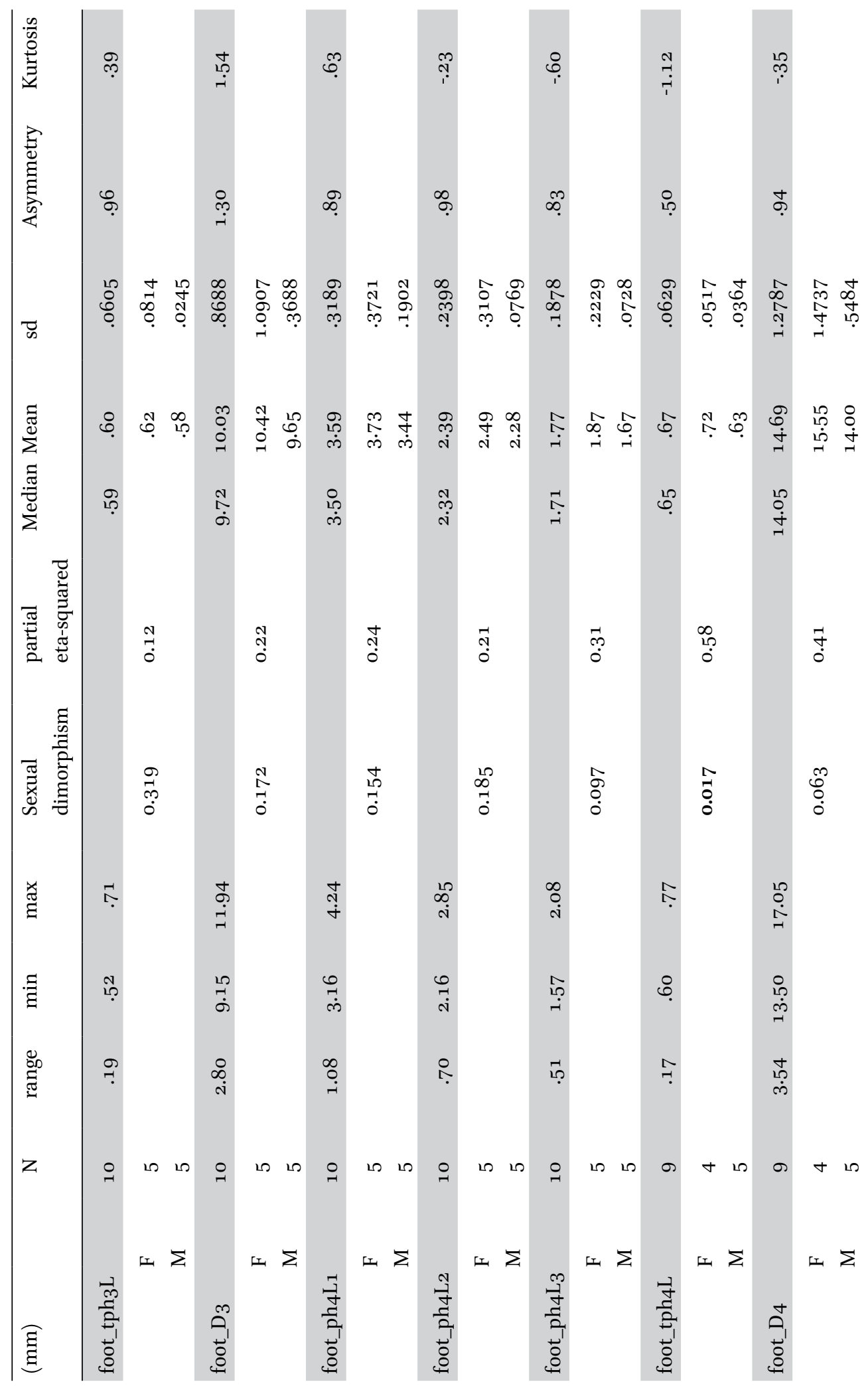




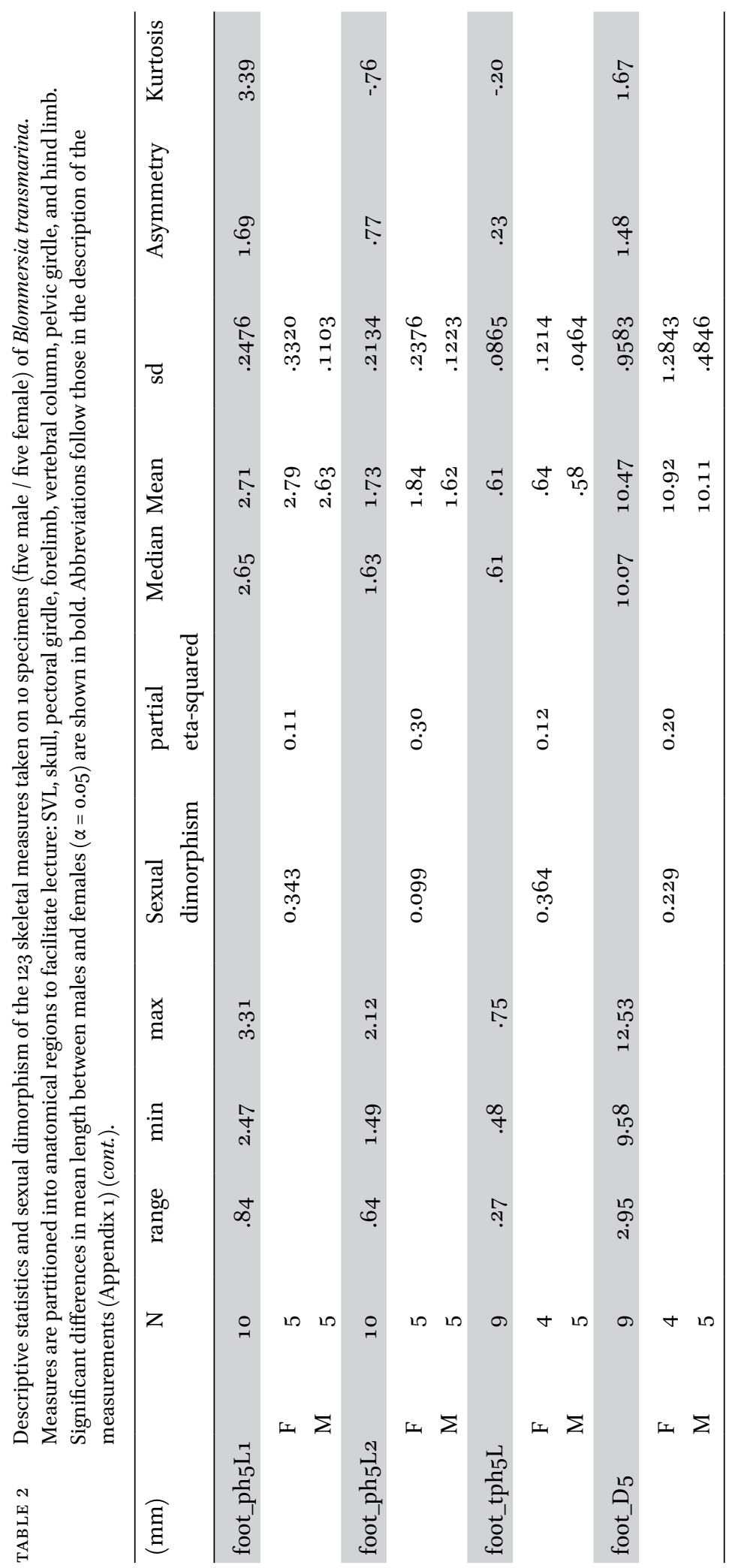



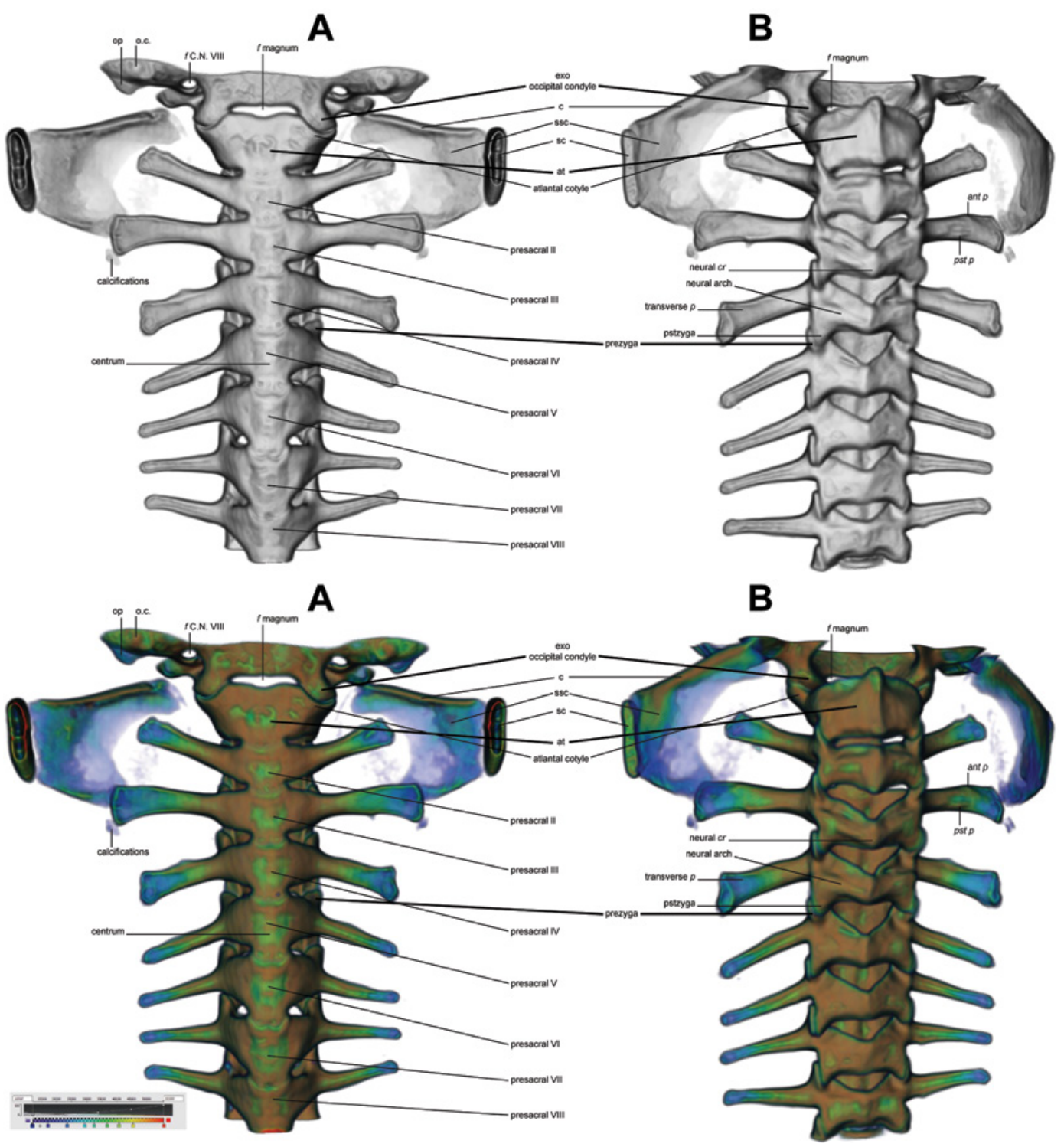

FIGURE 8 (A) Ventral view of the Blommersia transmarina vertebral column. (B) Dorsal view of the B. transmarina vertebral column. The volumes are clipped anteriorly at the foramen magnum and posteriorly immediately before the sacrum [MNCN50446 male; volrenWhite (A) and physics colormaps (B), grey [density] values: 12000-55500].

suprascapula is denominated the cleithrum. Ossification invades the suprascapular cartilage from the cleithrum and extends toward the anterior medial edge, and posteriorly and medially, resembling a crab claw (fig. 8). The anteromedial edge of the cleithrum is narrowly separated from the posterior epiotic eminence of the prootic, even making contact in some individuals (e.g., MNCN50430, 50431, 50446; fig. 1, DRV6851). At its distal end the suprascapula also presents varying levels of ossification and articulates with the scapula, but a cleft is clear between both elements. 


\section{Forelimb}

Humerus. The humerus head is round and slightly elongated. There is a large prominent cranial process at its proximal end denominated the deltopectoral crest (i.e., crista ventralis; Duellman \& Trueb, 1994). The anterior ridge of the deltopectoral crest articulates medially with the humerus head, leaving an opening (i.e., fenestra) directly below the articulation that also forms the beginning of an intertubercular groove that extends distally below the deltopectoral crest to the lateral border of the diaphysis (fig. 7). The crista lateralis (Špinar, 1972; Roček, 2005) is greatly reduced and limited to the proximal portion of the humerus immediately following the greater tubercle of the humerus head; otherwise the diaphysis is smooth. The diaphysis presents a slight sigmoidal curve that follows the line of the deltopectoral crest and ends at the distal lateral epicondyle.

Radioulna. The radius and ulna of tetrapods are fused into a single bone in anurans, although they can be differentiated at their distal end due to the presence of a groove (i.e., sulcus longitudinalis; Bolkay, 1919). Proximally, the ulna articulates with the humerus at the concave olecranon and with the radius at the capitulum. Distally, the ulna articulates with the ulnare and the intermedium (here ulnare'; see Discussion), while the radius articulates with the radiale and the centrale (fig. 9).

Hand. Following Fabrezi \& Alberch (1996), the hand consists of five mesopodial elements (i.e., ulnare, radiale, Element Y, Distal Carpal 5-4-3, and Distal Carpal 2), four metapodial elements (i.e., metacarpals), the prepollex, the phalanges, and intercalary cartilage elements. The ulnare articulates postaxially with the lateral border of the ulna's distal epiphysis. It has the shape of a laterally compressed square with two projections along its posterior margin, one dorsal, one ventral, and with another projection extending medially from its dorsoanterior border. Ventral to the ulnare lies the compound bone Distal Carpal 5-4-3. This bone
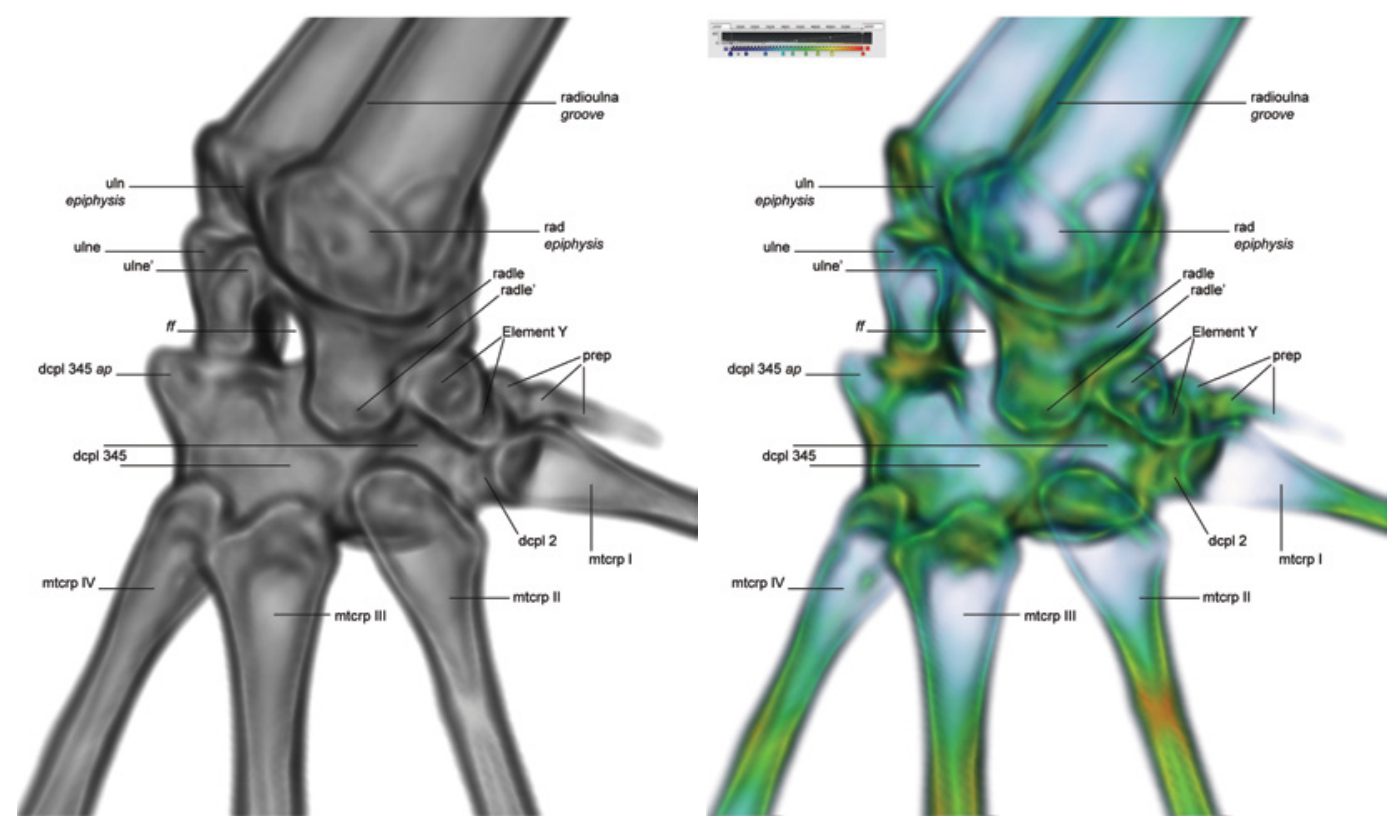

FIGURE 9 Dorsoanterior view of the Blommersia transmarina carpus. [MNCN50446 male; volrenWhite (A) and physics* colormaps (B), grey [density] values: $12000-55500] .{ }^{*}$ This individual is relatively less developed than $\mathrm{MNCN}_{5} \mathbf{0 4 4 6}$, and as such is less densely ossified. 
articulates distally with Metacarpals IV-II and displays a lateral apophysis on its anterodorsal border. Its ventral side extends below the metacarpals to constitute the palmar surface, which presents two points of contact: postaxially at the level between Metacarpals IV-III and preaxially below Metacarpal II. Above the latter, slightly lower, point of contact, Distal Carpal 5-4-3 presents a traverse tunnel along the anterior-posterior axis, plausibly a remnant from the secondary fusion of embryonic Distal Carpal 3 into this compound bone (Fabrezi \& Alberch, 1996). The radiale articulates preaxially with the posterior margin of the distal end of the radius. It is cuboid in shape and presents two projections: one dorsomedially that contacts that of the ulnare, and another ventromedially that articulates with the dorsal surface of Distal Carpal 5-4-3 at the level of the postaxial border of Metacarpal II. The former results in the formation of two medial fenestrae between both carpals: a small dorsal one below the distal end of the radioulna and another larger ventral one that ends at the dorsal surface of Distal Carpal 5-4-3. Element Y (Shubin \& Alberch, 1986) extends ventrolaterally from the radiale's posterior margin. This bone articulates medially with Distal Carpal 5-4-3, and distally along its dorsal margin with Metacarpal I and along its ventral margin with the reduced Distal Carpal 2. Preaxially and dorsal to Element Y lies the prepollex. It appears to be composed of three elements, the most distal of which is a less dense elongated acuminate process. Distal Carpal 2 articulates distally with Metacarpal I, while the second segment of the prepollex articulates postaxially and only along its anterolateral border with this same element.

There are four Digits (I-IV), with the metacarpal of Digit I lacking the nuptial tubercle distinctive of anurans that perform amplexus (Altig, 2008). The phalangeal formula is 22-3-3 (Digits I-IV), Digit III being more elongated than the rest and Digit I shorter. Preaxial to Digit I is the prepollex (Fabrezi \& Alberch, 1996). Between the terminal and subterminal phalanges there is an intercalary element that can be found in all digits (of both hands and feet) believed to be related to the mechanical requirements of arboreal habits (Manzano et al., 2007). It is fully mineralized, wedge-shaped, and presents biaxial articulations both distally with the subterminal phalanx (sellaris type) and proximally with the terminal phalanx (plane type) (Manzano et al., 2007). The terminal phalanges are differentiated from the other phalanges by lacking a terminal epiphysis; they are straight or slightly curved downward with a V-shaped tip, lack apophyses, and have an ellipsoidal proximal epiphysis (Manzano et al., 2007). The other phalanges are elongate and articulate at their proximal end with their corresponding digit's metacarpal. Both the non-terminal phalanges and the metacarpals present a denser diaphysis than epiphysis (fig. 10).

\section{Vertebral column}

The vertebral column (fig. 8) is composed of nine vertebrae [eight presacrals (I-VIII) and the sacrum (IX)] and the urostyle (i.e., fused postsacrals; coccyx). Each vertebra is composed of a centrum and a neural arch, which ossify separately and then fuse. The neural arches in B. transmarina are non-imbricate, decrease slightly in height posteriorly, and join medially above the spinal cord in a blunt neural spine, or crest, which serves as a muscle and ligament attachment site. Each vertebra bears two pairs of processes located dorsally on the neural arches for articulation with adjacent vertebrae: the prezygapophyses anteriorly and the postzygapophyses posteriorly. In addition, a pair of transverse processes emanate laterally from the neural arches; these rise from a more ventral position on presacral II to a more dorsal one on presacral 


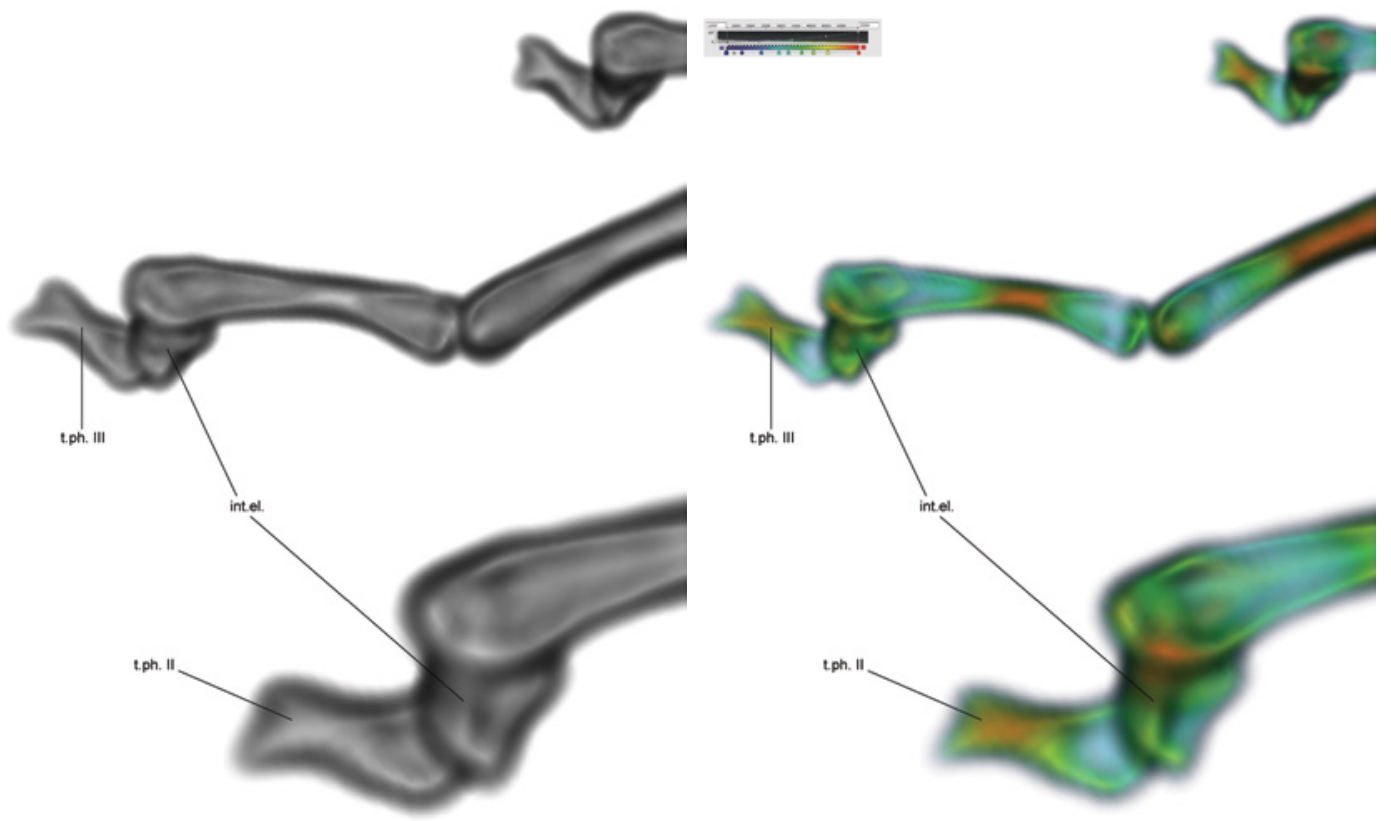

FIGURE 10 Medial/preaxial view of the Blommersia transmarina intercalary elements and terminal phalanges [MNCN50446 male; volrenWhite (A) and physics colormaps (B), grey [density] values: 12000-55500].

VII and are expanded in presacrals II-IV due to the attachment of musculature for suspension of the pectoral girdle. Ribs are absent in B. transmarina.

In addition to the vertebral articulations, the successive monospondylous vertebral centra (Duellman \& Trueb, 1994) articulate via condyloid joints. These articulations are displasiocoelous in B. transmarina, meaning all articulations are procoelous (i.e., centrum concave anteriorly and intervertebral cartilage associated with the posterior end of each centrum; allows movement in two planes) except for that of the presacral VIII, which is amphicoelous (i.e., centrum biconcave and separated by intervertebral cartilage that may or may notbe independent of adjacent centra).

The centra of $B$. transmarina do not fit perfectly into the categories for the developmental classification of anuran vertebral centra (i.e., ectochordal, holochordal, stegochordal: Griffiths, 1959; perichordal, epichordal: Mookerjee, 1931; Mookerjee \& Das, 1939;
Kluge \& Farris, 1969; perichordal with chordacentral additions: Wake, 1970; Gardiner, 1983). The centra in this species are dorsoventrally depressed (characteristic of stegochordal and epichordal development) with a less dense core (probably a remnant of the notochord, or hypochord) toward its posterior end (characteristic of perichordal development). The hypochord remnants are absent in the atlas and increase in size caudally.

Presacral I (Atlas). The first vertebra (i.e., presacral I) is known as the atlas and is modified anteriorly at its articulation with the skull, bearing two cup-shaped atlantal cotyles (instead of prezygapophyses) that form condyloid joints with the occipital condyles of the skull. Transverse processes are absent and some individuals present an incompletely ossified neural spine (e.g., MNCN50431, 50432).

Presacral II. The transverse process of presacral II is located relatively more ventrally on the neural arch than presacrals IV-VIII.It is dorsoventrally flattened along its full length and 
its leading edge displays a slight ventrodorsal inclination. It branches from the neural arch anterolaterally. Additionally, the transverse process is relatively shorter than in the rest of presacral vertebrae (table 2). In two individuals (i.e., MNCN50431, 50437) the neural spines of the atlas and presacral II are imbricate.

Presacral III. Presacral III displays the longest transverse processes of all vertebrae (table 2). The transverse process branches laterally from the neural arch lower than in presacral II. Additionally, its leading edge presents a steeper ventrodorsal inclination relative to presacral II. The transverse process of presacral III displays the largest disparity of all vertebrae; there are three different characters that appear developed to different degrees depending on the individual and with no particular pattern (e.g., sexual dimorphism, symmetry, ...): (A) The development of a protuberance nearly three-fourths the distal distance on the tranverse process's anterodorsal edge ranges from a small protuberance (e.g., MNCN50446, DRV6851) to a large anteriorly directed process with a triangular profile (e.g., MNCN50432, 50435). From the tip of this process, the transverse process flattens dorsoventrally to its extreme in the lateral direction. (B) Another protuberance, displaying significantly less variation in size and position, is located on the posterodorsal edge of the transverse process slightly more proximal than (A). (C) At the distal extremity of the transverse process some individuals (e.g., MNCN50433, 50436) present light calcifications that can contact ossified portions of the posterior suprascapula.

Presacral IV. Relative to presacrals IIIII, presacral IV's transverse process is less dorsoventrally flattened, and branches more dorsally on the neural arch in a similar manner to the succeeding vertebrae (presacrals V-VIII). It branches from the neural arch in a posterolateral direction and ends in a truncated cylinder. Its distal extremity is thickened to different degrees, more so posteriorly, depending on the individual.

Presacrals V-VIII. The transverse processes of presacrals V-VII branch from the neural arch in a posterolateral direction, presenting a gradient of decreasing magnitude from presacral IV to presacral VII; the presacral VIII breaks this trend, branching once more slightly in an anterolateral direction. Unlike presacrals II-IV, the transverse processes of posterior presacrals V-VIII are not expanded, but are narrower and rod-like in shape.

Sacral vertebra. The sacrum is a single specialized vertebra from which the pelvic girdle is suspended (fig. 11). It is located posterior to the presacrals and anterior to the urostyle, or coccyx. The sacrum bears a pair of prezygapophyses but lacks postzygapophyses, presenting two posterior condyles instead. Its transverse processes are expanded and articulate ventrolaterally with the ilia. In B. transmarina the sacral diapophyses are thick, rod-like, dorsoventrally compressed cylinders. These are located relatively more dorsally than in the rest of vertebrae nearly at the level of its neural spine, which leaves the anterior tip of the ilial shafts in line with the transverse processes of the presacral vertebra.

Urostyle. The urostyle is a long straight shaft that has a bicondylar articulation at its proximal end with the sacral vertebra (fig. 11). It presents a dorsal urostylic crest that occupies slightly less than $2 / 3$ of its shaft (table 2 ). The crest starts anteriorly at a large tubercle, which can be ossified to varying degrees depending on the individual, and progressively decreases in height in the caudal direction. Where the urostylic crest ends, the shaft reduces in density, flattens dorsoventrally, and continues until slightly before the caudal border of the ischium. 

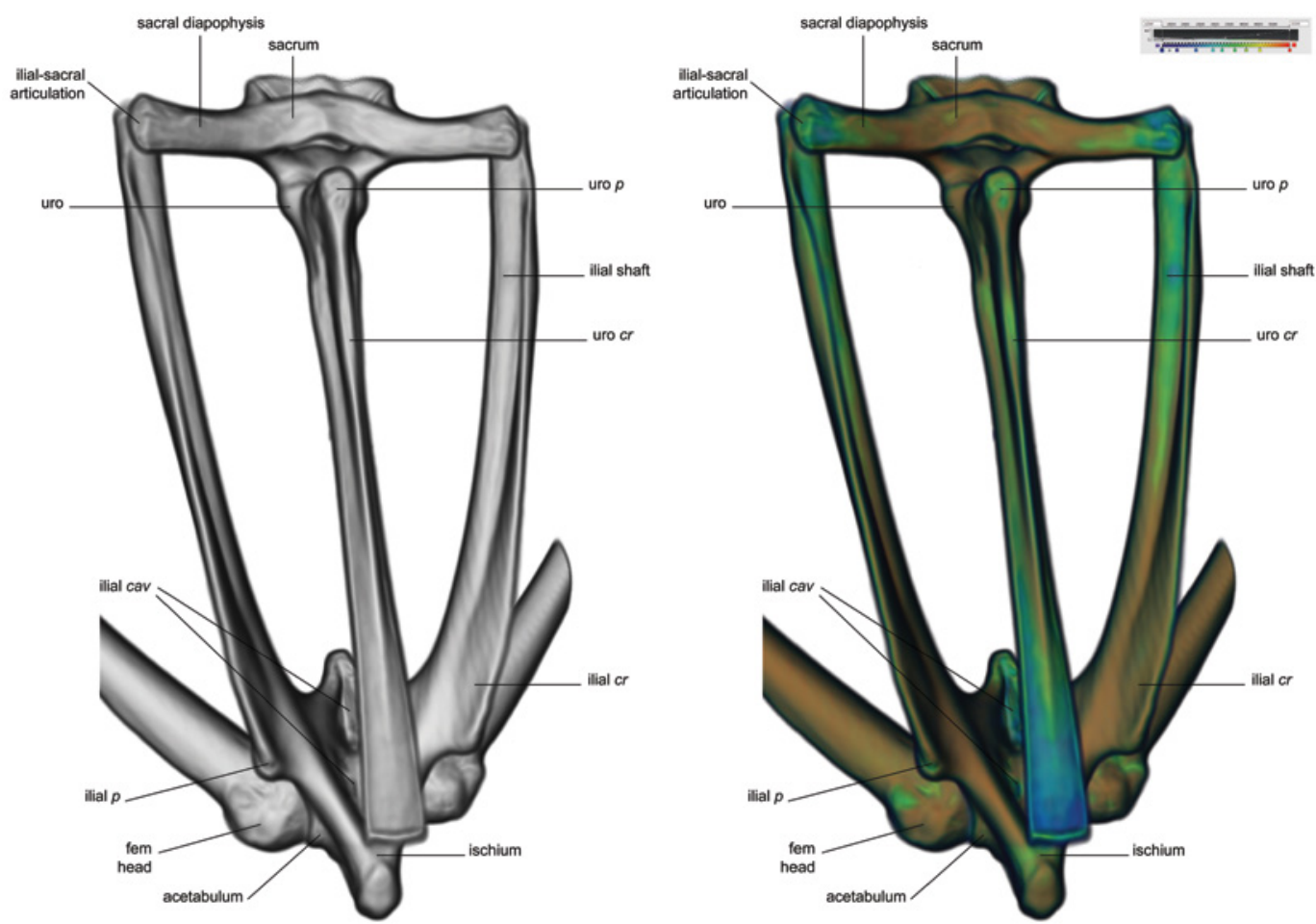

FIGURE 11 Dorsal view of the Blommersia transmarina pelvic girdle. The volume is inclined slightly to the right and clipped anteriorly immediately after presacral VIII [MNCN50446 male; volrenWhite (A) and physics colormaps (B), grey [density] values: $12000-55500]$.

\section{Pelvic girdle}

The pelvis comprises three paired elements that unite in a medial symphysis: the ilium, the ischium, and the pubis. The anterior half of the pelvic wheel is formed by the expanded posterior portion of the ilium, whereas the posterior half is comprised by the ischium; the cartilaginous pubis is limited to its ventral portion, presenting varying degrees of ossification and fusion (fig. 12).

Ilium. The ilial shafts articulate at their anterior end with the ventral side of the distal ends of the sacral transverse processes (fig. 11). In B. transmarina this articulation is of type IIB (Emerson, 1982) or of the sagittal-hinge type (Reilly \& Jorgensen, 2011). The configuration of the ilial-sacral articulation largely determines the locomotor mode of a species; the sagittal-hinge morphotype being characteristic of long-distance jumpers (i.e., > eight body lengths; Zug, 1978; Emerson, 1979) since it allows dorsoventral excursion of the pelvic girdle along the vertical plane. This morphotype in B. transmarina is characterized by posterolaterally oriented sacral diapophyses with round distal borders and well developed joint capsules at each ilial shaft articulation, presenting a narrow transverse ligament deep to the back musculature instead of a groove-like articulation characteristic of Emerson's (1982) type I. In some individuals (e.g., MNCN50430, $50436,50437)$, there are sesamoid bones within the ligament of the articulation that align with the tips of the sacral diapophyses.

The ilial shafts of B. transmarina have large crests along their full length, which originate 

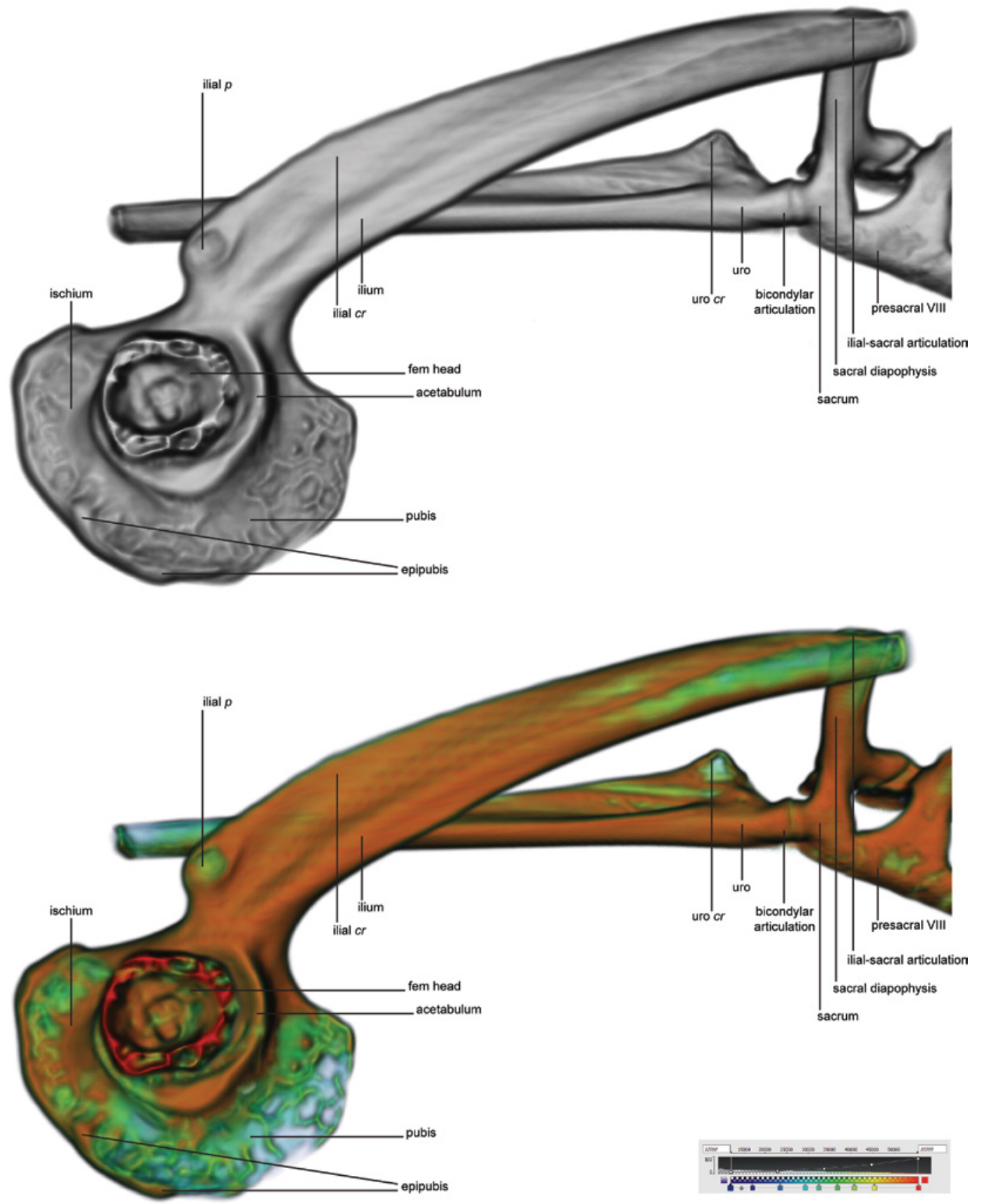

FIGURE 12 Right lateral view of the Blommersia transmarina pelvic girdle. The volume is clipped anteriorly at presacral VIII [MNCN50446 male; volrenWhite (A) and physics colormaps (B), grey [density] values: $12000-55500]$. 


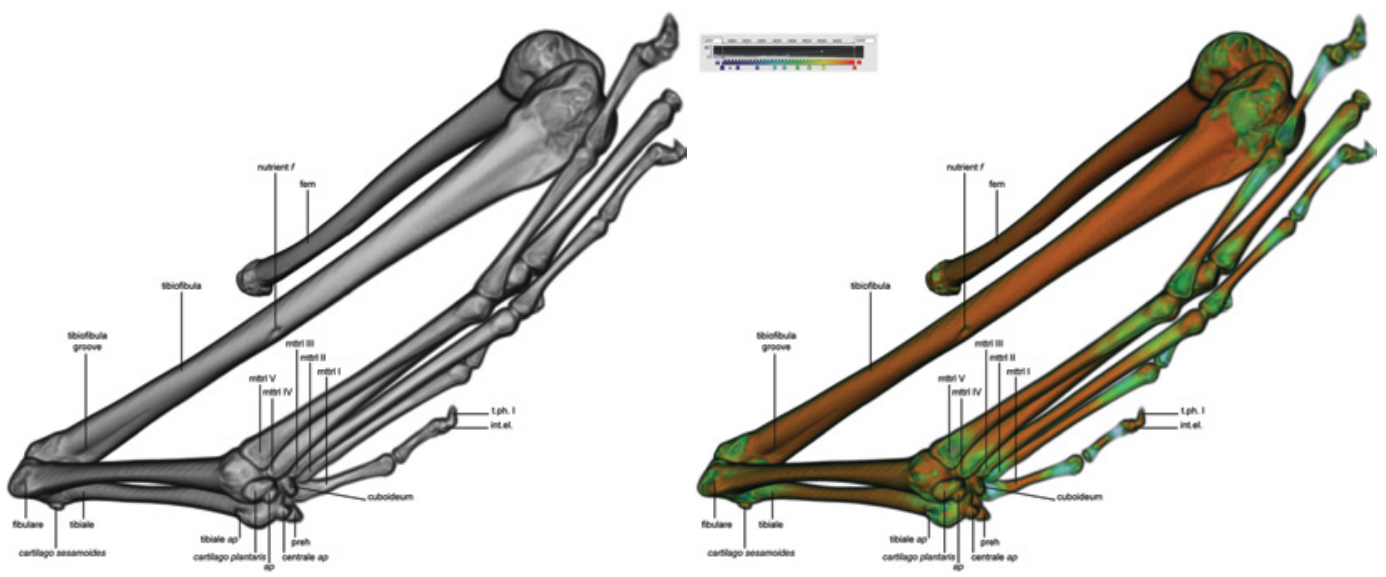

FIGURE 13 Ventrolateral view of the right Blommersia transmarina hind limb [MNCN50446 male; volrenWhite (A) and physics colormaps (B), grey [density] values: 12000-55500].

anteriorly lateral to the ilial-sacral articulation and terminate at a well-developed lateral protuberance (i.e., tuber superius; Roček, 1994) immediately before the ilium expands to form the anterior part of the acetabulum (ilial $p$ in fig. 12). The crest increases in height posteriorly and presents two grooves: one medially along three-fourths its length due to the medial curvature of the crest tip, and one laterally below the posterior protuberance that extends $1 / 4$ its length in the rostral direction. The anterior and posterior expansions of the ilium (i.e., pars ascendens and pars descendens, respectively; Roček, 1994) are prominent, slightly more posteriorly, and present varying degrees of ossification depending on the individual. There are two concavities between the ilial shafts: one posterior to the acetabulum and another anterior to it that is relatively deeper (ilial cav in fig. 11).

Ischium and Pubis. The ischium comprises the posterior half of the pelvic wheel and can vary considerably in shape due to the mechanical stresses exerted by the musculature in this area (Duellman \& Trueb, 1994). The pubis is mostly calcified in B. transmarina, more densely posteriorly, and its articulations with the ischium and ilium are difficult to distinguish (fig. 12). However, the presence of a bony plate, suggestive of an 'epipubis' (i.e., De Villiers, 1925: chondrification of the posterior linea alba; Ritland, 1955; Ročková \& Roček, 2005: praepubis), at the posterior border of the acetabulum may indicate its articulation with the ischium. At the proposed articulation, the posterior origin of the plate presents two lateral processes that invade the acetabulum medially. The articulation of the ischium with the ilium is equally difficult to distinguish; however, we note a thickened bony cap on the tip of the posterior-most border of the pelvic wheel where other authors propose the location of this articulation (Ecker, 1889; Duellman \& Trueb, 1994).

\section{Hind limb}

Femur. The femur is a long bone with a smooth diaphysis that presents a slight sigmoidal curve (fig. 13). The femur head is round and articulates with the acetabulum of the pelvis (fig. 12). At its distal end the bone widens and terminates in a truncated surface with two condyles (i.e., medial and lateral) that articulate with the tibiofibula.

Tibiofibula. The tibia and fibula are completely fused into a single bone (i.e., the tibiofibula). Its head bears two condyles with a 
TABLE 3 Statistical results of one-way, two-way, and three-way analyses of covariance for the 123 skeletal measures taken of Blommersia transmarina. Measures are partitioned into anatomical regions to facilitate lecture: SVL, skull, pectoral girdle, forelimb, vertebral column, pelvic girdle, and hind limb. Significant results $(\alpha=0.05)$ are shown in bold. Abbreviations follow those indicated in the description of the measurements (Appendix 1).

\begin{tabular}{|c|c|c|c|c|c|c|c|}
\hline & \multicolumn{7}{|c|}{ ANCOVAS } \\
\hline & \multicolumn{3}{|l|}{ 3-way } & \multirow{2}{*}{$\begin{array}{c}\text { 1-way } \\
\text { SVLsk }\end{array}$} & \multirow{2}{*}{$\frac{\text { 1-way }}{\text { pelvL }}$} & \multicolumn{2}{|l|}{ 2-way } \\
\hline & SVLext & SVLsk & $\overline{\text { SVLsum }}$ & & & SVLsk & pelvL \\
\hline SVLext & - & - & - & .002 & .000 & $\cdot 374$ & .035 \\
\hline SVLsk & - & - & - & - & .000 & - & - \\
\hline SVLsum & - & - & - & .000 & .000 & .805 & .132 \\
\hline skullL & .658 & .009 & .429 & .000 & .000 & .035 & .634 \\
\hline skullW & .840 & .073 & $\cdot 365$ & .000 & .000 & .579 & .057 \\
\hline oticsW & .276 & .029 & .381 & .000 & .000 & .386 & $\cdot 377$ \\
\hline colmL & .188 & .740 & .851 & .008 & .005 & .965 & .417 \\
\hline pmaxH & .013 & .002 & .009 & .001 & .001 & .591 & .449 \\
\hline pmaxW & .175 & .012 & .181 & .000 & .000 & .393 & $\cdot 35^{8}$ \\
\hline pmaxD & .087 & .079 & .139 & .004 & .005 & .604 & .686 \\
\hline MmbL & .500 & .555 & .699 & .141 & .770 & .225 & .422 \\
\hline $\operatorname{maxL}$ & .504 & .000 & .039 & .000 & .000 & .007 & .321 \\
\hline mandL & $.15^{0}$ & .001 & .062 & .000 & .000 & .118 & .640 \\
\hline nasL & .825 & .381 & .911 & .004 & .003 & .945 & $\cdot 374$ \\
\hline nasW & .058 & .726 & .493 & .112 & .660 & .288 & .537 \\
\hline intnasW & .349 & .956 & .297 & .135 & .264 & $.25^{2}$ & .154 \\
\hline intnsptH & .414 & .720 & .355 & .434 & .634 & .297 & .242 \\
\hline sphH & .796 & .283 & .761 & .004 & .009 & .224 & .717 \\
\hline sphW & .681 & .768 & .461 & .023 & .016 & .965 & .468 \\
\hline frptlL & .176 & .010 & .088 & .001 & .001 & .485 & .574 \\
\hline frptlW & .090 & .875 & .654 & .044 & .013 & .200 & .061 \\
\hline proH & .021 & .007 & .009 & .024 & .028 & .626 & .879 \\
\hline exoL & $\cdot 342$ & .131 & .708 & .000 & .000 & .965 & .135 \\
\hline psphH & .746 & .198 & .517 & .049 & .043 & .919 & .653 \\
\hline psphW & .006 & .173 & .030 & .040 & .020 & .589 & $.25^{0}$ \\
\hline vomH & .649 & .928 & .566 & .424 & $\cdot 557$ & .493 & $\cdot 394$ \\
\hline vomW & .454 & .489 & .545 & .115 & .067 & .284 & .529 \\
\hline pltnL & .787 & .440 & .727 & .120 & .068 & .268 & .502 \\
\hline ptygdH & .849 & .136 & .821 & .002 & .001 & .816 & $\cdot 355$ \\
\hline ptygdW & .658 & .019 & .608 & .000 & .000 & .037 & .896 \\
\hline squaH & .168 & .011 & .137 & .000 & .000 & .172 & .939 \\
\hline squaW & .936 & .009 & .301 & .000 & .005 & .010 & .103 \\
\hline hyoL & 1.000 & .864 & .434 & .007 & .007 & .706 & .636 \\
\hline omostH & .899 & .228 & .682 & .001 & .001 & .600 & $.45^{1}$ \\
\hline
\end{tabular}


TABLE 3 Statistical results of one-way, two-way, and three-way analyses of covariance for the 123 skeletal measures taken of Blommersia transmarina. Measures are partitioned into anatomical regions to facilitate lecture: SVL, skull, pectoral girdle, forelimb, vertebral column, pelvic girdle, and hind limb. Significant results $(\alpha=0.05)$ are shown in bold. Abbreviations follow those indicated in the description of the measurements (Appendix 1) (cont.).

\begin{tabular}{|c|c|c|c|c|c|c|c|}
\hline & \multicolumn{7}{|c|}{ ANCOVAS } \\
\hline & \multicolumn{3}{|l|}{ 3-way } & \multirow{2}{*}{$\begin{array}{l}\text { 1-way } \\
\text { SVLsk }\end{array}$} & \multirow{2}{*}{$\begin{array}{c}\text { 1-way } \\
\text { pelvL }\end{array}$} & \multicolumn{2}{|l|}{ 2-way } \\
\hline & SVLext & SVLsk & $\overline{\text { SVLsum }}$ & & & SVLsk & pelvL \\
\hline omostL & .578 & .955 & .265 & .013 & .018 & .472 & .997 \\
\hline clavL & .485 & .587 & .942 & .005 & .003 & .932 & .309 \\
\hline clav_pL & $\cdot 794$ & .976 & .227 & .005 & .002 & .935 & .299 \\
\hline coraL & $\cdot 777$ & .497 & .603 & .001 & .000 & .909 & .185 \\
\hline sterH & $\cdot 307$ & .214 & $\cdot 338$ & .001 & .004 & .192 & .760 \\
\hline sterWsup & .769 & .275 & .928 & .016 & .009 & .863 & $\cdot 35^{8}$ \\
\hline sterWmin & .407 & .446 & .532 & .065 & .028 & $\cdot 361$ & .148 \\
\hline sterWinf & $.45^{8}$ & $.35^{8}$ & .726 & .074 & .063 & .574 & .661 \\
\hline scapL & .881 & $\cdot 79^{2}$ & $\cdot 310$ & .003 & .003 & .661 & .574 \\
\hline cleiL & $\cdot 323$ & .083 & $\cdot 307$ & .003 & .003 & .630 & .605 \\
\hline supraH & .928 & .667 & .661 & .019 & .007 & $\cdot 5^{27}$ & .173 \\
\hline supraW & .521 & .105 & .901 & .000 & .000 & .190 & .878 \\
\hline humLcap & .136 & .021 & $.5^{28}$ & .000 & .000 & .482 & .083 \\
\hline humLtroc & .125 & .009 & .406 & .000 & .000 & $\cdot 362$ & .060 \\
\hline dltd_crH & $\cdot 713$ & .172 & .503 & .030 & .019 & .867 & .417 \\
\hline dltd_crW & .201 & .498 & .360 & .094 & .064 & .411 & .723 \\
\hline radulnL & .115 & .005 & .056 & .000 & .001 & .364 & .660 \\
\hline mtcpl 1 & $.43^{2}$ & .195 & .602 & .003 & .002 & $.75^{8}$ & .470 \\
\hline mtcpl2 & .182 & .084 & .199 & .005 & .006 & .573 & .744 \\
\hline $\mathrm{mtcpl}_{3}$ & .868 & .210 & .968 & .008 & .004 & .889 & .319 \\
\hline $\mathrm{mtcpl}_{4}$ & .681 & .225 & .812 & .003 & .002 & .934 & $\cdot 342$ \\
\hline hand_ph1L1 & .488 & .270 & .209 & .000 & .000 & .398 & .525 \\
\hline hand_tph1L & .932 & .078 & .633 & .003 & .010 & .090 & $\cdot 394$ \\
\hline hand_D1 & $\cdot 769$ & .157 & .968 & .001 & .001 & $.65^{0}$ & .414 \\
\hline hand_ph2L1 & .901 & .242 & $\cdot 772$ & .001 & .001 & $\cdot 317$ & .838 \\
\hline hand_tph2L & .685 & .301 & .960 & .105 & .141 & .767 & .486 \\
\hline hand_D2 & .472 & .131 & .494 & .003 & .004 & $.85^{2}$ & .442 \\
\hline hand_ph $3 L_{1}$ & .623 & .110 & .857 & .000 & .000 & .507 & .245 \\
\hline hand_ph3L2 & .483 & .029 & .561 & .000 & .000 & .050 & .789 \\
\hline hand_tph3L & .631 & .142 & .835 & .041 & .059 & .438 & .811 \\
\hline hand_D3 & .961 & .111 & .870 & .001 & .001 & .476 & .588 \\
\hline hand_ph4L1 & .879 & .233 & .924 & .016 & .027 & $\cdot 363$ & .807 \\
\hline hand_ph4L2 & .205 & .287 & $\cdot 301$ & .008 & .017 & .233 & .654 \\
\hline hand_tph4L & .681 & .206 & .532 & .031 & .041 & .512 & .947 \\
\hline hand_D4 & .888 & .202 & .964 & .004 & .005 & .853 & .462 \\
\hline column & .794 & .711 & .133 & .000 & looded & Briłl.com & $\begin{array}{r}.100 \\
26 / 2023\end{array}$ \\
\hline
\end{tabular}




\begin{tabular}{|c|c|c|c|c|c|c|c|}
\hline & \multicolumn{7}{|c|}{ ANCOVAS } \\
\hline & \multicolumn{3}{|l|}{ 3-way } & \multirow{2}{*}{$\begin{array}{l}\text { 1-way } \\
\text { SVLsk }\end{array}$} & \multirow{2}{*}{$\begin{array}{l}\text { 1-way } \\
\text { pelvL }\end{array}$} & \multicolumn{2}{|l|}{ 2-way } \\
\hline & SVLext & SVLsk & SVLsum & & & SVLsk & pelvL \\
\hline atlasH & .259 & .369 & .367 & .018 & .042 & .171 & .444 \\
\hline $\mathrm{V}_{2} \mathrm{H}$ & $.85^{\circ}$ & .445 & .467 & .001 & .002 & .403 & .803 \\
\hline $\mathrm{V}_{3} \mathrm{H}$ & .525 & .584 & .904 & .017 & .008 & .718 & .270 \\
\hline $\mathrm{V}_{4} \mathrm{H}$ & .685 & .885 & .241 & .001 & .000 & .987 & .200 \\
\hline $\mathrm{V}_{5} \mathrm{H}$ & .367 & .361 & 168 & .007 & .002 & .618 & .159 \\
\hline V6H & .784 & .579 & .127 & .008 & .005 & .904 & .329 \\
\hline $\mathrm{V}_{7} \mathrm{H}$ & .755 & .330 & .193 & .027 & .007 & .262 & .073 \\
\hline V8H & $.45^{\circ}$ & .093 & .529 & .000 & .000 & .724 & .045 \\
\hline sacrumH & $.33^{2}$ & $.15^{1}$ & .471 & .002 & .000 & .340 & .037 \\
\hline V2_tpL & .454 & .846 & .229 & .009 & .018 & .291 & .743 \\
\hline V3_tpL & .922 & .175 & .449 & .000 & .000 & .220 & .741 \\
\hline V4_tpL & .361 & .257 & .053 & .000 & .000 & .472 & .273 \\
\hline $\mathrm{V}_{5}$ _tpL & .931 & .673 & $.05^{8}$ & .000 & .000 & .916 & .127 \\
\hline V6_tpL & .692 & .385 & .033 & .002 & .001 & .820 & .161 \\
\hline V7_tpL & .998 & .119 & .017 & .012 & .005 & .658 & .236 \\
\hline V8_tpL & .697 & .045 & .005 & .005 & .001 & .686 & .166 \\
\hline sacrum_tpL & .650 & .700 & $.35^{0}$ & .001 & .000 & .898 & .244 \\
\hline uroL & .267 & .609 & .371 & .000 & .000 & .337 & .013 \\
\hline uroH & .275 & .019 & .005 & .000 & .000 & .313 & .096 \\
\hline uro_crL & .672 & .043 & .084 & .876 & .860 & .202 & .203 \\
\hline uro_crH & .286 & .330 & .620 & .000 & .000 & .208 & .003 \\
\hline iliL_lft & .668 & .071 & .263 & .000 & .000 & .923 & .002 \\
\hline pelvL & .175 & .013 & .963 & .000 & - & - & - \\
\hline pelwL & .856 & .019 & .524 & .000 & .001 & .062 & .631 \\
\hline epipH & .345 & .102 & .312 & .006 & .009 & .465 & .888 \\
\hline epipW & .630 & .480 & .597 & .211 & .141 & .366 & .576 \\
\hline femL & .196 & .003 & .123 & .000 & .000 & .029 & .632 \\
\hline tibfibL & .109 & .007 & .124 & .000 & .000 & .133 & .850 \\
\hline tiblfiblL & .064 & .007 & .035 & .001 & .003 & .281 & .995 \\
\hline mttrsl 1 & .639 & .234 & .670 & .009 & .013 & .445 & .991 \\
\hline mttrsl2 & .408 & .076 & .361 & .002 & .005 & .216 & .777 \\
\hline mttrsl 3 & .257 & .032 & .177 & .002 & .004 & .239 & .864 \\
\hline mttrsl 4 & .132 & .002 & .033 & .000 & .002 & .126 & .728 \\
\hline $\mathrm{mttrsl}_{5}$ & .225 & .022 & .160 & .001 & .001 & .360 & .761 \\
\hline foot_ph1L1 & .928 & .130 & .786 & .003 & .006 & .282 & .885 \\
\hline foot_tph1L & .681 & .103 & .857 & .009 & .021 & .191 & $.55^{\circ}$ \\
\hline foot_D1 & .819 & .158 & .722 & .004 & .008 & .890 & .320 \\
\hline foot_ph2L1 & .885 & .198 & .949 & .001 & .001 & .723 & .386 \\
\hline foot_tph2L & .711 & .211 & .910 & .041 & .710 & .301 & .603 \\
\hline foot_D2 & .603 & .085 & .561 & .001 & $\begin{array}{l}.002 \\
\text { aded from }\end{array}$ & $\begin{array}{l}.987 \\
\text { th. come4 }\end{array}$ & $\begin{array}{r}.276 \\
023 \quad 12:\end{array}$ \\
\hline
\end{tabular}


TABLE 3 Statistical results of one-way, two-way, and three-way analyses of covariance for the 123 skeletal measures taken of Blommersia transmarina. Measures are partitioned into anatomical regions to facilitate lecture: SVL, skull, pectoral girdle, forelimb, vertebral column, pelvic girdle, and hind limb. Significant results $(\alpha=0.05)$ are shown in bold. Abbreviations follow those indicated in the description of the measurements (Appendix 1) (cont.).

\begin{tabular}{|c|c|c|c|c|c|c|c|}
\hline & \multicolumn{7}{|c|}{ ANCOVAS } \\
\hline & \multicolumn{3}{|l|}{ 3-way } & \multirow{2}{*}{$\begin{array}{l}\text { 1-way } \\
\text { SVLsk }\end{array}$} & \multirow{2}{*}{$\frac{\text { 1-way }}{\text { pelvL }}$} & \multicolumn{2}{|l|}{ 2-way } \\
\hline & SVLext & SVLsk & SVLsum & & & SVLsk & pelvL \\
\hline foot_ph $3 L_{1}$ & $.85^{6}$ & .278 & .510 & .001 & .000 & $.95^{1}$ & .170 \\
\hline foot_ph3L2 & .988 & .046 & .785 & .000 & .000 & .449 & .462 \\
\hline foot_tph $3 \mathrm{~L}$ & .661 & .031 & .694 & .002 & .007 & .091 & .438 \\
\hline foot_D3 & .578 & .038 & .513 & .000 & .000 & .684 & .288 \\
\hline foot_ph4L1 & .660 & .108 & .908 & .000 & .000 & .819 & .054 \\
\hline foot_ph4L2 & $.95^{8}$ & .134 & .768 & .000 & .000 & .871 & .148 \\
\hline foot_ph4L3 & .232 & .002 & .963 & .000 & .000 & .032 & .618 \\
\hline foot_tph $4 \mathrm{~L}$ & .905 & .006 & .217 & .001 & .005 & .133 & .649 \\
\hline foot_D4 & .530 & .012 & .321 & .000 & .000 & .560 & .218 \\
\hline foot_ph 5 L1 & .919 & .383 & .883 & .006 & .003 & .879 & .282 \\
\hline foot_ph 5 L2 & .722 & .012 & .668 & .000 & .000 & .162 & .959 \\
\hline foot_tph ${ }_{5} \mathrm{~L}$ & .116 & .094 & .388 & .009 & .029 & .126 & .406 \\
\hline foot_D5 & .787 & .068 & .660 & .001 & .001 & .576 & .422 \\
\hline
\end{tabular}

thick bony ridge that crosses three-fourths of their medial surface. The diaphysis is smooth and straight, presenting the nutrient foramen halfway along its length. Its epiphysis also presents two condyles, which articulate with the tibiale and fibulare.

Foot. The foot consists of six mesopodial elements (i.e., tibiale, fibulare, centrale, halluxtarsal, and two distal tarsals), five metapodial elements (i.e., metatarsals), the prehallux, the phalanges, intercalary cartilage elements, and a heterotopic sesamoid (Hall, 2005). There are five Digits (I-V) with relatively more elongated metapodial elements and phalanges than the hand. The phalangeal formula is $2-2-3-$ 4-3 (Digits I-V).

Tibiale and Fibulare. The preaxial tibiale and postaxial fibulare are mesopodial elements of the hind limb that are extremely elongated relative to their homologues in other tetrapods. They are fused both proximally and distally at their epiphyses and metaphyses, and only a short distance along the most distal part of their smooth diaphyses. The tibiale presents a sesamoid bone (i.e., ossification of the cartilago sesamoides; Nussbaum, 1982) on its proximal ventral epiphysis, and a pointed, medially-oriented apophysis on its distal epiphysis (fig. 13).

Sole. Ventral to the fibulare's distal epiphysis is an ovoid plantar (Ponssa et al., 2010) os sesamoideum (Nussbaum, 1982). Its longitudinal axis lies in the proximal-distal direction and only its proximal margin is in contact with the fibulare (fig. 13). Its distal border ends ventral to the separation of the proximal epiphyses of Metatarsals V and IV. In addition, its distal segment presents preaxially either a rounded apophysis or an additional sesamoid bone (e.g., ossification of the cartilago plantaris; Hoyos, 2003). The centrale (aka naviculare; Howes, 1888) articulates along its complete surface preaxially on the tibiale's distal epiphysis. It presents an extensive 
ventral apophysis below the tibiale that extends distally at its base, producing a sort of fulcrum. The centrale articulates postaxially with Metatarsal I, and with the prehallux preaxially before the branching of its apophysis. Embryonic Distal Tarsals 2 and 3 fuse into a diagonally-oriented ellipsoidal bone along the preaxial-postaxial axis (i.e., cuboideum; Howes, 1888). The cuboideum's preaxial margin lies below Metatarsal II, articulating with this element only at its dorsal margin (fig. 13), whereas it articulates with Metacarpal III along its complete distal postaxial margin. In between the dorsal segment of the centrale and the preaxial head of the cuboideum, lies the hallux-tarsal (Howes, 1888); a small nodule of calcified cartilage. The fused distal epiphyses of the tibiale and fibulare articulate preaxially with the cuboideum and postaxially with the metatarsals of Digits IV and V. The morphological characteristics of the intercalary elements in the foot are the same as those for the hand (see above).

\section{Intraspecific variation and statistical analyses}

A multivariate ANOVA on the 123 skeletal measures detected sexual dimorphism in $B$. transmarina (Pillai $\mathrm{F}=2874.45 ; \mathrm{p}=0.014$; partial eta-squared $=1$ ), with females presenting larger values for all measured variables (table 2). Between-subject effects showed sexual dimorphism in the following variables (table 2): skull length, skull width, premaxilla width, premaxilla depth, maxilla length, mandible length, nasal length, sphenethmoid width, parasphenoid height, palatine length, pterygoid height and width, squamosal width, omosternum height, sternum inferior length, hand Digit III phalanx 2 length, and foot Digit IV terminal phalanx length.

Univariate three-way ANCOVAs including all three snout-vent measurements (i.e., SVLext, SVLsk, SVLsum) determined that the skeletal SVL measure was the best size predictor, being the only significant covariable in most cases and presenting the lowest p-value when more than one covariable was significant (table 3). One-way ANCOVAs showed that all variables covaried with SVLsk and pelvL except mentomeckelian bone length, nasal width, inter-nasal width, internasal septum height, vomer height and width, palatine length, sternum inferior widths, deltopectoral crest width, hand Digit II terminal phalanx length, urostyle crest length, and epipubis width. In addition, sternum minimum width did not covary with SVLsk, and hand Digit III and foot Digit II terminal phalanx lengths did not covary with pelvL (table 3). Two-way ANCOVAs, including both SVLsk and pelvL, resulted in SVLsk showing significant covariation with skull length, maxilla length, pterygoid width, squamosal width, hand Digit III terminal phalanx length, femur length, and foot Digit IV terminal phalanx length; and with pelvL showing significant covariation with exterior snout-vent length, presacral VIII height, sacrum height, urostyle length, urostyle crest height, and ilial shaft length (table 3).

\begin{tabular}{ll}
\multicolumn{2}{l}{ Figure abbreviations } \\
$a$ & alae \\
ant & anterior \\
$a p$ & apophysis \\
$c$. & cartilage \\
C.N. & cranial nerve \\
cav & cavity \\
cr & crest/crista \\
dor & dorsal \\
epio. $e$. & epiotic eminence \\
$f$ & foramen \\
$f f$ & fontanelle/fenestra \\
med & medial \\
$p$ & process/protuberance \\
$p l$ & plate \\
$p p$ & pars
\end{tabular}




\begin{tabular}{|c|c|c|c|}
\hline pst & posterior & pltn & palatine \\
\hline$r$ & ramus & ptyd & pterygoid \\
\hline so.fl. & supraorbital flange & qdj & quadratojugal \\
\hline ven & ventral & qu & quadrate \\
\hline \multirow[t]{2}{*}{ zygo } & zygomatic & $\mathrm{rad}$ & radius \\
\hline & & radle & radiale \\
\hline a.c. & alary cartilage & s.n. & septum nasi \\
\hline agspl & angulosplenial & sc & scapula \\
\hline amph.r. & amphibiorum recess & sph & sphenethmoid \\
\hline at & atlas & sptm & septomaxilla \\
\hline clei & cleithrum & $\mathrm{sq}$ & squamosal \\
\hline $\operatorname{clv}$ & clavicle & ssc & suprascapula \\
\hline cntl & centrale & st & sternum \\
\hline col & columella & t.n. & tectum nasi \\
\hline crc & coracoid & t.ph. & terminal phalanx \\
\hline d & dentary & uln & ulna \\
\hline dcpl & distal carpal & ulne & ulnare \\
\hline elym & endolymph & uro & urostyle \\
\hline E.t. & Eustachian tube & vom & vomer \\
\hline exo & exoccipital & & \\
\hline fem & femur & & \\
\hline $\mathrm{fp}$ & frontoparietal & Discu & \\
\hline hms & humerus & & \\
\hline hyob & hyobranchial & Blomr & ia transmarina osteological \\
\hline int.el. & intercalary element & peculi & \\
\hline $\lg$ & lagena & There & many aspects of hyperdiverse tropi- \\
\hline Mm.b. & mentomeckelian bone & cal ra & ions for which we lack data that \\
\hline mtcrp & metacarpal & could & us to understand the patterns and \\
\hline mttrl & metatarsal & proce & related to species' diversification \\
\hline $\mathrm{mx}$ & maxilla & and $s$ & ation mechanics. These include de- \\
\hline $\mathrm{n} / \mathrm{nas}$ & nasal & tailed & on anatomical structures as well as \\
\hline o.c. & otic capsule & pheno & c variation (i.e., intraspecific dispar- \\
\hline omst & omosternum & ity), w & have been key to diagnose species \\
\hline op & operculum & since & aeus. However, despite the fact that \\
\hline oto & otoccipital & osteol & al and anatomical data have been \\
\hline phy & parahyoid & at the & of species descriptions in the clas- \\
\hline plym & perilymph & sical 1 & ture, for most species we currently \\
\hline preh & prehallux & only r & n data of their external morphology \\
\hline prem & premaxilla & (Venc & al., 2002; Glaw et al., 2006; Glaw \& \\
\hline prep & prepollex & Vence & 07). This is the case in the hyperdi- \\
\hline prezyga & prezygapophysis & verse & ly Mantellidae, where the majority \\
\hline pro & prootic & of the & ently described species mostly inte- \\
\hline psph & parasphenoid & grate & rnal morphology, genetic data, and \\
\hline pstzyga & postzygapophysis & bioacc & ics (Vieites et al., 2009; Vences et al., \\
\hline
\end{tabular}


2010, 2015; Scherz et al., 2017b), with few examples including internal structures such as the presence or absence of vomerine teeth in the skull or bone structures in hands or feet (Manzano et al., 2007; Kamermans \& Vences, 2009). Here, we present the thus far most detailed osteological description of a mantellid frog with two main purposes: (1) characterize the skeletal (cranial and postcranial) anatomy of a mantellid species with its intraspecific variation, and (2) provide a reference base for future studies concerning the comparative anatomy, phenotypic variation, and taxonomic relationships between the members of this family.

The genus Blommersia comprises 10 described species from Madagascar and one candidate species from the Comoros. All species vary from 14 to $30 \mathrm{~mm}$ snout-vent length and are within the smaller-size range of the mantellid frog spectrum. However, B. transmarina from the Comoros, the one for which we here describe its osteology, is larger than the rest and has likely undergone a process of moderate gigantism (Glaw et al., 2019), which is commonly found in island taxa (Daugherty et al., 1993; Lomolino, 2005; Li et al., 2011). This makes it an interesting species to study its musculoskeletal system as a prior to comparative morphological analyses with other Blommersia and mantellid frogs. So far, there are no studies on the evolution of the musculoskeletal system in mantellids, nor on their jumping performance and kinematics, all of which are directly linked to dispersal capacity, habitat selection, and speciation. This lack of information precludes inferring conclusions about the relationships between their functional morphology and adaptive processes such as dispersion, size evolution, or phenotypic plasticity and adaptation to specific habitats. Postcranial morphology in anurans has been linked numerous times to a specific locomotor mode and/or habitat use (Zug, 1978; Emerson, 1979, 1982; Nauwelaerts et al., 2007;
Reilly \& Jorgensen, 2011; Soliz et al., 2017). A better understanding of the functional significance of skeletal traits could significantly improve the ecomorphological interpretation of the interactions between these characteristics and locomotor mode and/or habitat use (Arnold, 1983), and help to understand the evolution of the mantellid adaptive radiation.

The clavicular process in $B$. transmarina is located at the proximal end of the clavicle and articulates with the posterior branches of the omosternum (fig. 7). This structure has not been reported so far in any anuran species (e.g., Emerson, 1988; Duellman \& Trueb, 1994; Soliz et al., 2018); however, some have suggested that the clavicle may be involved in impact absorption during landing (Emerson, 1984, 1988). In CT-scans of stained specimens (J.H.S.-S., pers. obs.) this process was observed to be embedded within the mm. deltoideus and coracoradialis, which flex at the shoulder and elbow joint, respectively. Furthermore, we cannot exclude the possibility that the pectoral and forelimb musculature in B. transmarina or other mantellines presents a more elaborate architecture than that of other frog taxa, involving supplementary musculotendon connections between the clavicular process and the deltopectoral crest of the humerus or other forelimb elements. To test this idea, we are working on a segmentation of the pectoral girdle's and forelimbs' muscular architecture in B. transmarina. However, we have also observed the presence of the clavicular process in several more species within the genus Blommersia (e.g., B. wittei, B. sarotra, B. grandisonae, B. domerguei, B. blommersae). Thus, for the time being, we put forward a different locomotor function than those suggested by Emerson (1988), which is in line with the unique reproductive behavior of Mantellinae frogs (Glaw \& Vences, 2006): As part of their distinctive reproductive behavior (Blommers-Schlösser, 1975), Mantellinae frogs cling 
vertically in parallel on leaves or walls during fertilization. This position does not involve the frog grasping a solid border to ascend with its forelimbs, thus we hypothesize that the presence of the clavicular process may provide some sort of biomechanical structural support for the musculature involved in the adhesion of the frog to the leaf's surface. Until segmentation of the involved musculature is complete, we cannot make any inferences on the muscular mechanism involved since most studies on frog adhesion focus on the digit pads, which are also present in B. transmarina (see below).

This species also has several sesamoids (i.e., appendicular ossicles; Hall, 2007) and a heterotopic bone (i.e., cartilage plantaris ap in fig. 13) on the sole. The most extensive review of sesamoids in anurans (Ponssa et al., 2010) presents many missing data for the Mantellidae family on which we can now shed light with the inclusion of an additional genus (i.e., Blommersia). Of the sesamoids recognized by Ponssa et al. (2010) in Mantellidae, we confirm in $B$. transmarina the presence of the cartilago sesamoides embedded in the m. plantaris profundus at the articulation of the tibiofibula with the tibiale. The presence of this sesamoid was thought to have phylogenetic relevance (Nussbaum, 1982); however, this hypothesis has been put in doubt since Hoyos (2003). Other sesamoids observed in B. transmarina that had not been described before for the family are those lateral to the sacral diapophyses, only in some individuals, and that on the plantar surface of the foot. The latter is located where Hoyos (2003) considered the cartilago plantaris to be; however, in B. transmarina this heterotopic element possesses an additional apophysis or associated os sesamoides (fig. 13). Ponssa et al. (2010) described three bony sesamoids in the adult embedded in the plantar aponeurosis tendon that may correspond to those found in B. transmarina. Such skeletal elements have been reported in other anuran groups (Nussbaum, 1982; Hoyos, 2003) and are said to be biomechanically advantageous in that they maintain the shape of and strengthen tendons, as well as increase the mechanical advantage of force translation at articulations (Olson, 2000; Summer \& Koob, 2002; Abdala et al., 2018). Other developmental studies have revealed that certain sesamoids differentiate before a mature tendon tissue is recognizable, thus showing their origination not to be solely due to extrinsic factors such as mechanical loading. If we consider the categories of sesamoid distribution (i.e., omnipresent and fluctuating; Hall, 2007), these different circumstances relating to their presence suggest that the origin of phylogenetically ubiquitous sesamoids may be more linked to conservative genetic and developmental stimuli, while extrinsic factors may dominate over genetic ones more in those whose occurrence is irregular (Ponssa et al., 2010). In Neobatrachia, the cartilago sesamoides is considered an autapomorphy, while the plantar sesamoid and those lateral to the sacral diapophyses are considered to be plesiomorphic in Anura (Ponssa et al., 2010). The presence of the latter in several additional Blommersia species, with scarce morphological differences between them (only one individual of $B$. wittei and one of $B$. domerguei differed), suggests that these sesamoides may have arisen in the genus in response to the same extrinsic factors, possibly involving biomechanical adaptations.

In addition to heterotopic elements, $B$. transmarina presents two peculiar apophyses in the sole that may also have a locomotor function: a pointed apophysis on the tibiale's distal epiphysis (absent in lightly ossified MNCN50431 and B. blommersae) and a fulcrum that extends ventrally from the centrale (Fig. 13). In a similar manner the Distal 
Carpal 5-4-3 presents a lateral apophysis and ventral expansions that result in two points of contact (fig. 9). The sesamoid-traction epiphysis hypothesis (Parsons, 1904; Hall, 2007) postulates that certain bony projections where tendons or ligaments insert develop independent of the limb itself, suggesting that these apophyses represent sesamoids that have been incorporated onto the long bones of the appendicular skeleton. This may most likely be the case for the tibiale's apophysis, and even for that of Distal Carpal 5-4-3. The bony projections on the palmar and sole surface may serve as a fulcrum for better control and mechanical advantage during jumping locomotion (Biewener, 2003) analogous to the function hooves serve mountainous ungulates on steep slippery slopes.

In contrast, the presence of intercalary elements has been hypothesized to be related to arboreal lifestyles, with distal phalanges, intercalary elements, muscles, and digit pads acting as integrated units to enhance climbing abilities (Burton, 2004; Fabrezi et al., 2017). These are functionally integrated into a complex system, with distinctive morphostructural patterns between Hyloides and Ranoides (Manzano et al., 2007), related to different types of movements produced by a similar set of muscles and tendons. This system allows the angular movements necessary for the attachment and detachment of the adhesive digit pad (Hanna \& Barnes, 1991). Kamermans \& Vences (2009) found evidence for concerted evolution between climbing habits and bifurcated terminal phalanges in that this architecture has two additional articulations that allow to move the digit without detaching the digit pad. These movements are produced by the action of the mm. extensores breves profundus and distalis, whose presence is variable in Mantellidae (Kamermans \& Vences, 2009). We observed bifurcated terminal phalanges in $B$. transmarina, but for the moment have not confirmed the presence of their actuating muscles; however, there is no obvious correlation between the presence of intercalary elements or bifurcated terminal phalanges and climbing habits: These characters exist in several taxa, such as the mantellid genus Aglyptodactylus, which possess these elements and are completely terrestrial. As such, these elements appear to not cause any disadvantages to non-arboreal frogs and to not be under strong selective pressure. In B. transmarina the intercalary elements are strongly mineralized and we suspect they aid the frogs during their reproduction when they hang vertically. The intercalary element in anurans seems to be a morphological novelty that appeared early within the Neobatrachia and is interpreted as an autopomorphy for the Rhacophoroidea (Frost et al., 2006).

Furthermore, B. transmarina presents several osteological peculiarities; the first that jumps into view is its evident signs of hyperossification. Several regions of the skull (i.e., internasal septum, prootics, sphenethmoid, and parasphenoid) present dermal sculpting, or exostosis, that evidence this phenomenon and have been observed affecting the structure of the skull in different ways in other anuran genera (Duellman \& Trueb, 1994; Yeh, 2002; Clemente-Carvalho et al., 2009; Evans et al., 2014). Other signs of hyperossification in dermal elements of $B$. transmarina include the fusion of the prootics and exoccipitals into the otoccipital and the production of extensive marginal flanges, such as that of the frontoparietals' supraorbital flange or posterior protuberance (fig. 1). Hyperossification is unrelated with the absolute size of a species (Duellman \& Trueb, 1994), and accordingly we found differing levels of ontogenetic ossification across the 10 individuals of $B$. transmarina in this study. The degree of ossification of several 
skeletal elements varied independently from size (i.e., SVL), sex, and each other, obfuscating the functional purpose of hyperossification in these structures, but suggesting that their calcification may depend more on environmental cues rather than developmental ones (i.e., genetic). For example, the development of bony crests on the humerus has been associated to hypertrophied musculature in male frogs (Duellman \& Trueb, 1994). In $B$. transmarina the deltopectoral crest is not only well developed in both sexes, but also displays a continuation on the humerus head separated by a fenestra of varying size. Thus, we hypothesize that hyperossification of this structure may play an important role in the musculoskeletal functional performance of both males and females in the Blommersia genus. Furthermore, hyperossification of certain skeletal elements evokes the idea of structural compensation due to increasing individual size or improved mechanical performance at more developed stages (PérezBen et al., 2018). This is especially true for structures that serve as muscle attachment sites such as the bony crest on the hyobranchial's posteromedial processes or the level of development of diverse processes on the transverse processes of presacral vertebrae IIIV. However, the asymmetry in the degree of development of the latter observed in several individuals (i.e., MNCN50430, 50435, 50437) suggests that hyperossification of these skeletal structures does not alter their functional performance since an asymmetrical musculoskeletal lever system would obviously be biomechanically unstable in a bilateral animal. This ambiguity in the role of the observed hyperossification still leaves unresolved the issue if this process has any (biomechanical) adaptive value in non-burrowing frogs other than that of water conservation due to exostosis (Ruibal \& Shoemaker, 1984; Evans et al., 2014).

\section{Intraspecific osteological variation in Blommersia transmarina}

When describing the variation within a species, it is important to distinguish individual from sexual and ontogenetic variation. The inclusion of 10 individuals of $B$. transmarina in its osteological description has made it possible to discriminate the different status and directionality of ontogenetic ossification in several skeletal elements (e.g., skull, vertebral transverse processes, and pelvic wheel), establish the ubiquity of appendicular ossicles, discriminate between individual artifacts and the general characteristics of the species, and determine what structures present sexual dimorphism. Characterization of the observed intraspecific variation leads us to interpret the variables with positive values of asymmetry (>1; table 2) to indicate skeletal structures in $B$. transmarina that are under a continuous process of ontogenetic ossification since all sampled individuals are adults and annual cohort survival in anurans decreases with increasing age. In B. transmarina we also observed an overall sexual dimorphism with females being relatively larger in all measurements (table 2). However, univariate analyses show that this does not hold true for snout-vent length and that most sexually dimorphic characters are located in the head with the exception of the omosternum, sternum, and a couple of phalanges (table 2). Increased size of the head in females may indicate an increased cranial volume and vomeronasal organ. This would be a logical evolutionary outcome in view of the transmission of volatile compounds from the males' femoral glands to the females' vomeronasal organ during courtship (Nowack \& Vences, 2016; Nowack et al., 2017). Larger sterna and phalanges may likewise aid the female biomechanically in maintaining her vertical position during the reproductive act (Altig, 2008) by increasing muscle attachment area 
and potentially providing longer input levers relative to output levers.

The observation of sexual dimorphism distributed throughout the skeleton of $B$. transmarina (table 2) allows us to test for size covariation of skeletal characteristics. The traditional length measurement in anurans has always been (external) snout-vent length; however, the precision and repeatability of this measure is highly dependent on the observer. This is because the structure of the pelvic girdle in most anurans can compress under vertical load and their vertebral column is flexible, thus different measurement habits across observers can lead to different values for the same individuals. With this in mind we tested three different snout-vent measurements to evaluate which one was a better predictor of size covariation. Our results (table 3 ) indicate that the snout-vent length directly measured on the volume-rendered skeleton of the frog in its resting position is a better size covariate than either exterior snout-vent length or the summed skeletal snout-vent length (Appendix 1). That the SVLsum measurement calculated by summing up the skeletal length distances of each anatomical region is a worse predictor than the SVL measured directly on the rendered skeleton, suggests that the "crouched" resting position of B. transmarina is correlated with size variation in the entire anatomy of a particular individual and may play a role in the allometric scaling of jumping performance in this species (Choi et al., 2000; Azizi \& Roberts, 2010; Gillis, 2010). Another proposed length measurement for anurans that focuses on their locomotor function is that of pelvic length. When compared to skeletal snout-vent length, pelvic length presents very similar size covariation with skeletal elements (table 3); however, each covariable showed higher predictive power than the other in specific anatomical regions: skeletal snout-vent length was a better predictor of the skull and limb elements, while pelvic length was a better predictor of the elements of the vertebral column and pelvic girdle (table 3 ). These observations in size covariation suggest that the anuran skeletal architecture is organized in modular developmental units. In this context, Soliz et al. (2017) determined that the girdles and vertebral column in hylids adjusted to different evolutionary modes of evolution that may well reflect a morphological continuum between locomotor modes (Fabrezi et al., 2017). This may also hold true for other anurans like $B$. transmarina that we have described here, although further research including additional species of the genus is required to develop this hypothesis further.

\section{Modern methods in anatomical reconstructions}

Despite the fact that osteological data have been a substantial source for phylogenetically informative characters, the vast majority of phylogenies produced these days rely on genetic/genomic data. Nevertheless, the availability and expansion of $\mu \mathrm{CT}$ is facilitating the generation of massive amounts of osteological data from vouchers deposited in natural history collections, and it is likely to become more common as the technology further develops shortening CT generation times(Cole et al., 2018). In this view, there are currently several ongoing projects and open resources that together are making osteological data across almost all vertebrate genera readily available for phylogenetic research (Cross, 2017). However, osteological data are sometimes hard to interpret and compare as they can be influenced by the age of the specimen (i.e., ontogeny), allometric and/or heterochronic processes, or phenotypic plasticity in response to local ecological conditions; in addition, the impact of all these factors varies across time, phylogeny, and different parts of the skeleton. Despite this, osteological data are routinely 
used in paleontological studies to describe fossils and infer their phylogenetic relationships (e.g., Kluge \& Farris, 1969; Hall, 2007; Biton et al., 2013; Laloy et al., 2013; Gao \& Chen, 2017; Marjanovic \& Laurin, 2019).

Another potential issue with osteological data generated from $\mu \mathrm{CT}$ is the processing and rendering of the CT-scans. Due to the differential ossification of skeletal structures and the small size of many frog species, the thresholds between ossified and non-ossified structures are usually hard to establish. This has caused discrepancies in the skeletal description when interpreting surface renders versus volume renders (Scherz et al., 2017c). The production of surface models requires the establishment of an isosurface density value for the rendering, and this threshold may not be the most adequate for the complete anatomy of the sample, creating artifacts and obfuscating the precise description of certain morphological structures. The development of software tools that could allow to differentially surface render distinct modules of the volume, and/or advances in the computational weighting of isosurfaces that could allow to equalize differences between those generated between different anatomical modules for their assemblage, may lead in the future to more precise surface model interpretation. In contrast to isosurfaces that are generated based on a particular density value, volume rendering allows for a dynamic visualization of the model along a user-defined density curve with different options of transparency and coloration for predefined subranges of grey values. This allows exploring anatomical structures along their complete density gradient and to render tissues that correspond to different subranges of grey values within the sample differentially, in consequence increasing the contrast between them during visualization.

Density differentiation in the CT-scans of B. transmarina allowed us to make some inferences on the development of the carpus (fig. 9), whose nomenclature has been a controversial topic in anurans until the works by Fabrezi and Alberch (e.g., 1996). They proposed the absence of centralia in the anuran carpus because these arise from the intermedium. The intermedium in anurans has a dubious homology with that in other tetrapods because its embryonic origin is by segmentation off the ulnare rather than branching off the ulna. In B. transmarina we observed a medial projection off the ulnare that corresponds to the embryonic structure Fabrezi (1992) designated to be homologous with the intermedium, or the ulnare'. We believe this structure is a chondrogenetic projection rather than a separate element in $B$. transmarina in view of the existing large fenestrae in-between the ulnare and radiale in this species (fig. 9). In the same way, Distal Carpal 5 is not a centrale since it arises from a single embryonic condensation (Fabrezi \& Alberch, 1996). In $B$. transmarina this element seems to segment twice, subsequently fusing primarily with Distal Carpal 4 and secondarily with Distal Carpal 3 as evidenced in the presence of a tunnel between both elements (Distal Carpal 5-4 and Distal Carpal 3 ) in the compound bone Distal Carpal 5-4-3 (Fabrezi \& Alberch, 1996). The radiale in $B$. transmarina also presents two projections (fig. 9), indicating two independent embryonic cartilaginous condensations: the (posterior) radiale dorsomedially and the (anterior) radiale' ventromedially (Fabrezi \& Alberch, 1996). The latter is considered a new element characteristic of the hand ontogeny of some anuran species since the distal (posterior) end of the radiale gives rise to the Element Y and prepollex (Shubin \& Alberch, 1986). The Element $Y$ is a carpal element found exclusively in amphibians that arises from one to three embryonic condensations. In B. transmarina this element appears to originate from two independent embryonic chondrifications that fuse primarily later on (fig. 9). 
We are far from understanding how large tropical hyperdiverse endemic radiations, like those of frogs from Madagascar, evolved and diversified. These Malagasy radiations are particularly interesting as they involve several cases of miniaturization as well as a wide array of morphologies occupying different ecological niches. While from the molecular perspective we have a good position to understand phylogenetic relationships, from the anatomical one we are lacking a work of comparative morphology. Selection acted on the morphology of every species, allowing for adaptations and the colonization of novel environments, and future research on the anatomy of Malagasy frog radiations will help to understand how these species radiated and colonized all the environments in which they are present.

\section{Acknowledgements}

We would like to thank Dominique Adriaens, for extensive feedback on the anatomical description, and Barbara de Kegel, for helping in the realization of the staining protocol, from the Evolutionary Morphology of Vertebrates Lab at Ghent University, and the members of the UGCT that aided us in the CT processing of stained specimens. We thank the Unité Biodiversité-DEAL of Mayotte for research authorization. This research was funded by the Spanish Ministerio de Economía y Competitividad (FEDER, EU) CGL2013-40924-P, and Agencia Española de Investigación CGL201789898-R (AEI/FEDER, EU) to David Vieites.

\section{Supplementary material}

Supplementary material is available online at: https://doi.org/10.6o84/mg.figshare.9699731

\section{References}

Abdala, V., Ponssa, M.L., Tulli, M.J., Fabre, A.C. \& Herrel, A. (2018) Frog tendon structure and its relationship with locomotor modes. J. Morphol., 279, 895-903.

Altig, R. (2008) Notes on the breeding biology of four species of mantellid frogs from Madagascar. Trop. Zool., 21, 187-194.

Arnold, S.J. (1983) Morphology, performance and fitness. Am. Zool., 23, 347-361.

Azizi, E. \& Roberts, T.J. (2010) Muscle performance during frog jumping: influence of elasticity on muscle operating lengths. Proc. R. Soc. B-Biol. Sci., 277, 1523-1530.

Biewener, A.A. (2003) Animal Locomotion. Oxford University Press, Oxford, $285 \mathrm{pp}$.

Biton, R., Geffen, E., Vences, M., Cohen, O., Bailon, S., Rabinovich, R., Malka, Y., Oron, T., Boistel, R., Brumfeld, V. \& Gafny, S. (2013) The rediscovered Hula painted frog is a living fossil. Nat. Commun., 4, 1959.

Blommers-Schlösser, R.M. (1975) A unique case of mating behavior in a Malagasy tree frog, $\mathrm{Ge}$ phyromantis liber (Peracca, 1893), with observations on the larval development (Amphibia, Ranidae). Beaufortia, 23, 15-25.

Bolkay, S. (1919) Elements of the comparative osteology of the tailless batrachians. Glas. Zemal. Muz. u Bosni i Hercegovini, 31, 277-358.

Burton, T.C. (2004) Muscles of the pes of hylid frogs. J. Morphol., 260, 209-233.

Choi, I.-H., Shim, J.H., Lee, Y.S. \& Ricklefs, R.E. (2000) Scaling of jumping performance in anuran amphibians. J. Herpetol., 2000, 222-227.

Clack, J. (2001) The otoccipital region-origin, ontogeny and the fish-tetrapod transition. In: E. Ahlberg (Ed) Major Events in Early Vertebrate Evolution, pp. 400-413. CRC Press, London.

Clemente-Carvalho, R.B., Antoniazzi, M.M., Jared, C., Haddad, C.F., Alves, A.C., Rocha, H.S., Pereira, G.R., Oliveira, D.F., Lopes, R.T. \& dos Reis, S.F. (2009) Hyperossification in miniaturized toadlets of the genus Brachycephalus (Amphibia: Anura: Brachycephalidae): microscopic structure and macroscopic patterns of variation.J. Morphol., 270, 1285-1295.

Cole, J.M., Symes, D.R., Lopes, N.C., Wood, J.C., Poder, K., Alatabi, S., Botchway, S.W., Foster, Downloaded from Brill.com04/26/2023 12:20:50PM 
P.S., Gratton, S., Johnson, S., Kamperidis, C., Kononenko, O., De Lazzari, M., Palmer, C.A., Rusby, D., Sanderson, J., Sandholzer, M., Sarri, G., Szoke-Kovacs, Teboul, L., Thompson, J.M., Warwick, J.R., Westerberg, H., Hill, M.A., Norris, D.P., Mangles, S.P. \& Najmudin, Z. (2018) Highresolution $\mu \mathrm{CT}$ of a mouse embryo using a compact laser-driven X-ray betatron source. Proc. Natl. Acad. Sci. U.S.A., 115, 6335-6340.

Cross, R. (2017) The inside story on 20,00o vertebrates. Science, 357, 742-743.

Crottini, A., Madsen, O., Poux, C., Strauss, A., Vieites, D.R. \& Vences, M. (2012) Vertebrate timetree elucidates the biogeographic pattern of a major biotic change around the K-T boundary in Madagascar. Proc. Natl. Acad. Sci. U.S.A., 109, $535^{8}-5363$.

Daugherty, C.H., Gibbs, G.W. \& Hitchmough, R. (1993) Mega-island or micro-continent? New Zealand and its fauna.Trends Ecol. Evol., 8, 437-442.

De Villiers, C. (1925) On the development of the "epipubis" of Xenopus. Annals of the Transvaal Museum, 11, 129-135.

Dempster, W.T. (1930) The morphology of the amphibian endolymphatic organ. J. Morphol., 50, 71-126.

Duellman, W.E. \& Trueb, L. (1994) Biology of Amphibians. John Hopkins University Press, Baltimore, $696 \mathrm{pp}$.

Ecker, A. (1889) The Anatomy of the Frog. Clarendon Press, Oxford, 484 pp.

Emerson, S.B. (1979) The ilio-sacral articulation in frogs: form and function. Biol. J. Linn. Soc., 11, 153-168.

Emerson, S.B. (1982) Frog postcranial morphology: identification of a functional complex. Copeia, 1982, 603-613.

Emerson, S.B. (1983) Functional analysis of frog pectoral girdles.The epicoracoid cartilages. $J$. Zool., 201, 293-308.

Emerson, S.B. (1984). Morphological variation in frog pectoral girdles: testing alternatives to a traditional adaptive explanation. Evolution, 38 , $376-388$.
Emerson, S.B. (1988) Testing for historical patterns of change: a case study with frog pectoral girdles. Paleobiology, 14, 174-186.

Evans, S.E., Groenke, J.R., Jones, M.E., Turner, A.H. \& Krause, D.W. (2014) New material of Beelzebufo, a hyperossified frog (Amphibia: Anura) from the Late Cretaceous of Madagascar. PLOS ONE, 9, e87236.

Fabrezi, M. (1992) El carpo de los anuros. Alytes, 10, 1-29.

Fabrezi, M. \& Alberch, P. (1996) The carpal elements of anurans. Herpetologica, 1996, 188-204.

Fabrezi, M., Goldberg, J. \& Chuliver-Pereyra, M. (2017) Morphological variation in anuran limbs: constraints and novelties. J. Exp. Zool. B, 328, 546-574.

Frost, D.R., Grant, T., Faivovich, J., Bain, R.H., Haas, A, et al. (2006) The amphibian tree of life. Bull. Am. Mus. Nat. Hist., 297, 1-291.

Gao, K-Q. \& Chen, J. (2017) A new crown-group frog (Amphibia: Anura) from the Early Cretaceous of Northeastern Inner Mongolia, China. Am. Mus. Novitates, 3876, 1-39.

Gardiner, B.G. (1983) Gnathostome vertebrae and the classification of the Amphibia. Zool. J. Linn. Soc. Lond., 79, 1-59.

Gillis, G.B. (2010) Frog muscles start stretched. J. Exp. Biol., 213, vi.

Glaw, F. \& Vences, M. (2006) Phylogeny and genuslevel classification of mantellid frogs (Amphibia, Anura). Org. Divers. Evol., 6, 236-253.

Glaw, F. \& Vences, M. (2007) A Field Guide to the Amphibians and Reptiles of Madagascar, Third Edition. Vences and Glaw Verlag, Cologne, 496 pp.

Glaw, F., Hoegg, S. \& Vences, M. (2006) Discovery of a new basal relict lineage of Madagascan frogs and its implications for mantellid evolution. Zootaxa, 1334, 27-43.

Glaw, F., Hawlitschek, O., Glaw, K. \& Vences, M. (2019) Integrative evidence confirms new endemic island frogs and transmarine dispersal of amphibians between Madagascar and Mayotte (Comoros archipelago). The Science of Nature, 106,19 . 
Griffiths, I. (1959) The phylogeny of Sminthillus limbatus and the status of the Brachycephalidae (Amphibia Salientia). J. Zool., 132, 457-487.

Guibé, J. (1978) Les Batraciens de Madagascar. Bonner Zoologische Monographien, 11, 1-144.

Hall, B.K. (2005) Bones and Cartilage: Developmental and Evolutionary Skeletal Biology. Elsevier/ Academic Press, London, $792 \mathrm{pp}$.

Hall, B.K. (2007) Fins into Limbs: Evolution, Development, and Transformation. The University of Chicago Press, Chicago, 433 pp.

Hanken, J. (1993) Adaptation of bone growth to miniaturization of body size. In: B.K. Hall (Ed) Bone. Vol. 7: Bone Growth-B, pp. 79-104. CRC Press, Boca Raton, FL.

Hanna, G. \& Barnes, J.P. (1991) Adhesion and detachment of the toe pads of tree frogs. J. Exp. Biol., 155, 103-125.

Howes, G.B. (1888) On the carpus and tarsus of the Anura.J. Zool., 56, 141-182.

Hoyos, J.M. (2003) Additions to our knowledge of anuran sesamoids. Herpetol. Rev., 34, 112.

Kamermans, M. \& Vences, M. (2009) Terminal phalanges in ranoid frogs: morphological diversity and evolutionary correlation with climbing habits. Alytes, 26, 117-152.

Kluge, A.G. \& Farris, J.S. (1969) Quantitative phyletics and the evolution of anurans. Syst. Biol., $18,1-32$.

Laloy, F., Rage, J.-C., Evans, S.E., Boistel, R., Lenoir, N. \& Laurin, M. (2013) A re-interpretation of the Eocene anuran Thaumastosaurus based on microCT examination of a 'mummified' specimen. PLOS ONE, 8, e74874.

Laurent, R. (1946) Mises au point dans la taxonomie des ranidés. Revue de Zoologie et de Botanique Africaines, 39, 336-338.

Li, Y., Xu, F., Guo, Z., Liu, X., Jin, C., Wang, Y. \& Wang, S. (2011) Reduced predator species richness drives the body gigantism of a frog species on the Zhoushan Archipelago in China.J. Anim. Ecol., 80, 171-182.

Lomolino, M.V. (2005) Body size evolution in insular vertebrates: generality of the island rule. $J$. Biogeogr., 32, 1683-1699.
Maglia, A.M., Pugener, L.A. \& Mueller, J.M. (2007) Skeletal morphology and postmetamorphic ontogeny of Acris crepitans (Anura: Hylidae): a case of miniaturization in frogs. J. Morphol., 268, 194-223.

Manzano, A.S., Fabrezi, M. \& Vences, M. (2007) Intercalary elements, treefrogs, and the early differentiation of a complex system in the Neobatrachia. Anat. Rec., 290, 1551-1567.

Marjanovic, D. \& Laurin, M. (2019) Phylogeny of Paleozoic limbed vertebrates reassessed through revision and expansion of the largest published relevant data matrix. PeerJ, 6, e5565.

Mason, M.J., Segenhout, J.M., Cobo-Cuan, A., Quiñones, P.M. \& van Dijk, P. (2015) The frog inner ear: picture perfect? J. Assoc. Res. Otolaryngol., 16, 171-188.

Mookerjee, H.K. (1931) IV. On the development of the vertebral column of Anura. Phil. Trans. $R$. Soc. $B, 219,165^{-196 . ~}$

Mookerjee, H.K. \& Das, S.K. (1939) Further investigation on the development of the vertebral column in Salientia (Anura). J. Morphol., 64, 167-209.

Nauwelaerts, S., Ramsay, J. \& Aerts, P. (2007) Morphological correlates of aquatic and terrestrial locomotion in a semi-aquatic frog, Rana esculenta: no evidence for a design conflict.J. Anat., 210, 304-317.

Nowack, C. \& Vences, M. (2016) Ontogenetic development of the derived olfactory system of the mantellid frog Mantidactylus betsileanus. Anat. Rec., 299, 943-950.

Nowack, C., Peram, P.S., Wenzel, S., Rakotoarison, A., Glaw, F., Poth, D., Schulz, S. \& Vences, M. (2017) Volatile compound secretion coincides with modifications of the olfactory organ in mantellid frogs. J. Zool., 303, 72-81.

Nussbaum, R.A. (1982) Heterotopic bones in the hind limbs of frogs of the families Pipidae, Ranidae and Sooglossidae. Herpetologica, 1982, $312-320$.

Olson, W. (2000) Phylogeny, ontogeny, and function: extraskeletal bones in the tendons and joints of Hymenochirus boettgeri (Amphibia: Downloaded from Brill.com-4/26/2023 12:20:50PM 
Anura: Pipidae). Zool.-Anal. Complex Syst., 103, $15^{-24 .}$

Pabijan, M., Gehring, P.-S., Koehler, J., Glaw, F. \& Vences, M. (2011) A new microendemic frog species of the genus Blommersia (Anura: Mantellidae) from the east coast of Madagascar. Zootaxa, 2978, 34-50.

Pabijan, M., Wollenberg, K. \& Vences, M. (2012) Small body size increases the regional differentiation of populations of tropical mantellid frogs (Anura: Mantellidae). J. Evol. Biol., 25, 2310-2324.

Parsons, F. (1904) Observations on traction epiphyses. J. Anat. Physiol., 38, 248.

Pérez-Ben, C.M., Schoch, R.R. \& Báez, A.M. (2018) Miniaturization and morphological evolution in Paleozoic relatives of living amphibians: a quantitative approach. Paleobiology, 44, 58-75.

Ponssa, M.L., Goldberg, J. \& Abdala, V. (2010) Sesamoids in anurans: new data, old issues. Anat. Rec., 293, 1646-1668.

Reilly, S.M. \& Jorgensen, M.E. (2011) The evolution of jumping in frogs: morphological evidence for the basal anuran locomotor condition and the radiation of locomotor systems in crown group anurans. J. Morphol., 272, 149-168.

Reynolds, S.H. (1897) The Vertebrate Skeleton. Cambridge University Press Warehouse, London, 559 pp.

Richards, C.L. (2006) Has the evolution of complexity in the amphibian papilla influenced anuran speciation rates? J. Evolution Biol., 19, 1222-1230.

Roček, Z. (1994) Taxonomy and distribution of Tertiary discoglossids (Anura) of the genus Latonia (v. Meyer, 1843). Geobios, 27, 717-751.

Roček, Z. (2005) Late Miocene amphibia from Rudabánya. Palaeontographia Italica, 90, 11-29.

Ročková, H. \& Roček, Z. (2005) Development of the pelvis and posterior part of the vertebral column in the Anura.J. Anat., 206, 17-35.

Ruibal, R. \& Shoemaker, V. (1984) Osteoderms in anurans. J. Herpetol., 1984, 313-328.

Santos-Santos, J.H. (2019) Ecomorphological discrimination of vertebrate sister species with recent phylogenetic divergence using novel non-destructive morphometric methods. Ph.D. dissertation, University of Barcelona, Barcelona, $320 \mathrm{pp}$.

Samonds, K.E., Godfrey, L.R., Ali, J.R., Goodman, S.M., Vences, M., Sutherland, M.R., Irwin, M.T. \& Krause, D.W. (2013) Imperfect isolation: factors and filters shaping Madagascar's extant vertebrate fauna. PLOS One, 8, e62086.

Scherz, M.D., Vences, M., Borrell, J., Ball, L., Nomenjanahary, D.H., Parker, D., Rakotondratsima, M., Razafimandimby, E., Starnes, T., Rabearivony, J. \& Glaw, F. (2017a) A new frog species of the subgenus Asperomantis (Anura, Mantellidae, Gephyromantis) from the Bealanana District of northern Madagascar. Zoosyst. Evol., 93, 451.

Scherz, M.D., Razafindraibe, J.H., Rakotoarison, A., Dixit, N.M., Bletz, M.C., Glaw, F. \& Vences, M. (2017b) Yet another small brown frog from high altitude on the Marojejy Massif, northeastern Madagascar (Anura: Mantellidae). Zootaxa, $4347,572-582$.

Scherz, M.D., Hawlitschek, O., Andreone, F., Rakotoarison, A., Vences, M. \& Glaw, F. (2017c) A review of the taxonomy and osteology of the Rhombophryne serratopalpebrosa species group (Anura: Microhylidae) from Madagascar, with comments on the value of volume rendering of micro-CT data to taxonomists. Zootaxa, 4273, 301-340.

Scott, E. (2005). A phylogeny of ranid frogs (Anura: Ranoidea: Ranidae), based on a simultaneous analysis of morphological and molecular data. Cladistics, 21, 507-574.

Shubin, N.H. \& Alberch, P. (1986) A morphogenetic approach to the origin and basic organization of the tetrapod limb. In: M.K. Hecht, B. Wallace \& G.T. Prance (Eds) Evolutionary Biology, pp. 319-387. Springer, Boston.

Simmons, D., Bertolotto, C. \& Narins, P. (1992) Innervation of the amphibian and basilar papillae in the leopard frog: reconstructions of single labeled fibers. J. Comp. Neurol., 322, 191-200.

Soliz, M.C., Tulli, M.J. \& Abdala, V. (2017) Osteological postcranial traits in hylid anurans indicate a Downloaded from Brill.com04/26/2023 12:20:50PM 
morphological continuum between swimming and jumping locomotor modes. J. Morphol., 278, 403-417.

Soliz, M.C., Ponssa, M.L. \& Abdala, V. (2018) Comparative anatomy and development of pectoral and pelvic girdles in hylid anurans. J. Morphol, 279, 904-924.

Špinar, Z.V. (1972) Tertiary Frogs From Central Europe. Academia, Prague, $286 \mathrm{pp}$.

Summers, A.P. \& Koob, T.J. (2002) The evolution of tendon-morphology and material properties. Comp. Biochem. Phys. A, 133, 1159-1170.

Trueb, L. (1968a) Variation in the tree frog Hyla lancasteri. Copeia, 1968, 285-299.

Trueb, L. (1968b) Cranial osteology of the hylid frog, Smilisca baudini. University of Kansas Publications, Museum of Natural History, 18, 11-35.

Vences, M. \& Glaw, F. (2001) When molecules claim for taxonomic change: new proposals on the classification of Old World treefrogs. Spixiana, 24, 85-92.

Vences, M., Andreone, F., Glaw, F. \& Mattioli, F. (2002) New dwarf species of Mantidactylus from northwestern Madagascar (Anura: Mantellidae). Copeia, 2002, 1057-1062.

Vences, M., Vieites, D.R., Glaw, F., Brinkmann, H., Kosuch, J., Veith, M. \& Meyer, A. (2003) Multiple overseas dispersal in amphibians. Proc. R. Soc. B-Biol. Sci., 270, 2435-2442.

Vences, M., Wahl-Boos, G., Hoegg, S., Glaw, F., Oliveira, E.S., Meyer, A. \& Perry, S. (2007) Molecular systematics of mantelline frogs from Madagascar and the evolution of their femoral glands. Biol. J. Linn. Soc., 92, 529-539.
Vences, M., Pabijan, M., Kohler, J. \& Glaw, F. (2010) Two syntopic and microendemic new frogs of the genus Blommersia from the East coast of Madagascar. Afr. J. Herpetol., 59, 133-156.

Vences, M., Jovanovic, O., Safarek, G., Glaw, F. \& Koehler, J. (2015) A new arboreal frog of the genus Guibemantis from the Southeast of Madagascar (Anura: Mantellidae). Zootaxa, 4059, 569-58o.

Vieites, D.R., Wollenberg, K.C., Andreone, F., Köhler, J., Glaw, F. \& Vences, M. (2009) Vast underestimation of Madagascar's biodiversity evidenced by an integrative amphibian inventory. Proc. Natl. Acad. Sci. U.S.A., 106, 8267-8272.

Wake, D. (1970) Aspects of vertebral evolution in the modern Amphibia. Forma Functio, 3, 33-6o. Wollenberg, K.C., Vieites, D.R., Glaw, F. \& Vences, M. (2011) Speciation in little: the role of range and body size in the diversification of Malagasy mantellid frogs. BMC Evol. Biol., 11, 217.

Yeh, J. (2002). The effect of miniaturized body size on skeletal morphology in frogs. Evolution, 56, 628-641.

Zug, G.R. (1978) Anuran Locomotion-Structure and Function, 2: Jumping Performance of Semiaquatic, Terrestrial, and Arboreal Frogs. Smithsonian Contributions to Zoology, 276. Smithsonian Institution Press, Washington.

RECEIVED: 16 APRIL 2019 | REVISED AND ACCEPTED: 20 AUGUST 2019

EDITOR: J.W. ARNTZEN 


\section{APPENDIX 1}

Descriptions of measurements. All measurements were performed on the left side or paired element of the skeleton unless otherwise specified. (Para) sagittal planes may correspond to translations of the median plane to clip irrelevant structures for a given measurement.

Snout-vent length external (SVLext): snoutvent length measured externally on the preserved specimen.

Snout-vent length skeletal (SVLsk): in the right face of the sagittal plane; distance from the rostral tip of the premaxilla to the caudal-most margin of the pelvis.

Summed Snout-vent length (SVLsum): The sum of skull length (skullL), column length (column), and pelvis length (pelvL).

Skull length (skullL): in the ventral face of the coronal plane; linear distance from the anterior margin of the left premaxilla to the caudal border of the left exoccipital.

Skull width (skullW): in the ventral face of the coronal plane; maximum distance between the left and right jaw articulations.

Otic to Otic capsule distance (oticsW): in the ventral face of the coronal plane; maximum transverse distance between the lateral margins of the left and right otic capsules.

Columella (colmL): distance along the columella's midline from its lateral tip to its medial articulation with the oval window.

Premaxilla height (pmaxH): in the left face of the sagittal plane; distance from the premaxilla's anteroventral margin (i.e., pars dentalis) to the dorsal tip of its alary process.
Premaxilla width (pmaxW): in the ventral face of the coronal plane; distance between the medial and lateral tips of the premaxilla's pars palatina.

Premaxilla depth (pmaxD): in the ventral face of the coronal plane; distance from the premaxilla's anterior medial margin to the caudal (medial) tip of its pars palatina.

Mentomeckelian bone length (MmbL): in the ventral face of the coronal plane; distance along the mentomeckelian bone's midline from its medial margin to its lateral margin.

Upper jaw length (maxL): distance along the upper jaw's surface from the anteromedial margin of the premaxilla to the caudal-most tip of the quadratojugal.

Lower jaw length (mandL): distance along the lower jaw's surface from the anteromedial margin of the mentomeckelian bone to the caudal-most margin of the angulosplenial plate.

Nasal length (nasL): in the left face of the sagittal plane; maximum distance along the nasal's lateral border from its cranial tip to the caudal termination of its maxillary process.

Nasal width (nasW): in the dorsal face of the coronal plane; transverse distance from the left nasal's most-medial articulation point with the internasal septum to its lateral margin.

Inter-nasal width (intnasW): in the dorsal face of the coronal plane; transverse distance between the medial calcified articulation points of the left and right nasals with the tectum nasi.

Internasal septum height (intnsptH): in the ventral face of the coronal plane; distance from the left cranial margin of the internasal septum to the caudal tip of the left vomer (i.e., left olfactory foramen). 
Sphenethmoid height (sphH): in the ventral face of the coronal plane; distance from the left vomer's caudal tip (i.e.,left olfactory foramen) to the caudalmost margin of the sphenethmoid's left lateral ala.

Sphenethmoid width (sphW): in the ventral face of the coronal plane; distance from the caudalmost margin of the sphenethmoid's left lateral ala to the caudal-most margin of its right ala.

Frontoparietal length (frptlL): in the dorsal face of the coronal plane; distance from the posterolateral margin of the tectum nasi to the caudal tip of the posterior frontoparietal protuberance.

Frontoparietal width (frptlW): in the dorsal face of the coronal plane; maximum distance between the left frontoparietal's medial and lateral margins.

Prootic height (proH): in the dorsal face of the coronal plane; distance from the anterior border of the anterior epiotic eminence to the caudal-most margin of the prootic at the prominentia ducti semicircularis posterioris.

Exoccipital length (exoL): in the ventral face of the coronal plane; transverse distance from the caudolateral border of the left exoccipital to that of the right exoccipital.

Parasphenoid height (psphH): in the ventral face of the coronal plane; distance from the lateral intersection of the parasphenoid with the left ala of the sphenethmoid to the cranial margin of the origin of the parasphenoid's left posterolateral ala.

Parasphenoid width (psphW): in the ventral face of the coronal plane; transverse distance from the anterior, lateral-most corner of the parasphenoid's left posterior ala to that of its right.

Vomer height (vomH): in the ventral face of the coronal plane; distance from the caudal tip of the vomer's dentigerous process to its branching point with the postchoanal portion along its lateral edge.
Vomer width (vomW): in the ventral face of the coronal plane; length of the anterolateral margin of the vomer's anterior portion.

Palatine length (pltnL): distance along the palatine's caudal margin from its medial articulation with the alary cartilage to its lateral articulation with the maxilla.

Pterygoid height (ptygdH): in the right face of the sagittal plane; distance from the tip of the left pterygoid's dorsoposterior ramus to the pterygoid's ventral margin along its ventral border.

Pterygoid width (ptygdW): in the right face of the sagittal plane; distance along the left pterygoid's surface from its anterior-most articulation with the maxilla to its caudal-most tip at the jaw articulation.

Squamosal height (squaH): in the left face of the sagittal plane; distance along the squamosal's zygomatic ramus midline from its ventrocaudal tip to the dorsal border of the squamosal's otic ramus

Squamosal width (squaW): in the left face of the sagittal plane; distance along the squamosal's otic ramus midline from its anterior to posterior margins.

Hyoid bone length (hyoL): distance along the left hyoid's midline from its cranial tip to its caudal end.

Omosternum superior branch height (omostH): in the ventral face of the coronal plane; distance along the omosternum's midline from its cranial edge to its caudal border at its posterior bifurcation.

Omosternum branch length (omostL): in the in the ventral face of the coronal plane; distance along the left omosternum branch's midline from its articulation with the clavicular process to the lateral border of the opposing branch's bifurcation. Downloaded from Brill.com04/26/2023 12:20:50PM 
Clavicle length (clavL): in the ventral face of the coronal plane; distance along the clavicle's midline from its proximal articulation with the epicoracoid cartilage to its distal articulation with the scapula.

Distance to the clavicular process (clav_pL): in the ventral face of the coronal plane; distance from the medial origin of the clavicle to the clavicular process.

Coracoid length (coraL): in the ventral face of the coronal plane; distance along the coracoid's midline from its proximal articulation with the epicoracoid cartilage to its distal articulation with the humerus head in the glenoid cavity.

Sternum height (sterH): in the ventral face of the coronal plane; distance along the sternum's midline from its cranial border to its caudal edge.

Sternum superior width (sterWsup): in the ventral face of the coronal plane; maximum transverse distance between the sternum's anterior left and right lateral edges.

Sternum minimum width (sterWmin): in the ventral face of the coronal plane; minimum transverse distance between the sternum's left and right lateral edges.

Sternum inferior width (sterWinf): in the ventral face of the coronal plane; maximum transverse distance between the sternum's posterior left and right lateral edges.

Scapula length (scapL): distance from the scapula's ventral point of articulation with the humerus in the glenoid cavity to its caudal edge that articulates with the suprascapula.

Cleithrum length (cleiL): in the dorsal face of the coronal plane; distance along the cranial edge of the suprascapula from its proximal border to its distal articulation with the scapula.
Suprascapula height (supraH): in the dorsal face of the coronal plane; anteroposterior distance along the articulation with the scapula.

Suprascapular caudal-medial projection (supraW): in the dorsal face of the coronal plane; distance from the posterolateral articulation with the scapula to the most medial point of the suprascapula's ossification.

Humerus length capitulum (humLcap): linear distance from the proximal end of the humerus head to the distal capitulum of the humerus (i.e., part of the epiphysis that articulates with the radius).

Humerus length trochlea (humLtroc): linear distance from the proximal end of the humerus head to the distal trochlea of the humerus (i.e., part of the epiphysis that articulates with the ulna).

Deltopectoral crest height (dltd_crH): in the ventral face of the coronal plane; maximum height of the deltopectoral crest from its anterior edge to its posterior base.

Deltopectoral crest width (dltd_crW): in the ventral face of the coronal plane; distance from the proximal end of the base of the deltopectoral crest where it touches the humeral head to its distal end on the humerus.

Radioulna length (radulnL): distance from the proximal end of the olecranon (articulation with the humerus) to the distal end of the ulna (articulation with the carpals).

Metacarpal lengths (mtcplX): distance along the metacarpal's midline from its proximal end (articulation with the carpals) to its distal end (articulation with the phalanges).

Phalanx lengths (hand_phXL/foot_phXL): distance along the phalanx's midline from its proximal end to its distal end. 
Terminal phalanx lengths (hand_tphL/foot_ tphL): distance from the terminal phalanx's left proximal end to its left projection on its distal end.

Digit lengths (hand_DX/foot_DX): sum of the metacarpal/metatarsal length ( $\mathrm{mtcpl} / \mathrm{mttrsl})$, phalanx lengths (hand_phXL/foot_phXL), and terminal phalanx length (hand_tphL/foot_tphL) for the same limb digit.

Column (column): sum of all vertebral body heights.

Vertebral body heights (atlasH/VXH/sacrumH): in the ventral face of the coronal plane; distance along the midline of the vertebra's centrum from its cranial border to its caudal margin.

Distances between vertebral transverse processes (VX_tpL/sacrum_tpL): in the ventral face of the coronal plane; distance from the tip of the left transverse process to the tip of that of the right along their midline.

Urostyle length (uroL): in the left face of the sagittal plane; distance along the urostyle's midline from its articulation with the sacral vertebra to its caudal tip.

Urostyle height (uroH): in the left face of the sagittal plane; distance from the urostyle's dorsal border to its ventral border at its cranial tip.

Urostyle crest length (uro_crL): in the left face of the sagittal plane; distance from the base of the cranial origin of the urostyle crest to its posterior end.

Urostyle crest height (uro_crH): in the left face of the sagittal plane; maximum distance from the dorsal edge of the urostyle crest to its ventral edge.
Ilial shaft length (iliL): in the left face of the sagittal plane; distance from the left ilial shaft's dorsocranial tip at the ilial-sacral articulation to the caudal edge of the ilial protuberance immediately before the acetabulum.

Pelvis length (pelvL): in the left face of the sagittal plane; maximum distance from the dorsoanterior tip of the ilial shaft to the caudalmost border of the pelvic wheel at the ischium.

Pelvic wheel length (pelwL): in the left face of the sagittal plane; maximum linear distance between the anterior and posterior edges of the pelvis.

Epipubis height (epipH): in the ventral face of the coronal plane; distance along the epipubis' midline from its anterior edge to its posterior edge.

Epipubis width (epipW): in the ventral face of the coronal plane; distance from epipubis' left lateral edge to its right lateral border.

Femur length (femL): distance along the femur's midline from its proximal end (articulation with the acetabulum) to its distal end (articulation with the tibiofibula).

Tibiofibula length (tibfibL): distance along the tibiofibula's midline from its proximal end (articulation with the femur) to its distal end (articulation with the tibiale and fibulare).

Tibiale and Fibulare length (tiblfiblL): distance along the fibulare's midline from its most proximal end (articulation with the tibiofibula) to its most distal end (articulation with the metatarsals).

Metatarsal lengths (mttrsIX): distance along the metatarsal's midline from its proximal end (articulation with the tarsals) to its distal end (articulation with the phalanges). 


\section{Erratum}

Santos-Santos, J.H., Guinovart-Castán, M. \& Vieites, D.R. (2020) Descriptive skeletal anatomy of Blommersia transmarina (Amphibia: Anura: Mantellidae) from the Comoro Islands. Contrib. Zool. 89, 14-73. doi:10.1163/18759866-20191405

Unfortunately, the image of Figure 5 on p. 21 of this article contains the incorrect image. The correct Figure 5 should look as below. The figure caption was also slightly corrected to increase its readability.
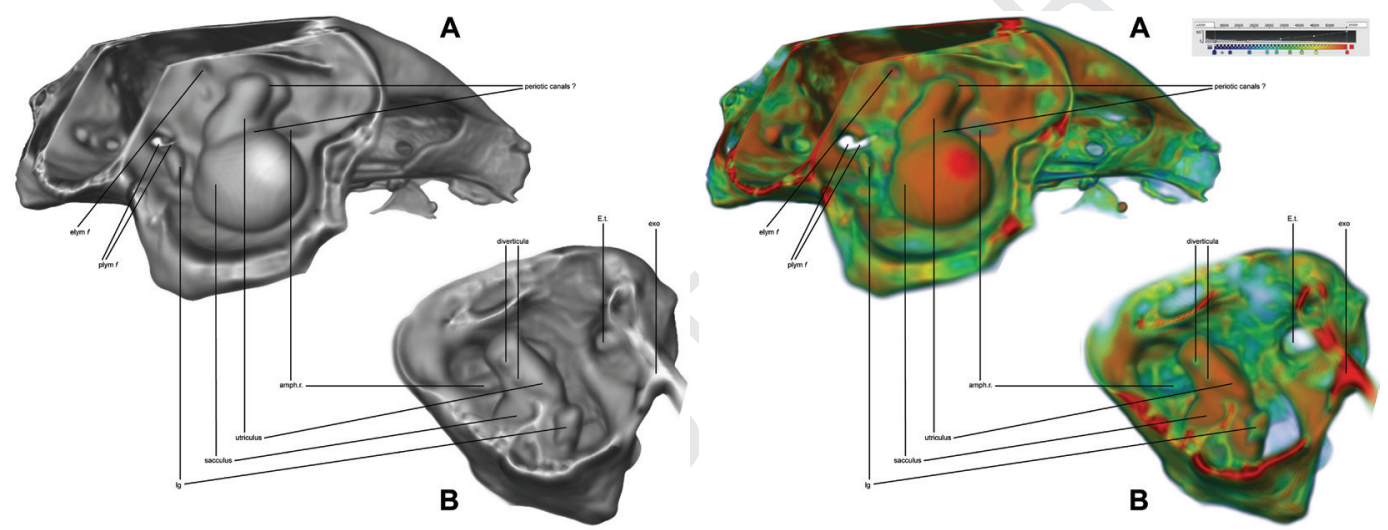

FIGURE 5 (A) Right lateral view of the Blommersia transmarina otic capsule. The cranium has been clipped laterally, posteriorly, and dorsally to facilitate visualization of the interior of the otic capsule. The anterior portion of the skull is clipped at the articulation of the palatine and alary cartilage. (B) Corresponding left sagittal plane, medial view of the B. transmarina otic capsule. The volume has been clipped to facilitate visualization of the interior of the otic capsule [MNCN50446 male; volrenWhite (Left) and physics colormaps (Right), grey [density] values: 12000-55500].

We would like to apologise for any inconvenience caused. 